\title{
GDSL-domain containing proteins mediate suberin biosynthesis and degradation, enabling developmental plasticity of the endodermis during lateral root emergence
}

\author{
Robertas Ursache $^{1 *}$, Cristovao De Jesus Vieira-Teixeira ${ }^{2}$, Valérie Dénervaud Tendon ${ }^{1}$, Kay Gully ${ }^{1}$, Damien De Bellis ${ }^{1,4}$, \\ Nawrath $^{1}$, Niko Geldner ${ }^{{ }^{*}}$ and Joop E.M. Vermeer ${ }^{2,3^{*}}$ \\ ${ }^{1}$ Department of Plant Molecular Biology, University of Lausanne, 1015 Lausanne, Switzerland \\ ${ }^{2}$ Laboratory of Cell and Molecular Biology, Institute of Biology, University of Neuchâtel, 2000, Neuchâtel, Switzerland \\ ${ }^{3}$ Department of Plant and Microbial Biology \& Zurich-Basel Plant Science Centre, University of Zurich, 8008 Zurich, Switzerland \\ ${ }^{4}$ Electron Microscopy Facility, University of Lausanne, 1015 Lausanne, Switzerland \\ ${ }^{5}$ Vital-IT Competence Center, Swiss Institute of Bioinformatics, 1015 Lausanne, Switzerland \\ ${ }^{6}$ Genomic Technologies Facility, University of Lausanne, 1015 Lausanne, Switzerland \\ \$ Current address: Max Planck Institute for Plant Breeding Research, Carl-Von-Linne-Weg 10, 50829 Cologne, Germany \\ ${ }^{5}$ Current address: NGSAI, Route de Corniche 3, CH-1066 Epalinges, Switzerland \\ *Corresponding authors: Robertas.Ursache@unil.ch,Niko.Geldner@unil.ch, Joop.Vermeer@unine.ch
} Emanuel Schmid-Siegert ${ }^{5 \varsigma}$, Tonni Grube Andersen ${ }^{1 \$}$, Vinay Shekhar ${ }^{2,3}$, Sandra Calderon ${ }^{5,6}$, Sylvain Pradervand ${ }^{5,6}$, Christiane

\begin{abstract}
Roots anchor plants and deliver water and nutrients from the soil. The root endodermis provides the crucial extracellular diffusion barrier by setting up a supracellular network of lignified cell walls, called Casparian strips, supported by a subsequent formation of suberin lamellae. Whereas lignification is thought to be irreversible, formation of suberin lamellae was demonstrated to be dynamic, facilitating adaptation to different soil conditions. Plants shape their root system through the regulated formation of lateral roots emerging from within the endodermis, requiring local breaking and re-sealing of the endodermal diffusion barriers. Here, we show that differentiated endodermal cells have a distinct auxin-mediated transcriptional response that regulates cell wall remodelling. Based on this data set we identify a set of GDSL-lipases that are essential for suberin formation. Moreover, we find that another set of GDSLlipases mediates suberin degradation, which enables the developmental plasticity of the endodermis required for normal lateral root emergence.
\end{abstract}

\section{INTRODUCTION}

Plants require a dynamic root system for optimal anchorage and to forage the soil environment for water and nutrients. Therefore, both functions need to be fine-tuned for optimal performance under challenging and fluctuating growth conditions. The root system architecture is modulated by regulated branching through the formation of lateral roots. In most angiosperms, including Arabidopsis thaliana (Arabidopsis), these organs initiate in the pericycle from de novo-formed meristems, often adjacent to the xylem, called xylem-pole pericycle cells (XPP). Auxin is required both for the initiation as well as for the development of lateral roots (Banda et al., 2019; Stoeckle et al., 2018). In Arabidopsis, lateral roots need to traverse three overlying cell layers in order to emerge; the endodermis, cortex and epidermis. Since plant cells are interconnected through their cell walls and under considerable turgor pressure, the newly formed organ must overcome the mechanical constraints posed by these cell layers. Especially the direct neighbor of the XPP, the endodermis, plays an essential role during lateral root formation, as it actively accommodates the expansion growth of the XPP through remodeling of cell shape and volume. It was shown that these responses were regulated via auxin-mediated signaling, and endodermal expression of a dominant repressor of auxin signaling, short hypocotyl 2-2 (shy2-2), completely blocked lateral root formation. Thus, after auxin-mediated priming, lateral root founder cells swell and this expansion growth needs to be accommodated via SHY2-mediated endodermal auxin signaling (Vermeer et al., 2014). The observation that lateral root primordia grow through the overlying endodermal cells without compromising their viability, is in agreement that this process is associated with extensive local cell wall remodeling (Kumpf et al., 2013; Swarup et al., 2008). In addition, it was reported that the Casparian Strip (CS), a lignified primary cell wall modification acting as a diffusion barrier, appears to get locally degraded in order to allow the growth of the lateral root through this cell layer (Li et al., 2017). It was also shown that suberin, a secondary cell wall modification, is deposited in the cell walls of endodermal cells in contact with the lateral root primordium during emergence. However, endodermal cells often are already suberized when lateral root formation occurs and it is still unknown how suberin is first degraded and later resynthesized. The growth of a lateral root through the endodermis needs to be tightly-controlled, in order to minimize both the leakage of nutrients from the stele into the rhizosphere and the entry of soil-borne pathogens to enter the stele. Therefore, a dynamic de-suberization and re-suberization is bound to play an important role in this process. It has been demonstrated that ABA- and ethylene signaling pathways are crucial for nutrientinduced plasticity of endodermal suberization during plant development (Barberon et al., 2016). However, although several studies have revealed roles of suberin deposition in adaptation to the soil environment and organ formation, we still lack understanding of the basic molecular machineries regulating suberin biosynthesis and deposition during root development (Andersen et al., 2020; Barberon et al., 2016; Li et al., 2017; Yadav et al., 2014). This is especially relevant for understanding the localized, dynamic suberin deposition found in roots. In this study we used the CASP1pro::shy2-2 line as a tool to identify cell wall remodeling factors during this process. The CASP1pro::shy2-2 mutant is specifically blocked in endodermal auxin-responses, which strongly impairs lateral root formation. In order to obtain a specific, endodermal auxin-response profile, we used a combination of CASP1pro::shy2-2 and solitary root $1(s l r-1)$, two mutants that repress auxin signaling in different spatial domains (Fukaki et al., 2002; Swarup et al., 2008; Vermeer et al., 2014). In the obtained data set, we identify a distinct set of 10 GDSL-motif containing enzymes that are 
bioRxiv preprint doi: https://doi.org/10.1101/2020.06.25.171389; this version posted June 27, 2020. The copyright holder for this preprint (which was not certified by peer review) is the author/funder, who has granted bioRxiv a license to display the preprint in perpetuity. It is made available under aCC-BY 4.0 International license.

\section{bioR Xiv PREPRINT}

A

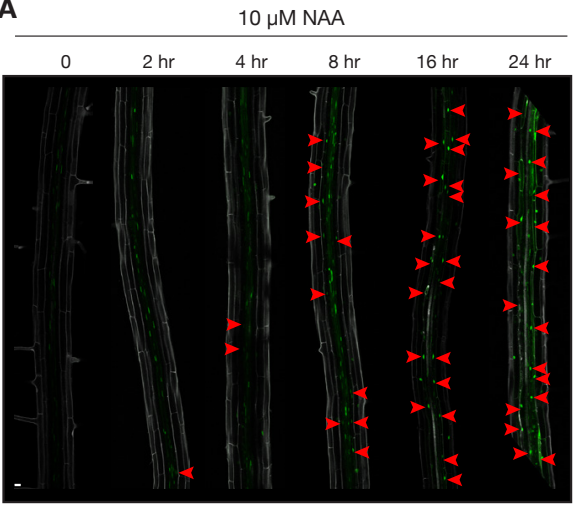

SHY2pro::NLS-3xmVENUS

D

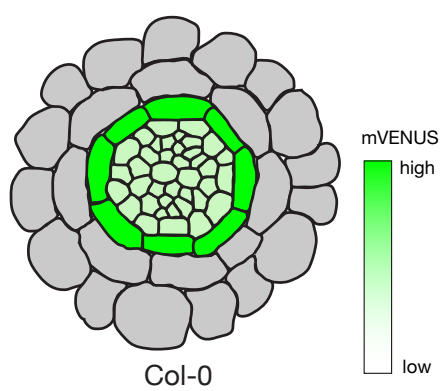

E

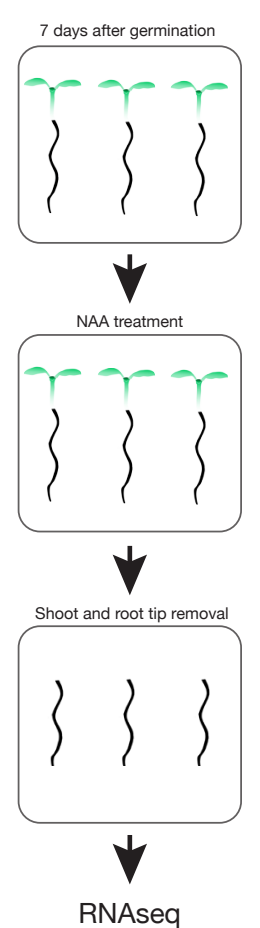

B

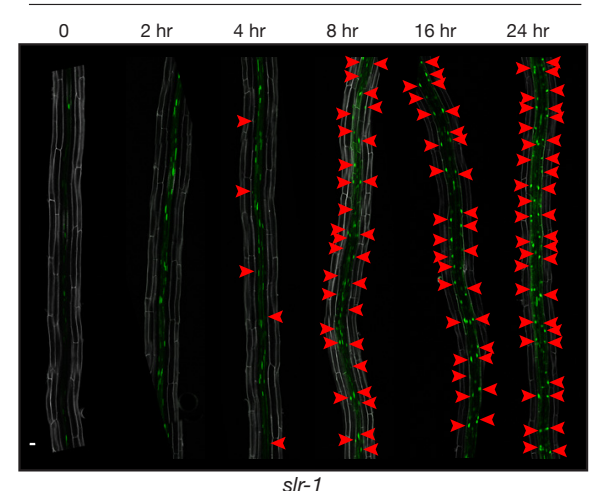

SHY2pro::NLS-3XmVENUS

SHY2pro::NLS-3xmVENUS + 16hr $10 \mu \mathrm{M}$ NAA

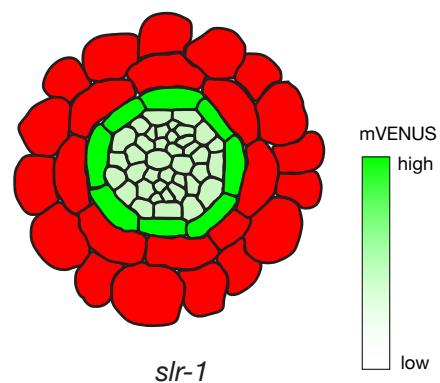

C

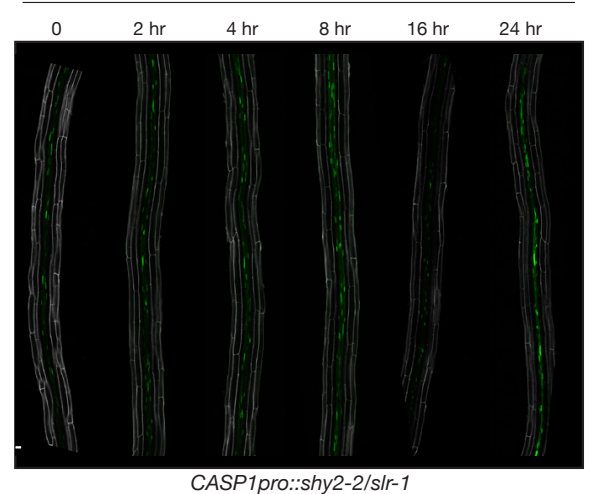

SHY2pro::NLS-3xmVENUS

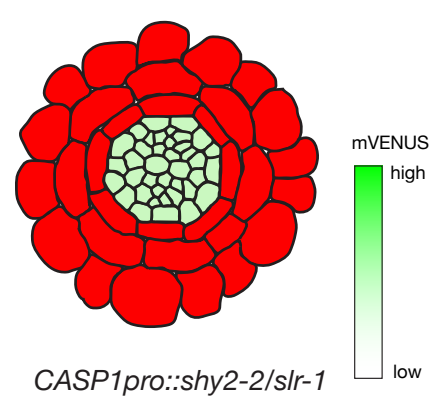

G

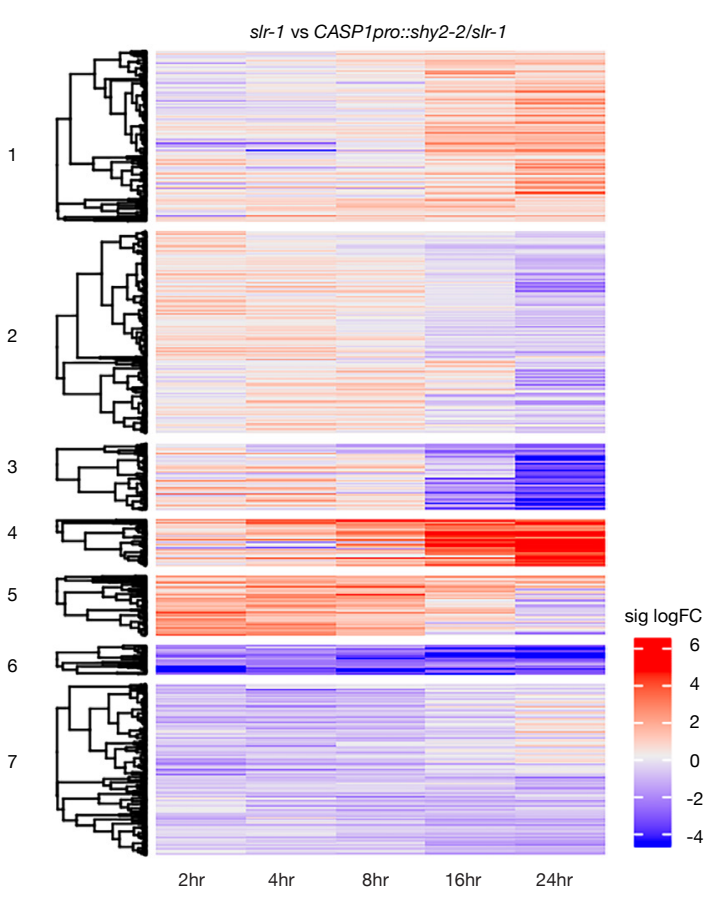

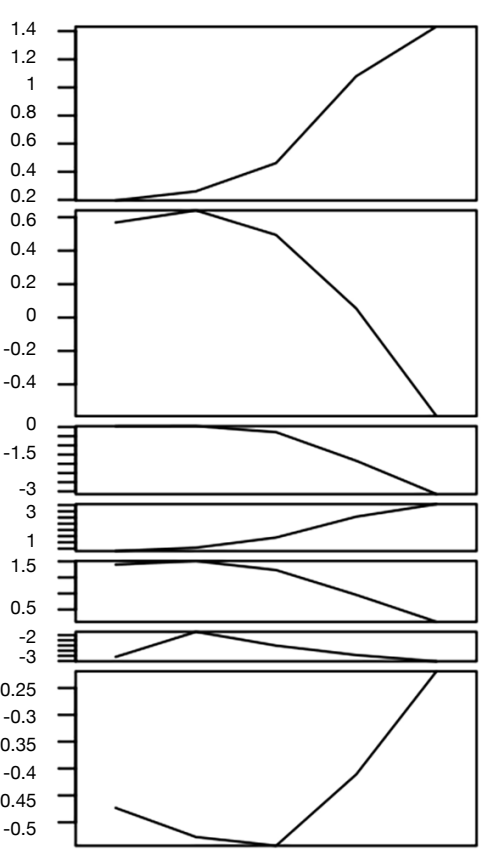

Figure 1. A genetic trick for mapping auxin responses in the differentiated endodermis.

A-C. Maximum images projections of roots expressing SHY2pro::NLS-3xmVENUS treated with $10 \mu \mathrm{M}$ NAA for 0, 2, 4, 8, 12 and 24 hrs. A. Col-0. B. slr-1. C. CASP1pro::shy2-2/slr-1. Red arrowheads indicate SHY2pro::NLS-3xmVENUS signal in the endodermis. D. Schematic representation of SHY2pro::NLS-3xmVENUS responses in the different genetic backgrounds after $10 \mu \mathrm{M}$ NAA for $16 \mathrm{hrs}$. Red indicates block of auxin signalling, green indicates induction of $S H Y 2$ E. Experimental setup of the RNAseq experiment. F. Heatmap showing the seven clusters containing the significant differentially expressed genes between slr-1 and CASP1pro::shy2-2/ $s l r-1$ during the NAA time course. G. Graphical presentation of the behavior of the seven cluster during the NAA time course depicted in $(\mathbf{E})$. Scale bar in $(\mathbf{A})=50 \mu \mathrm{m}$.

differentially expressed between slr-1 and CASP1pro::shy2-2 after auxin treatment. All of these ten GDSL-motif containing enzymes were either expressed in the endodermis, repressed or induced in this cell layer during auxin treatment or lateral root formation. We show that five of the GDSL-motif containing enzymes that are repressed by auxin are required for suberin biosynthesis, whereas another five auxin-induced GDSL-motif containing enzymes are required for suberin degradation in the endodermis during lateral root formation. Quintuple mutants of the suberin biosynthesis GDSL-motif containing enzymes were overly-sensitive to mild salt stress, which resulted in reduced fresh weight and a strong reduction in emerged lateral roots. Single 
bioRxiv preprint doi: https://doi.org/10.1101/2020.06.25.171389; this version posted June 27,2020 . The copyright holder for this preprint (which was not certified by peer review) is the author/funder, who has granted bioRxiv a license to display the preprint in perpetuity. It is made available under aCC-BY 4.0 International license.

knock-out mutants of several members of the auxin-induced group of suberin degrading enzymes resulted in a delayed lateral root emergence. Our work reveals for the first time essential enzymatic components that regulate suberin polymerization and degradation, strongly impacting our understanding of in vivo suberin formation, as well as its striking developmental plasticity.

\section{RESULTS}

\section{SHY2-mediated transcriptional responses in differentiated endodermal cells}

We have previously shown that during lateral root formation in Arabidopsis, overlying endodermal cells undergo drastic changes in cell volume and that the CS, a lignified primary cell wall modification, is locally modified to facilitate lateral root emergence (Vermeer et al., 2014). Furthermore, we showed that SHORT HYPOCOTYL 2 (SHY2/IAA3)-mediated auxin signaling drives these responses. SHY2 represses its own transcription in a typical, auxin-induced negative feedback loop and is thus a great, early transcriptional auxin-response marker (Tian et al., 2002; Vermeer et al., 2014). However, we do not know which SHY2 targets (direct or indirect) are required for the complex accommodating responses in the endodermis. Therefore, we set out to obtain a SHY2-mediated transcriptional response profile in the endodermis. Generating such a data set comes with particular challenges. First, most endodermal cells at the moment of lateral root emergence are lignified and suberized, making it impossible to employ protoplast isolation used for single cell or cell-type specific sequencing. Secondly, only endodermal cells overlying an auxin-emitting lateral root primordium from stage I and onwards will be stimulated in a SHY2-dependent fashion (Vermeer et al., 2014). Thus, only a subset of endodermal cells would display the transcriptome profile we are interested in. We therefore first thought to compare wild-type and CASP1pro::shy2-2 seedlings treated with auxin to obtain a differential, endodermis-specific set of auxin responsive genes. In wildtype, SHY2pro::NLS-3xmVENUS fluorescence peaks in the endodermis at -16 hours after NAA treatment (Figure $1 \mathrm{~A}$ and D). However, since the CASP1pro::shy2-2 mutant impairs the auxin-mediated induction of lateral root formation that is strongly induced in wild-type (Vermeer et al., 2014), a direct comparison of the auxin-induced transcriptomes of CASP1pro::shy2-2 roots to wild-type roots would result in a strong bias for pericycle and cell cycle-related genes and not necessary genes involved in endodermal accommodating responses. Therefore, we designed a genetic trick to enrich for auxin induced transcriptional changes in the endodermis.

To this end, we combined the dominant, solitary root 1 (slr-1)/IAA14 mutant with CASP1pro::shy2-2. Lateral root formation is impaired in the Arabidopsis slr-1 mutant (Fukaki et al., 2002). Importantly, SLR is expressed in the pericycle, cortex and epidermis, but not in the endodermis and the slr-1 mutant should thus specifically block auxin response in the surrounding cell layers (Fukaki et al., 2002; Swarup et al., 2008)(Figure S1). Indeed, we found that auxin-mediated induction of $S H Y 2$ in the endodermis was still occurring in $s l r-1$ roots (Figure $1 \mathrm{~B}$ and D). We predicted that, in the combined CASP1pro::shy2-2 Islr1 background auxin signaling is basically blocked in all differentiated root cell layers. As mentioned above, SHY2 represses its own expression (Tian et al., 2002), and indeed, as shown in Figure 1C, we could not detect induction of SHY2pro::NLS3xmVENUS in the endodermis of the CASP1pro::shy2-2/slr-1 background. Based on these results, we predicted that a comparison (subtraction) of the NAA-induced transcriptomes of roots from the slr1 single mutant with the CASP1 pro::shy2-2/slr-1 double mutant would allow us to extract a specific endodermal auxin signaling transcriptomic profile, otherwise obscured by the strong, proliferation-inducing auxin responses of the xylem-pole pericycle cells (Figure 1A-E).

\section{Differentiated endodermal cells have a distinct auxin- mediated transcriptional response}

We interrogated the genome-wide transcriptional responses in slr-1 and CASP1pro::shy2-2/slr-1 after NAA treatment $(10 \mu \mathrm{M})$ at multiple time points. After statistical analysis (fold change $>2$, false discovery rate $<0.05$ ), we established that $-800-900$ genes are differentially expressed at 2, 4, 8, $16 \mathrm{hr}$ after treatment and -1000 are significantly changed after $24 \mathrm{hr}$ treatment compared to the zero timepoint (Table S1). Using non-supervised methods and manual tests we settled on 7 clusters to describe the data (Figure 1F and G). As expected, the data set contained a large number of cell wall-related genes and hardly any cell cycle-related genes. When looking at the gene ontology (GO) annotations, we observed terms linked to auxin signaling and lateral root development (cluster 2 and 5), whereas terms related to lipid transport and fatty acid metabolism were enriched in clusters 3 and 5 . The fact that we observed in general little GO terms related solely to auxin signaling and lateral root development is most likely due to the unique experimental design, providing a previously undescribed auxin-response profile focused on a specific, differentiated cell type. To substantiate this, we compared the $s l r-1$ versus CASP1pro::shy2-2/slr-1 data with the two other published data sets from transcriptome analysis dealing either with roots treated with auxin or microdissection of root sections after gravistimulation mediated of lateral root induction (Lewis et al., 2013; Voß et al., 2015). After re-analyzing the differential gene-expression analysis for both data sets, we converted the $\log F C$ values of each gene to $\mathrm{z}$-scores in order to facilitate the comparison of the different data sets. Interestingly, there appeared to be little correlation between the differentially expressed genes in our data set and those in the data sets of Lewis et al., (2013) or Voß et al., (2015) (Figure S2). We took this as a confirmation of the unique and specific nature of our transcriptional profile. In order to try and identify novel genes involved in cell wall modification, as well as to confirm the validity of our transcriptional profile, we selected a wide range of genes possibly related to the observed endodermal responses, including genes linked to lignification, lipid transport and as well as several unknown genes showing particularly 
bioRxiv preprint doi: https://doi.org/10.1101/2020.06.25.171389; this version posted June 27, 2020. The copyright holder for this preprint (which was not certified by peer review) is the author/funder, who has granted bioRxiv a license to display the preprint in perpetuity. It is made available under aCC-BY 4.0 International license.

\section{bioR $\chi$ IV PREPRINT}
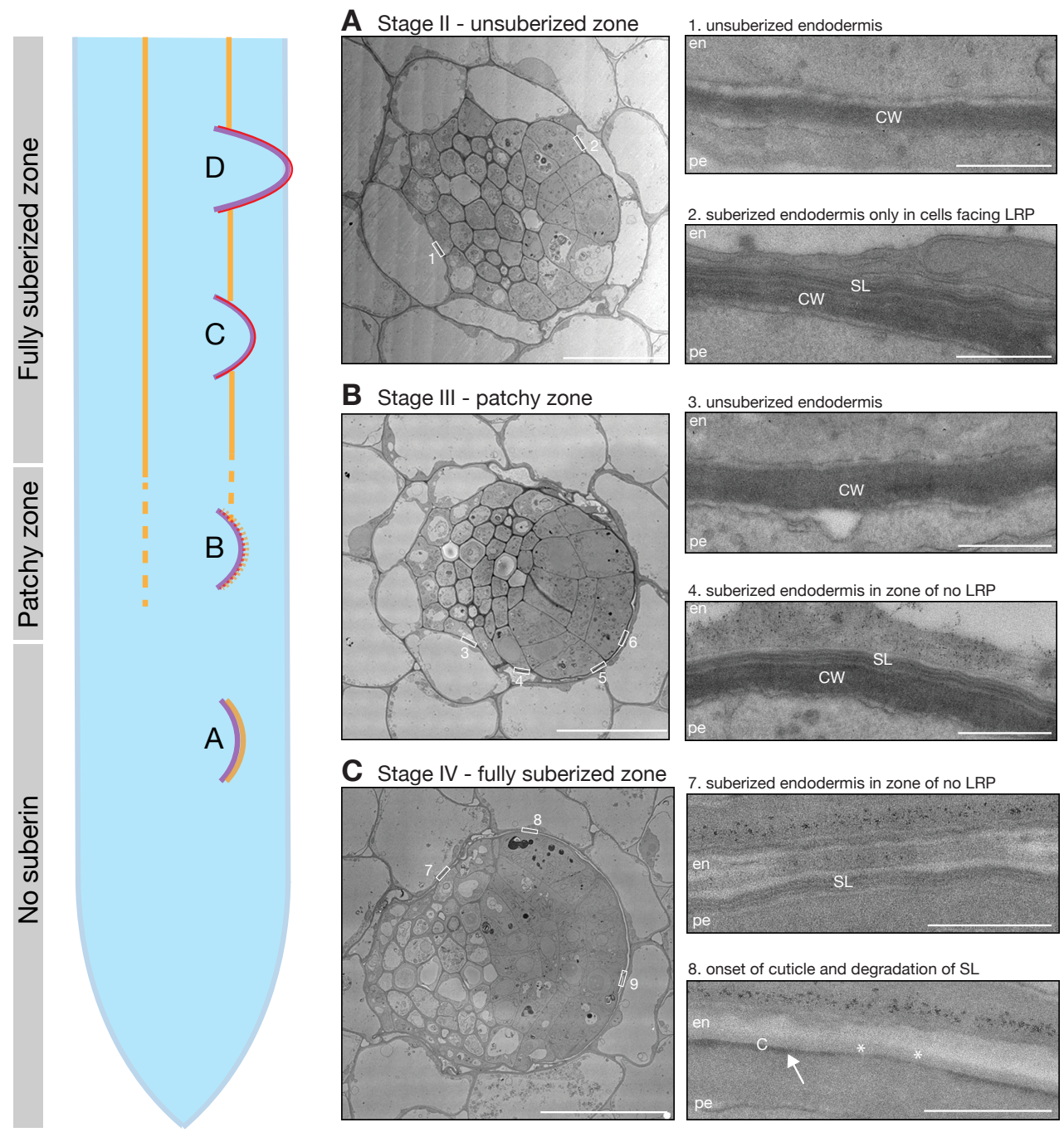

\section{B Stage III - patchy zone}

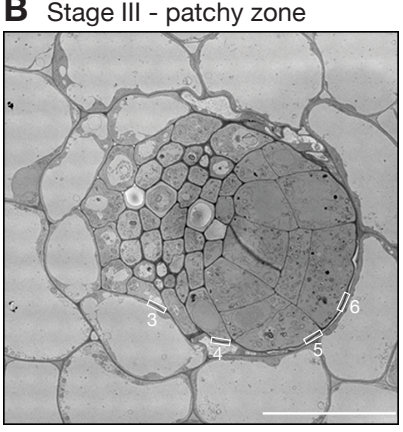

C Stage IV - fully suberized zone

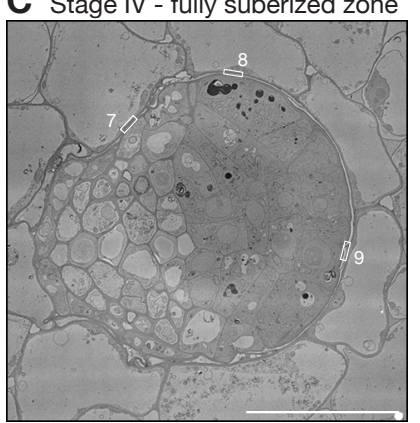

D Emerged - fully suberized zone

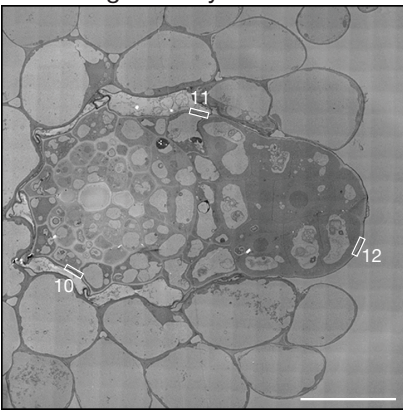

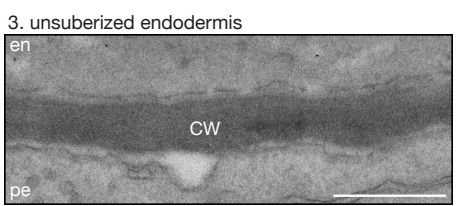
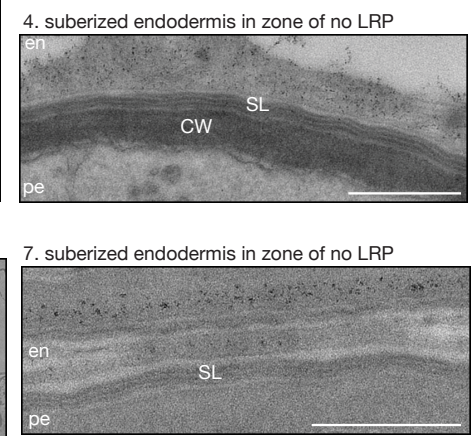

8. onset of cuticle and degradation of SL

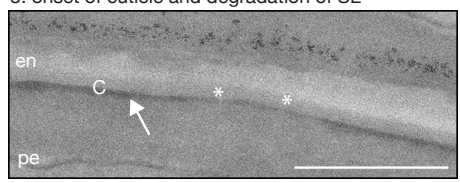

10. suberized endodermis in zone of no LRP
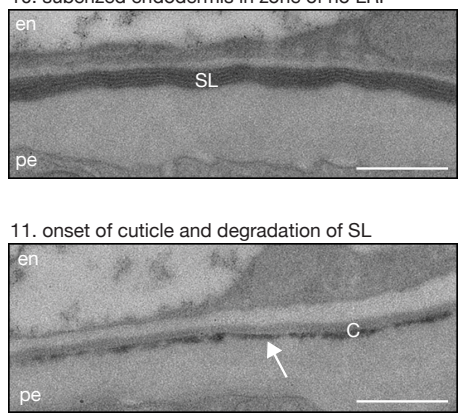

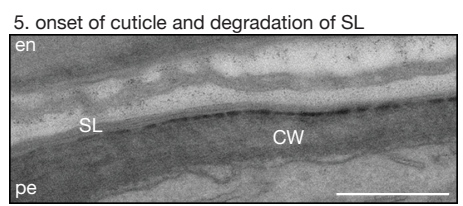

6. mature cuticle and lack of SL

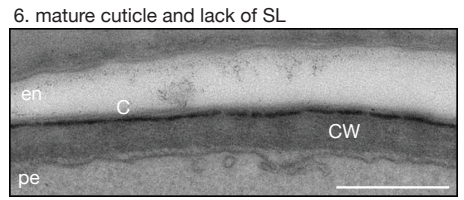

9. mature cuticle and lack of SL

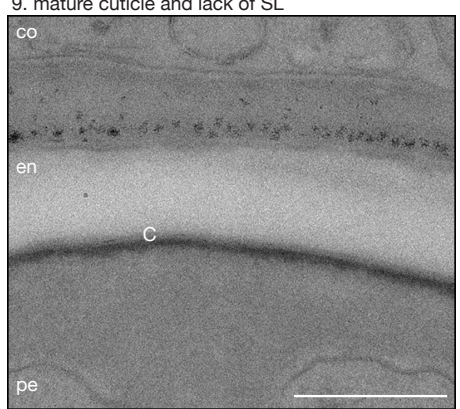

12. mature cuticle and lack of SL

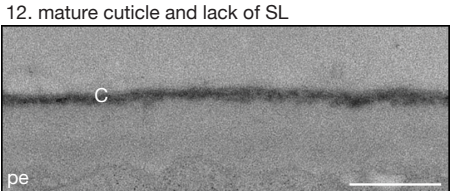

Figure 2. Suberin is degraded while the lateral root cap cuticle is established during lateral root formation.

Schematic drawing of a root highlighting the different stages of suberin formation in the endodermis. Letters refer to the TEM images with the corresponding letter. Cell wall is shown in purple, suberin lamellae in yellow and the lateral root cap cuticle in red. A. TEM micrograph of a root section containing a stage II lateral root primordium. The numbered boxed regions are shown as magnifications marked by the same number. B. TEM micrograph of a root section containing a stage III lateral root primordium. The numbered boxed regions are shown as magnifications marked by the same number. C. TEM micrograph of a root section containing a stage IV lateral root primordium. The numbered boxed regions are shown as magnifications marked by the same number. $\mathbf{D}$. TEM micrograph of a root section containing an emerged lateral root. The numbered boxed regions are shown as magnifications marked by the same number. $\mathrm{En}=$ endodermis, pe $=$ pericycle, $c 0=c o r t e x, \mathrm{SL}=s u b e r i n$ lamellae, $C=$ lateral root cap cuticle, $C W=$ cell wall. Scale bars in $(\mathbf{A}-\mathbf{D})=10 \mu \mathrm{m}$ and scale bars in $(1-12)$ panels $=1 \mu \mathrm{m}$. 
bioRxiv preprint doi: https://doi.org/10.1101/2020.06.25.171389; this version posted June 27,2020 . The copyright holder for this preprint (which was not certified by peer review) is the author/funder, who has granted bioRxiv a license to display the preprint in perpetuity. It is made available under aCC-BY 4.0 International license.

strong and high-confidence differential responses. We generated promoter-reporter lines to characterize their expression pattern during root development and lateral root formation. In a strong validation of our approach, most of the selected genes were found to display auxin-regulated expression in the endodermis (Figure S3 and Table S2). The transcriptional reporter for one of such candidate, the GDSL-type esterase/lipase 12 (GELP12), was expressed in the cortex of wild-type and CASP1pro::shy2-2 roots, but was not detected in the cortex of $s l r-1$ roots (Figure S3A). Treatment of slr-1/GELP12pro::NLS-3xmVENUS roots with auxin resulted in induction of GELP12 specifically in the endodermis, but did not restore cortex expression, as auxin-mediated gene expression is blocked by the presence of dominant slr-1 allele. Supplemental Figure S3C shows a selection of the candidates that all display expression in the endodermis (either constitutive or induced during lateral root formation). In contrast, the expression domain of LACCASE 2 (LAC2), although showing significant differential expression between $s l r-1$ and CASP1pro::shy2-2/ $s l r-1$, was not expressed in the endodermis, but rather in protoxylem cells (Figure S3D and Table S2). Nevertheless, out of the 27 candidates for which we generated transcriptional reporters, only 3 turned out not to be expressed or induced in the endodermis (Table S2). Since we were interested in possible cell wall modifying enzymes, we searched the list of differential expressed genes for cell wall-associated functions. This lead to the observation that many genes with functions attributed to cutin/suberin homeostasis such as 3-KETOACYL-COA SYNTHASE (KCS), FATTY ACID DESATURASE (FAD), FATTY ACID REDUCTASE (FAR), LIPID TRANSFER PROTEIN (LTP), GDSL-TYPE ESTERASE/LIPASE (GELP) and ATPBINDING CASSETTE G (ABCG) transporters (Edqvist et al., 2018; Fich et al., 2016; Lai et al., 2017; Salminen et al., 2018; Vishwanath et al., 2015) showed highly dynamic, differential expression in our dataset (Figure S3E). Suberin deposition has been shown to be highly plastic, might be continuously turned over and is also implicated in adaptation to the soil environment and during lateral root development (Andersen et al., 2020; Barberon et al., 2016; Li et al., 2017). However, fundamental aspects of suberin formation and deposition are still not understood, especially its synthesis, deposition and turnover in the apoplast. Therefore, we decided to investigate whether some of the cell wall-related differentially expressed genes in our endodermis-focused auxin response data set could be involved in suberization and reveal new insights into this process. In particular, we were intrigued by the high number of differentially expressed GELPs in our dataset (Figure S3E), since members of this large family have been shown to be involved in cutin polymerization, but also to be able to degrade both cutin and suberin (Bakan and Marion, 2017; Girard et al., 2012; Naseer et al., 2012; Philippe et al., 2016; Yeats et al., 2012). Thus, we decided to focus on the differentially regulated set of GELPs in our data set.

\section{Suberin is degraded while the lateral root cap cuticle is}

\section{established during lateral root formation}

\section{bioR XIV PREPRINT}

Fluorol Yellow (FY) staining of suberin and cutin is dynamic during lateral root formation. However, FY stains both suberin and cutin (Berhin et al., 2019) (Figure S7A), so it is not yet clear if, how and at which stage suberin might be degraded in the endodermis and replaced by a cutin-like structure in the emerging primordium. Therefore, to get a deeper insight into this process, we analyzed the dynamics of suberin and cutin during lateral root formation using transmission electron microscopy (TEM) (Figure 2). Analyzing stage II lateral root primordia, which usually form in the unsuberized zone, we could detect suberin lamellae only in the endodermal cell walls facing the lateral root primordia, but not in the cell wall of endodermal cells on the opposite side of the root (Figure 2A). Stage III primordia are found in the patchy suberized zone of the root and here we expectedly detected both suberized and non-suberized endodermal cells. At this stage we started to distinguish the onset of the lateral root cap cuticle formation, accompanied by the disappearance of the suberin in the cell walls of the endodermal cells overlying the primordium (Figure 2B). In stage IV primordia, which are usually found in the fully suberized zone, we could detect suberin deposition in all endodermal cells in the zone of no developing lateral roots. At this point it was difficult to observe any suberin in cell walls of endodermal cells facing the primordia. Indeed, it appeared that the suberin was degraded in coordination with the formation of the root cap cuticle (Figure 2C). In fully emerged lateral roots, we could only detect the lateral root cap cuticle, whereas endodermal cells not in contact with the primordium still maintained their suberin lamellae (Figure 2D). Thus, it is clear that suberin is gradually degraded in cell walls of endodermal cells surrounding the lateral root primordium while the lateral root primordium synthesizes its lateral root cap cuticle as a protective coating during emergence (Berhin et al., 2019).

\section{Suberin deposition strongly requires a cluster of auxin- repressed GELPs}

We have demonstrated that suberin deposition is regulated during lateral root formation and that it gradually is replaced by the lateral root cap cuticle (Figure 2). Whereas we have some insights regarding cutin polymerization within the apoplast, there are no factors known to mediate suberin polymerization (Philippe et al., 2020). Generally, very few strong mutants for suberin biosynthesis have been identified. gpat 5 mutants displayed reduced suberin levels in the main root and in the seed coat and were more susceptible to elevated salt concentrations. However, suberin deposition was only partially $(-30 \%)$ affected in gpat5-1 mutants (Beisson et al., 2007). Currently, the strongest available interference with suberin in roots relies on either endodermis-specific interference with ABA or cytokinin signaling, or on artificial overexpression of a cutin-degrading enzyme (Andersen et al., 2018; Barberon et al., 2016; Naseer et al., 2012).

It was previously demonstrated that a member of the large family of GELP proteins (Yeats et al., 2012), CUTIN DEFICIENT 1 (CD1), has cutin in vitro synthase activity 
bioRxiv preprint doi: https://doi.org/10.1101/2020.06.25.171389; this version posted June 27,2020 . The copyright holder for this preprint (which was not certified by peer review) is the author/funder, who has granted bioRxiv a license to display the preprint in perpetuity. It is made available under aCC-BY 4.0 International license.

\section{bioR XIV PREPRINT}

AB
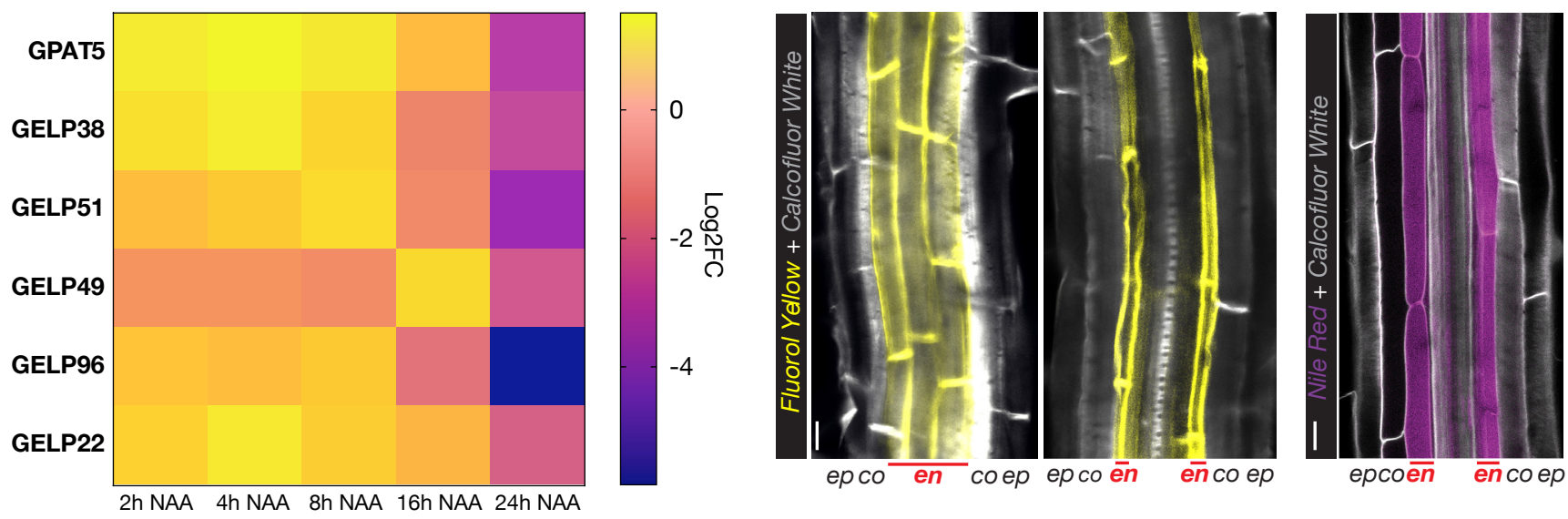

C

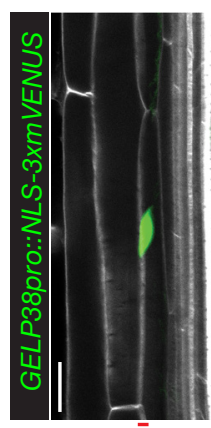

epco èn

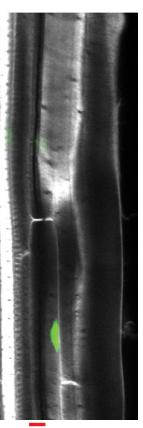

en coep

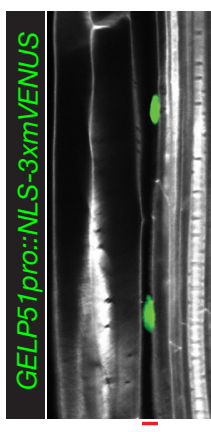

ep coèn

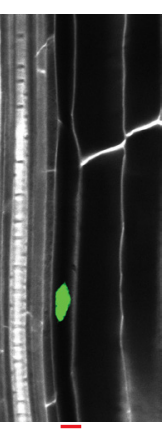

en co ep

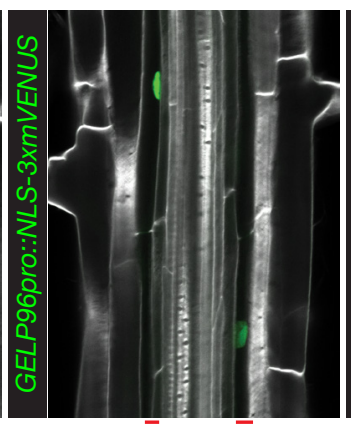

epcoen

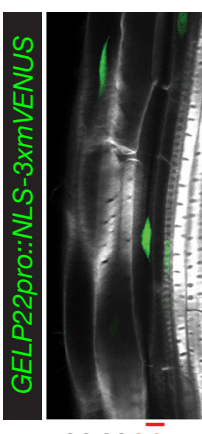

ep coen

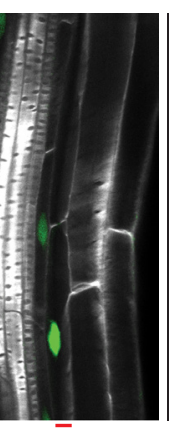

en coep

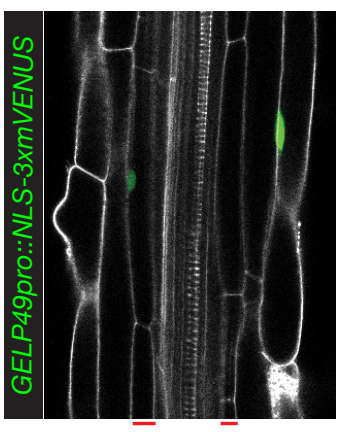

epcoen

en coep

Figure 3. A cluster of five, auxin repressed, GELPs is expressed in the differentiated endodermis.

A. Heatmap showing the differential expression of GPAT5 and GELP38, GELP51, GELP49, GELP96 and GELP22 during the time course of NAA treatment (10 $\mu \mathrm{M})$. B. Representative image of staining of suberin lamellae in the endodermis using Flurol Yellow (FY) (yellow) or Nile Red (magenta). C. Confocal images of root sections expressing transcriptional reporters for each of the GELPs mentioned in (A). NLS-3xmVENUS is shown in green, Calcofluor-White (CW) staining of cell walls in gray. Scale bar $=25 \mu \mathrm{m}$.

and $C D 1$ loss-of-function mutants in tomato show partial defects in cuticle formation, but no equivalent evidence exists for suberin synthases. Interestingly, we observed a group of five GELPs (GELP22, 38, 49, 51 and 96) to be differentially downregulated after prolonged auxin treatment (Figure 3A). Since auxin treatment results in a massive induction of lateral root formation, accompanied by degradation of suberin in overlying endodermal cells (Li et al., 2017), we hypothesized that suberin biosynthetic enzymes would be inhibited during formation of lateral root primordia. Therefore, we speculated that the five GELPs repressed by auxin treatment might have a role in suberin biosynthesis. This idea was corroborated by their expression pattern in the root obtained with transcriptional reporters for GELP22, 38, 49, 51 and 96. Clearly, GELPXpro::NLS-3xmVENUS reporter lines revealed endodermis-specific expression for GELP38, GELP51 and GELP96, and expression in endodermis and epidermis for GELP22 and GELP49 (Figure 3C). Since treatment of Arabidopsis seedlings with ABA results in a significant increase in suberin deposition and GPAT5 marker expression (Barberon et al., 2016), we further checked whether GELP22, 38, 49, 51 and 96 would be induced by ABA treatment. All GELP reporter lines were induced in response to $A B A$ treatment and also expanded their expression domain into the cortex, very similar to what has been reported for GPAT5 (Barberon et al., 2016) and
(Figure S4A and B). Together, our data establishes a strong correlation between suberin biosynthesis and the expression pattern of these five GELPs. In order to establish a function for these GELPs in suberin biosynthesis, we collected available T-DNA insertion mutants and characterized these for differences in suberin deposition using FY or Nile Red staining, two fluorescent dyes that both stain suberin (Figure 3B). In the absence of T-DNA insertion lines for GELP38, we generated two loss-of-function mutants using CRISPR/Cas9. None of the single knock-out or knockdown mutants showed any significant difference in suberin occupancy in Arabidopsis roots compared to the wild-type control (Figure S4C-E). Because of their likely functional redundancy, we generated two different allelic combinations of the five putative suberin biosynthesis-related GELPs: gelp22-c1/gelp38-c3/gelp49-c1/gelp51-c1/gelp96-c1 and gelp22-c2/gelp38-c4lgelp49-c2/gelp51-c2/gelp96-c2 (hereafter called gelpquint-1 and gelpquint-2) (Figure S5). To test whether suberin levels in roots of the gelpquint-1 and gelpquint-2 mutants were affected compared to wild-type, we stained roots of 5-day old plants with FY and Nile Red. Whereas suberin staining in wild-type resulted in the same pattern as described before (Naseer et al., 2012), both quintuple mutants showed a complete absence of suberin staining (Figure 4A-D and Figure S6A). ABA treatment strongly enhances suberin deposition in both the endodermis 
bioRxiv preprint doi: https://doi.org/10.1101/2020.06.25.171389; this version posted June 27, 2020. The copyright holder for this preprint (which was not certified by peer review) is the author/funder, who has granted bioRxiv a license to display the preprint in perpetuity. It is made available under aCC-BY 4.0 International license.

bioR Xiv PREPRINT

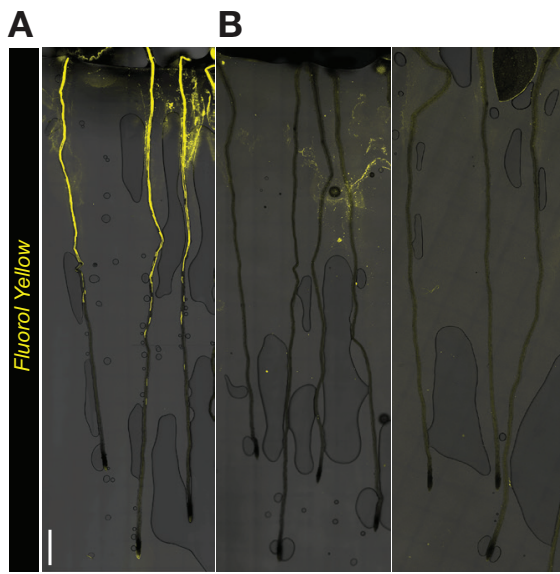

Col-0

H

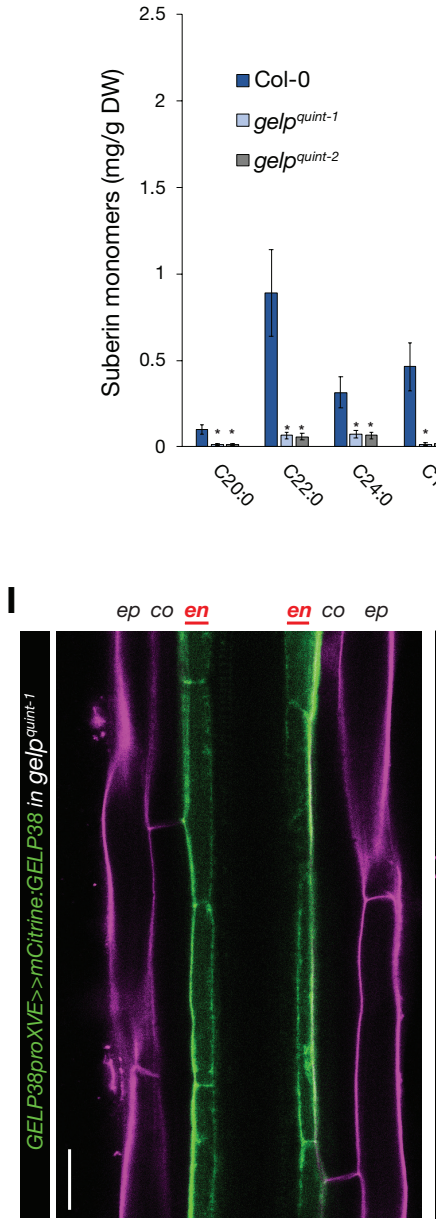

Single image

$\mathbf{L}$

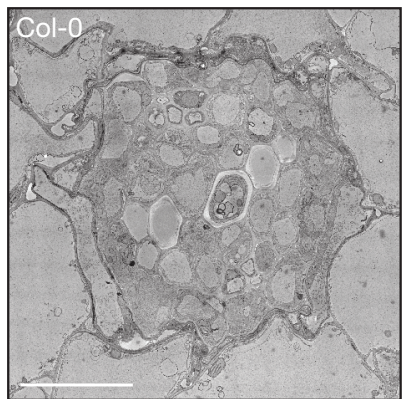

I

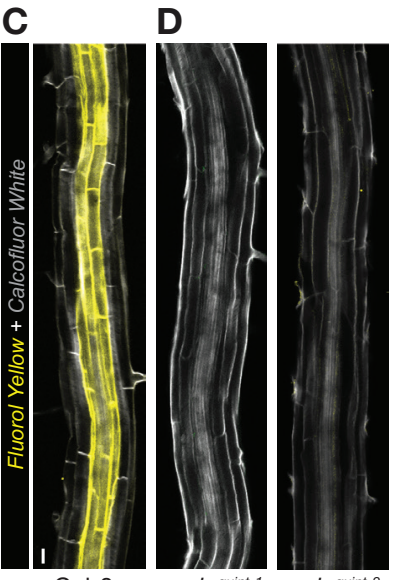

Col-0

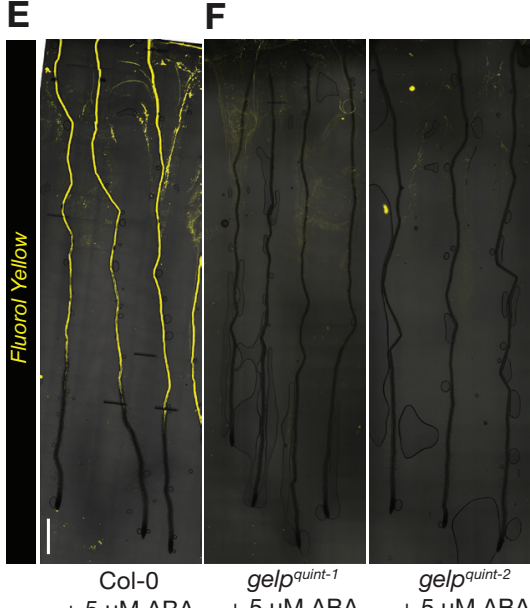

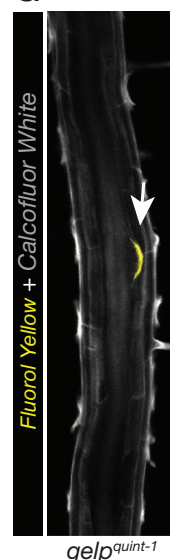

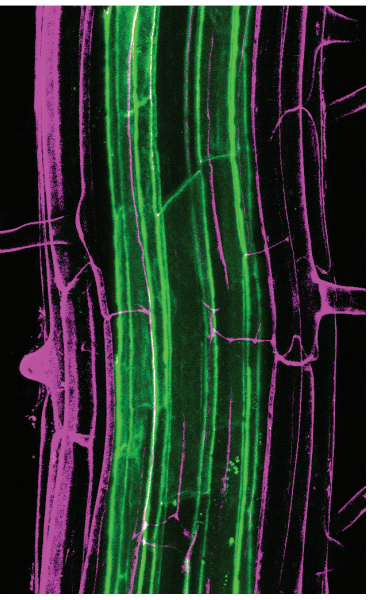

Maximum projection

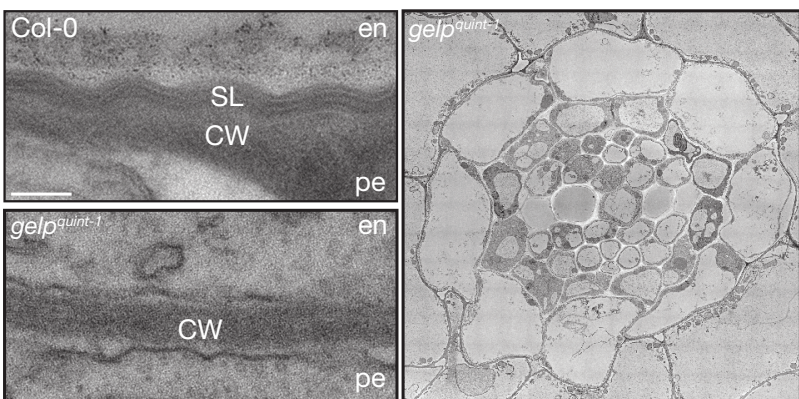

J

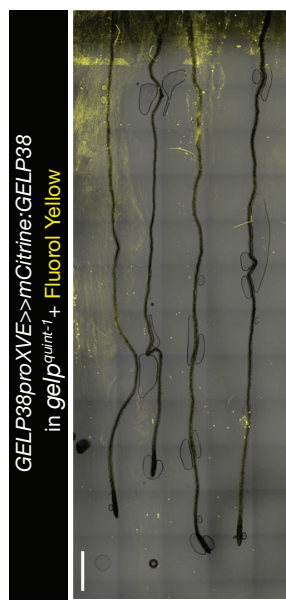

DMSO

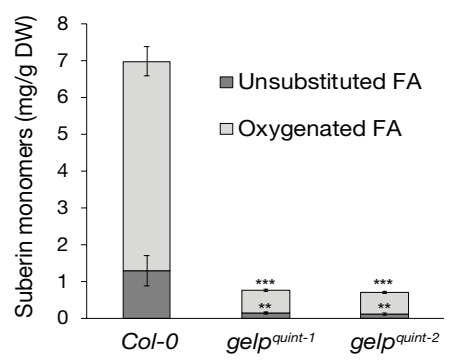

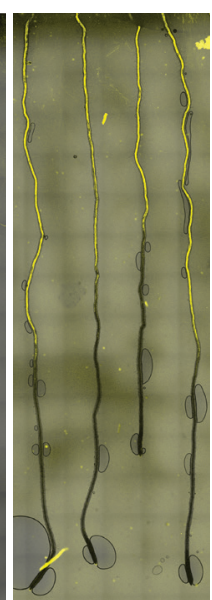

+ Estradiol
K

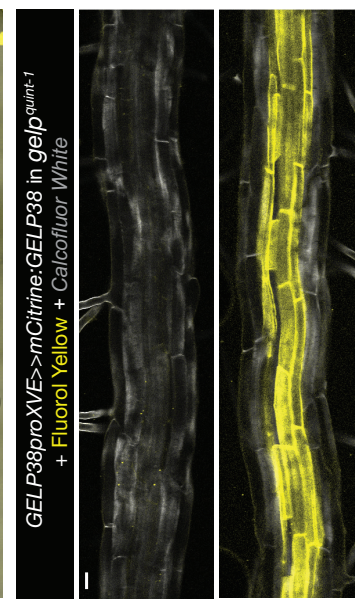

DMSO + Estradiol

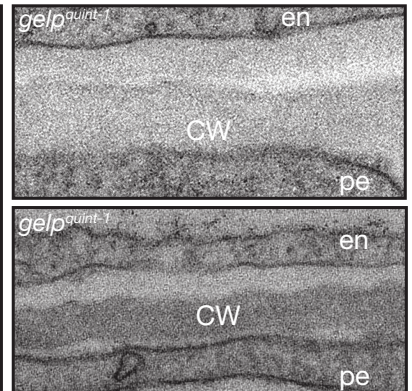


bioRxiv preprint doi: https://doi.org/10.1101/2020.06.25.171389; this version posted June 27, 2020. The copyright holder for this preprint (which was not certified by peer review) is the author/funder, who has granted bioRxiv a license to display the preprint in perpetuity. It is made available under aCC-BY 4.0 International license.

\section{bioR Xiv PREPRINT}

Figure 4. Suberin deposition strongly requires a cluster of auxin-repressed GELPs.

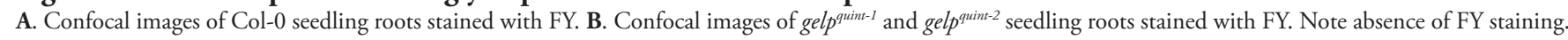

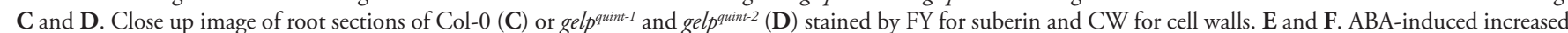
suberin deposition in Col-0 roots $(\mathbf{E})$ whereas $(\mathbf{F})$ shows ABA cannot induce suberin deposition in roots of gelp $p^{\text {quint-1 }}$ and gelp quint $2^{2}$ mutants. G. FY staining showing that the cuticle layer protecting emerging lateral roots appears not to be affected in the gelpquint-1 mutant. $\mathbf{H}$. Chemical analysis of the suberin content in roots of wild-type and gelpquint-I and gelpquint-2 reveals a $-85 \%$ decrease in total suberin monomers. Quantification of aliphatic and aromatic ester-bond suberin monomers isolated from 6-day-old roots of wild-type (Col-0) and gelpquint-1 and gel $p^{\text {quint-2 }}$ mutants. The graph shows the analysis of the principal suberin monomers and the inset shows the total monomers per genotype. Values represent the means $\pm S E, n=4$. Asterisks denote statistically significant differences to wild-type as determined by ANOVA and Tukey's test analysis: ${ }^{* * *} \mathrm{p}<0.001 ;{ }^{* *} \mathrm{p}<0.01 ;{ }^{*} \mathrm{p}<0.05$, ns, not significant. I. Confocal image and maximum image projection of a root expressing GELP38-XVEpro::mCITRINE:GELP38 (green) after $\beta$-Estradiol treatment $(5 \mu \mathrm{M})$ counterstained with propidium iodide (magenta). J-K. Induction of GELP38XVEpro::mCITRINE:GELP38 restores suberin deposition in the roots of gelpquint-I. L-M. TEM micrographs of root cross sections showing presence of suberin lamellae in wild-type, and absence of suberin lamellae in cross sections of gelpquint-1 roots. Note that the structure of the endodermis of the gelp puint-1 mutant is much better preserved compared to wild-type. Scale bars in $(\mathbf{A}, \mathbf{E}, \mathbf{J})=500 \mu \mathrm{m},(\mathbf{C}, \mathbf{G}, \mathbf{I}, \mathbf{K})=25 \mu \mathrm{m}$. Scale bars in $(\mathbf{L})$ and $(\mathbf{M})$ for the whole root sections $=10 \mu \mathrm{m}$ and for zoomed-in regions $=20 \mathrm{~nm}$.

and cortex (Barberon et al., 2016). Yet, despite this ABAinduced boost in suberin production, we again could not detect any suberin deposition using FY staining in the roots of gelpquint-1 and gelp quint-2 (Figure 4E and F). Since cutin and suberin are similar in structure and both can be stained by FY, we then investigated whether the lateral root cap cuticle was also affected in roots of the gelp quint-1 mutant, using FY staining of emerging lateral roots. FY still stained the dome of the emerging lateral root, suggesting that the gelpquint mutants are specifically affected in suberization and that the lateral root cap cuticle is still intact (Figure 4G). The TEM analysis confirmed that the cuticle is formed normally in the gelp quint mutants (Figure S6C). Since endodermal suberin was shown to interfere with uptake from the apoplast, we used the fluorescein diacetate (FDA) penetration assay (Barberon et al., 2016) to test for the presence of functional suberin lamellae in the endodermis of gelp $^{\text {quint-1 }}$ and gel $p^{\text {quint-2 }}$ roots. Whereas FDA could only enter the epidermis and cortex in the suberized zone of wild-type roots, it was entering the endodermis of gelp quint-1 and gelp quint $2^{2}$ roots, further supporting the absence or strong deficiency of a suberin barrier in the endodermis (Figure S6H-J). Both, the absence of FY staining in the gelp ${ }^{\text {quint } 1}$ and gelpquint-2 and the FDA uptake assay suggest that the gelpquint-1 and gelp quint-2 mutants have strongly reduced suberin deposition. To verify this, we performed a chemical analysis of the suberin content in roots of wild-type, gel $p^{\text {quint-1 }}$ and gel $p^{\text {quint-2 }}$ mutants. This revealed strong reductions in the amount of aliphatic and aromatic suberin monomers in gelpquint-1 and gelp quint-2 mutants that were nearly identical in both allelic combinations. Dicarboxylic acids were very nearly absent (98\% reduction), while $\omega$-hydroxy acids and fatty alcohols were reduced by $-90 \%$ and $50 \%$, respectively (Figure $4 \mathrm{H}$ ). Ferulate was reduced by $70 \%$, while coumarate showed only minor reductions. This resulted overall in a $-85 \%$ reduction in the amount of suberin monomers compared to wild-type roots (Figure $4 \mathrm{H}$ ), which correlates well with their FY phenotypes. Next, we complemented the suberin phenotype of the gelp $^{q u i n t-1}$ mutant by introducing a fluorescent protein-labelled biosynthetic GELP. Expression of an inducible GELP38proXVE>>GELP38-mCitrine fusion in the gelpquint-1 mutant restored the stereotypical FY staining in roots, indicating that the GELP38-mCitrine is a functional fusion protein. Moreover, we could show that GELP38-mCitrine is localized in the apoplast of the endodermis where suberin polymerization takes place (Figure 4I-K). We also tested whether the Casparian strip was unaffected in the gelpquint-1 and gelp quint-2 mutants. Both the lignin staining with Basic Fuchsin and uptake

of Propidium Iodide (PI) were not significantly affected compared to wild-type (Figure S6D-G). Thus, a cluster of five auxin-repressed GELPs is essential for normal suberin deposition in the endodermis, but not for the formation of the lateral root cap cuticle.

\section{Cell walls of endodermal cells in gelpquint- 1 are devoid of suberin lamellae}

TEM allows to directly observe the presence of suberin lamella in the endodermis. We therefore investigated the gelpquint-t mutant at the ultra-structural level. Whereas we could readily detect suberin lamellae deposition in endodermal cell walls of wild-type, we could not detect any indication of suberin lamellae formation in roots of gelpquint-1 (Figure 4L and M and Figure S6B). Instead, we observed a layer of low electron density in the cell wall of the gelpquint-1 mutant (Figure 4M and Figure S6B). This layer appears amorphous and bears no resemblance with the lamellar structures observed in wild-type. Hence, these results strongly support an absence of suberin in the endodermis of the gelp $p^{\text {quint-1 }}$ mutant. Since it has been repeatedly demonstrated that roots with nonfunctional suberin barriers are more susceptible to elevated concentrations of salt, we also subjected 4 DAG seedlings to a mild salt stress $(85 \mathrm{mM} \mathrm{NaCl})$ for 10 days. Both gel $p^{\text {quint }}$ mutants were much more affected by the salt stress compared to wild-type (Figure S6K-M). We observed much less emerged lateral roots and the fresh weight of the shoot was also significantly reduced (Figure S6K-M). These observations again strongly support the absence of a functional suberin barrier in the gelpquint mutants. Next, we checked whether the expression of known suberin biosynthesis-related genes was altered in the gelpquint-1 and gelpquint-2 mutants. Neither GLYCEROL-3PHOSPHATE SN-2-ACYLTRANSFERASE 5 (GPAT5), HYDROLASE OF ROOT SUBERIZED TISSUE (HORST), ALIPHATIC SUBERIN FERULOYL-TRANSFERASE (ASFT), FAR1, FAR4 or KCS2 were differentially expressed in the gelpuint-1 and gelpquint-2 mutants (Figure S6N). This excludes the possibility that the observed absence of suberin would be due to an indirect feedback regulation of suberin biosynthesis and supports a direct role for the five GELPs in suberin polymerization in the apoplast.

\section{A cluster of auxin-induced GELPs is required for suberin degradation}

Besides a cluster of GELPs repressed by auxin treatment, we 
bioRxiv preprint doi: https://doi.org/10.1101/2020.06.25.171389; this version posted June 27, 2020. The copyright holder for this preprint (which was not certified by peer review) is the author/funder, who has granted bioRxiv a license to display the preprint in perpetuity. It is made available under aCC-BY 4.0 International license.

bioR $\chi$ IV PREPRINT

A

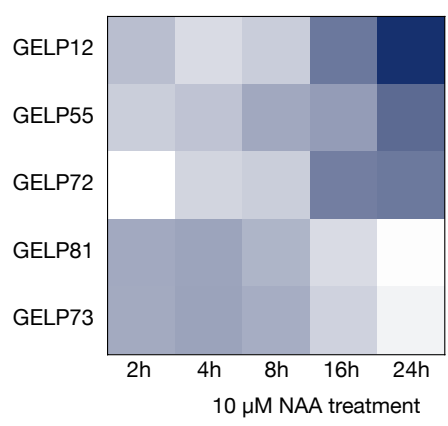

B

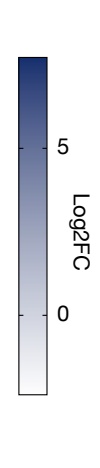

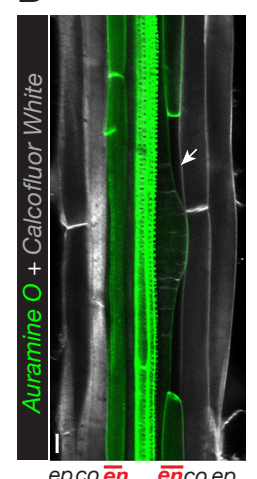

C

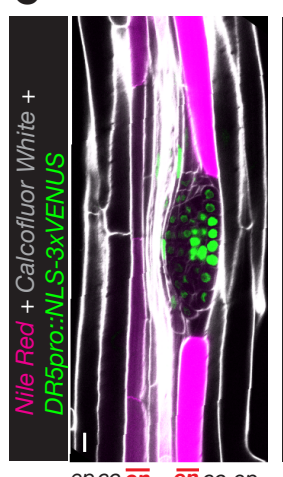

D

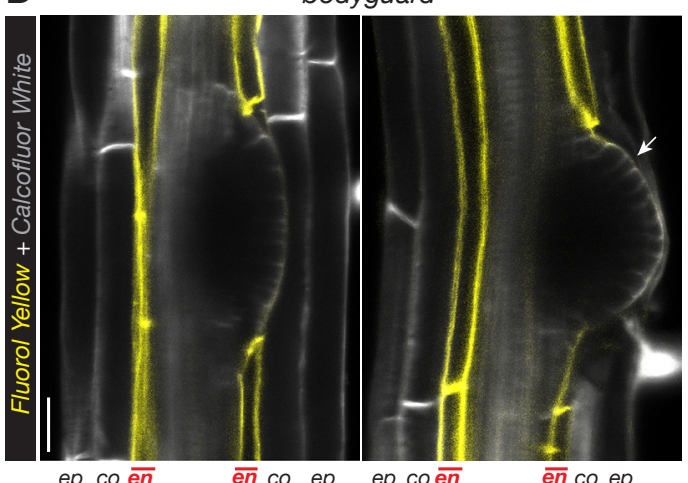

E

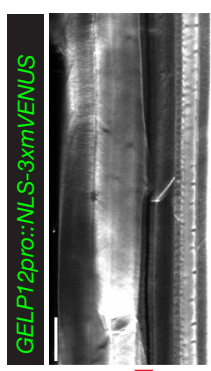

ep co en

$\mathbf{F}$

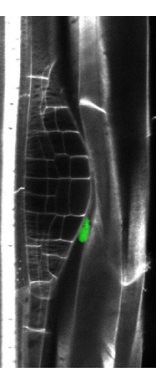

$\overline{e n}$ co ep

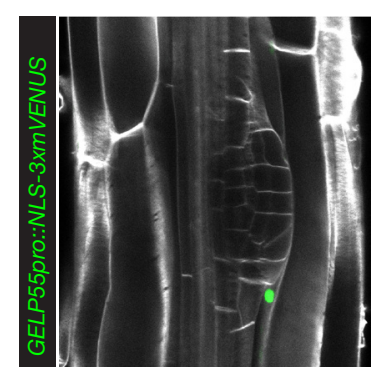

ep co en

èn co ep

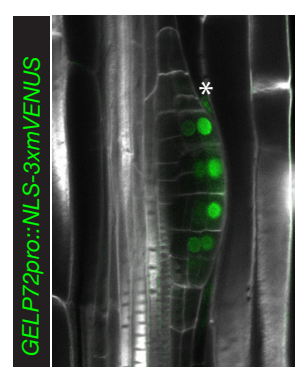

epcoēen

$\bar{e}$ n co ep

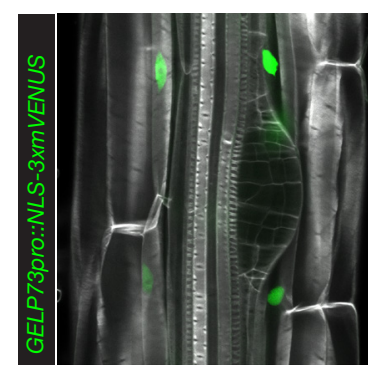

ep co èn

ē co ep

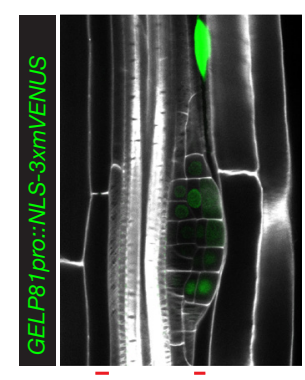

co èn

èn co ep

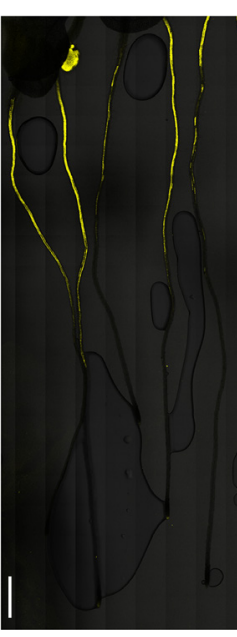

Col-0 + Estradiol

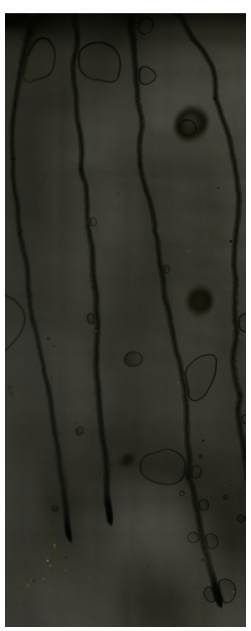

ELTPproXVE>> GELP12

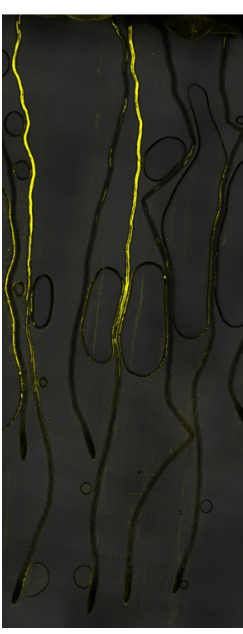

ELTPproXVE>> GELP55

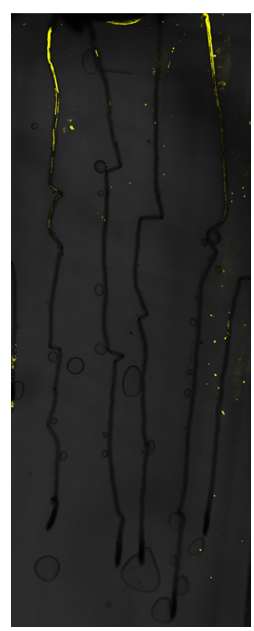

ELTPproXVE>> GELP72

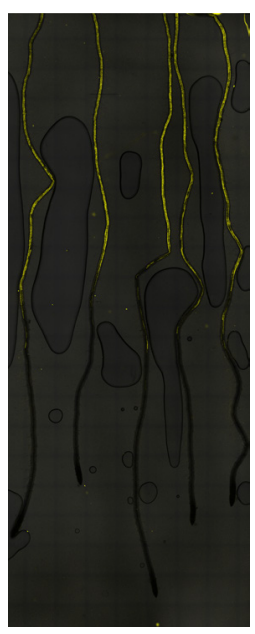

ELTPproXVE>> GELP73

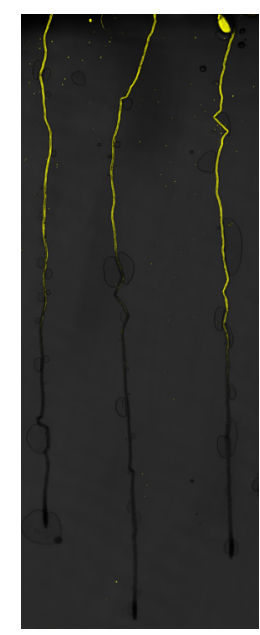

ELTPproXVE>> GELP81

Figure 5. A cluster of auxin-induced GELPs is required for suberin degradation.

A. Heatmap showing the differential expression of GELP12, GELP55, GELP72, GELP81 and GELP73 during the NAA (10 $\mu$ M) time course. B. Use of Auramine O (green) to visualize degradation of suberin in the cell wall of endodermal cells overlying a lateral root primordium. C. Use of Nile Red staining (magenta) to visualize suberin degradation in the cell wall of endodermal cells overlying a lateral root primordium. Auxin signaling is visualized by DR5pro::NLS-3xVENUS (green). D. FY staining in roots of bodyguard, demonstrating normal presence of suberin lamellae, whereas the cuticle layer surrounding the lateral root primordium is discontinuous (arrow). E. Confocal images showing the expression patterns of the isolated auxin-upregulated GELPs during lateral root formation. NLS-3xmVENUS signal in green and Calcofluor White staining of cell walls is in gray. Asterisk indicates endodermal signal. F. FY staining on roots of Col-0 treated with $\nabla$-Estradiol results in normal suberin pattern, whereas inducible endodermis-specific overexpression of GELP12, GELP55 or GELP72 results in degradation of suberin highlighted by absence of FY signal. The overexpression of GELP73 and GELP81 results in a normal suberin pattern similar to wild-type. Scale bars in $(\mathbf{B}, \mathbf{C}, \mathbf{D})$ and $(\mathbf{E})=25 \mu \mathrm{m}$. Scale bar in (F) $=500 \mu \mathrm{m}$.

also identified a group of five GELPs (GELP12, GELP55, GELP72, GELP73 and GELP81) that were induced by auxin (Figure 5A). Transcriptional reporters for GELP12, GELP55 and GELP72 revealed that their expression appeared to peak after $24 \mathrm{hr}$ of NAA treatment, whereas reporters for GELP73 and GELP81 revealed a peak in expression after $-4 \mathrm{hr}$ NAA treatment (Figure $5 \mathrm{E}$ and Figure S7D-F). In addition, both GELP73 and GELP81 were already expressed in the endodermis prior to lateral root formation (Figure 5E and Figure S7D).

We demonstrated that the endodermal suberin gradually disappears and a layer of cutin is formed at the lateral root priordium (Figure 2), confirming previous observations (Berhin et al., 2019; Li et al., 2017). Thus, we hypothesized that, in contrast to the suberin biosynthesis GELPs that are auxin repressed, these five GELPs could instead regulate 
bioRxiv preprint doi: https://doi.org/10.1101/2020.06.25.171389; this version posted June 27,2020 . The copyright holder for this preprint (which was not certified by peer review) is the author/funder, who has granted bioRxiv a license to display the preprint in perpetuity. It is made available under aCC-BY 4.0 International license.

\section{bioR XIV PREPRINT}

A

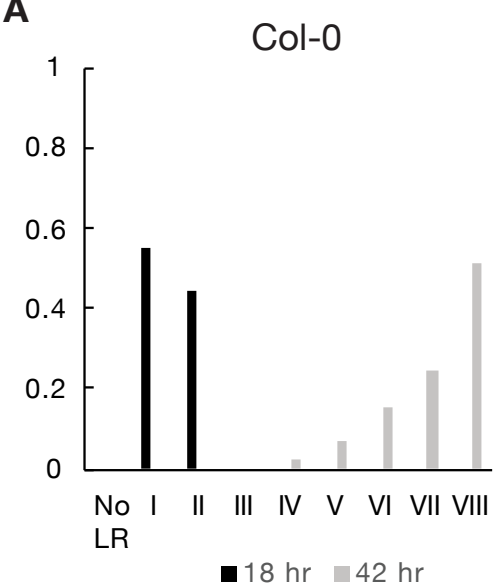

D

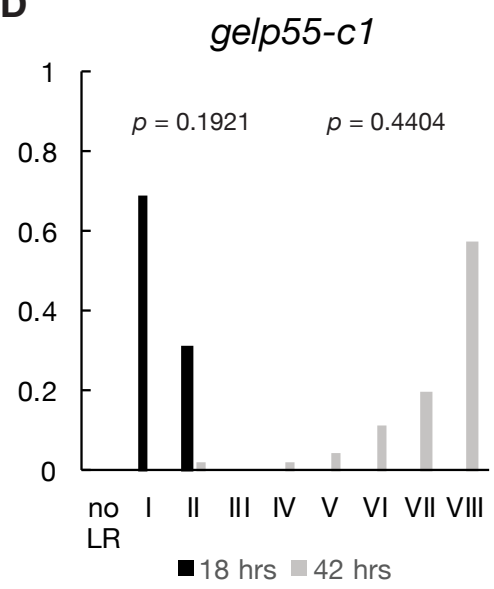

G

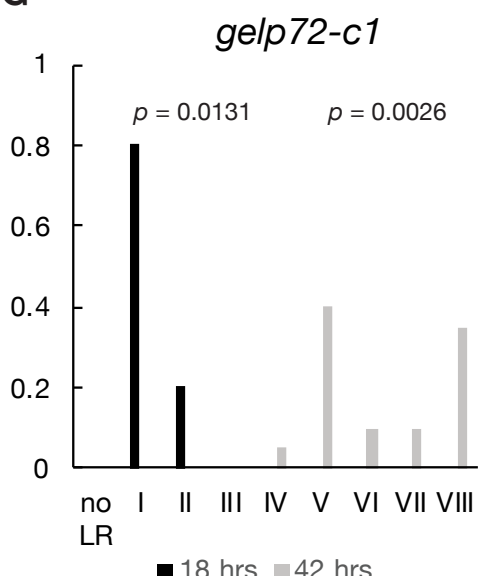

J

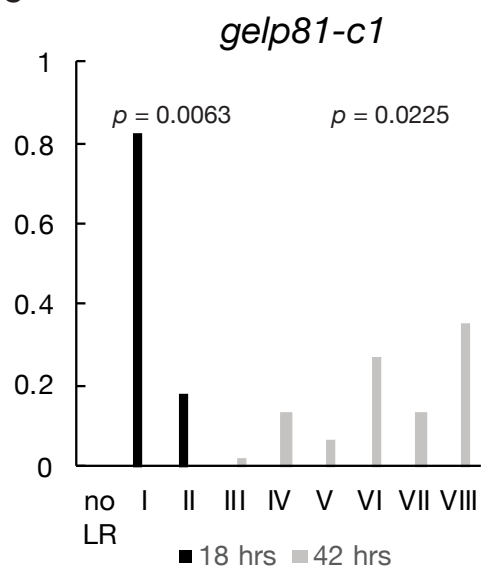

B

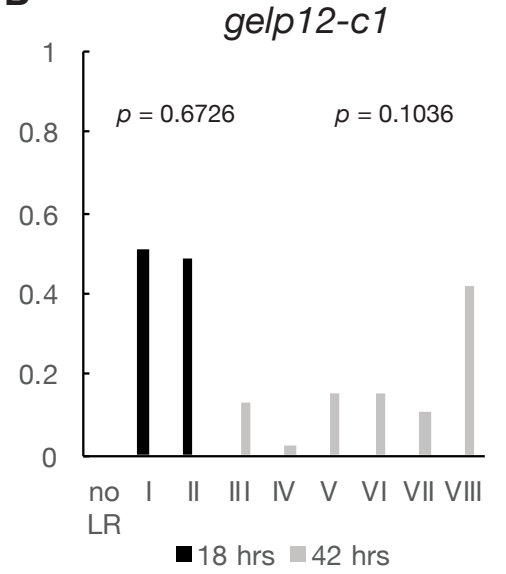

E

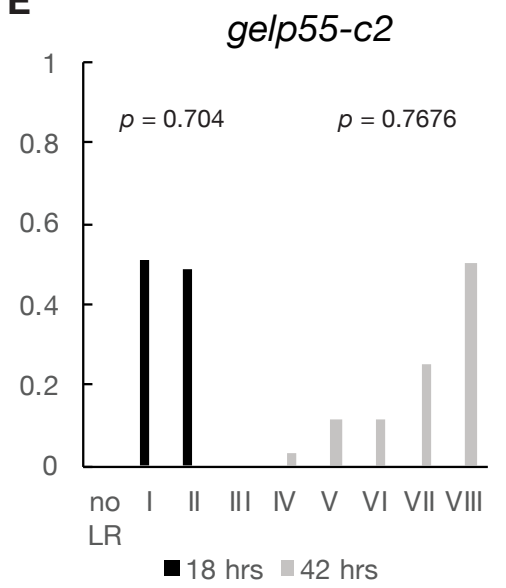

H

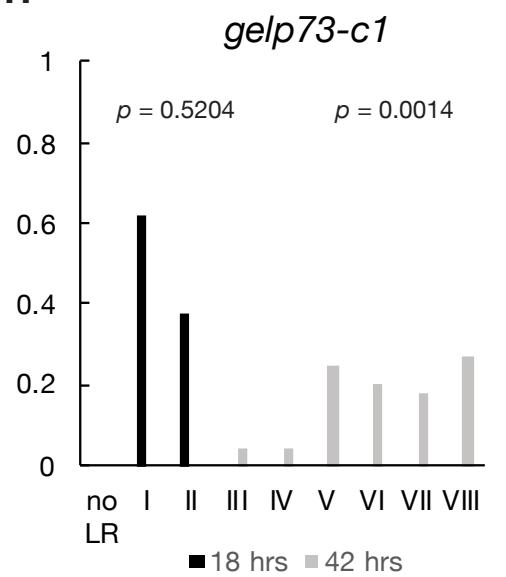

K

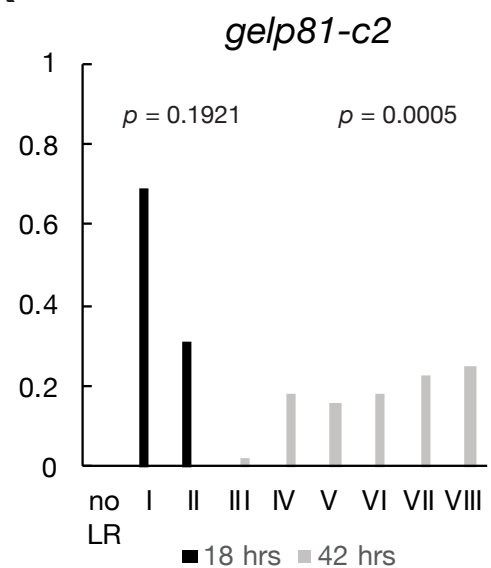

C

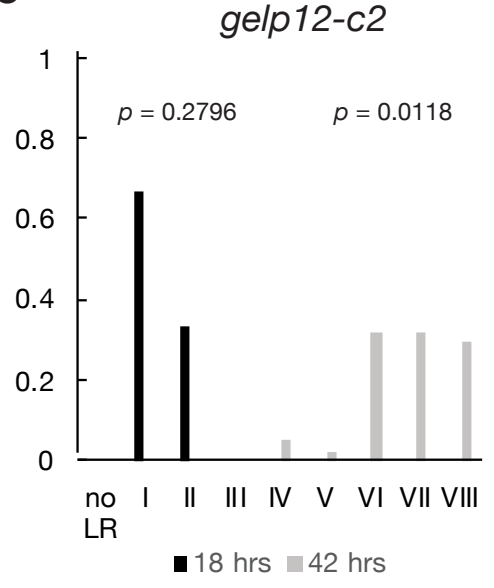

$\mathbf{F}$
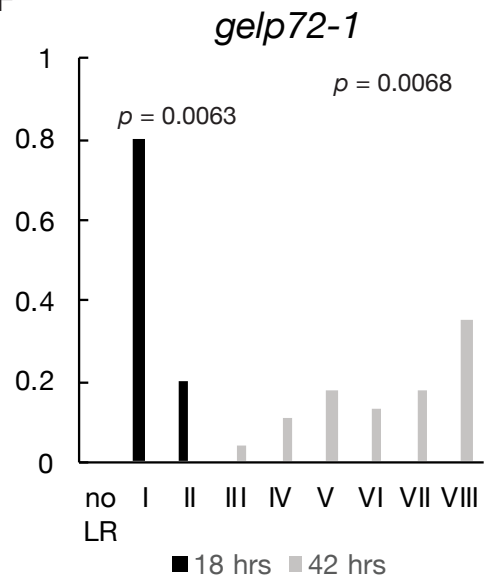

I

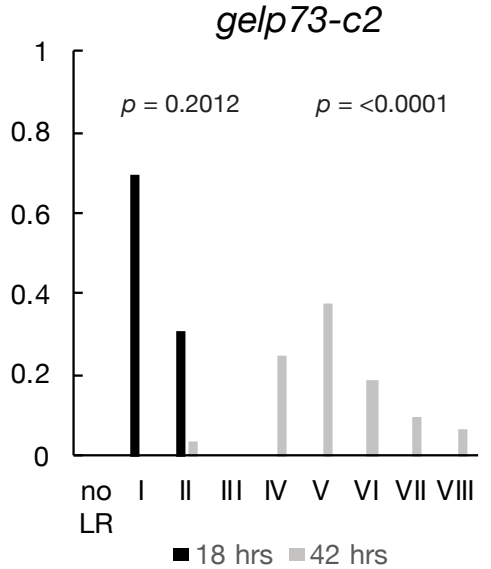


bioRxiv preprint doi: https://doi.org/10.1101/2020.06.25.171389; this version posted June 27, 2020. The copyright holder for this preprint (which was not certified by peer review) is the author/funder, who has granted bioRxiv a license to display the preprint in perpetuity. It is made available under aCC-BY 4.0 International license.

Figure 6. Auxin-inducible GELPs facilitate lateral root emergence.

Gravistimulation-mediated induction of lateral root formation to functionally characterize the role of auxin-induced GELPs during lateral root formation. Staging of lateral root development was performed at $18 \mathrm{hr}$ and $42 \mathrm{hr}$ after gravistimulation. A. Col-0. B and C. gelp12-c1 and gelp12-c2. D and E. gelp55-c1 and gelp55-c2. F and G. gelp 72-1 and gelp 72-c1. H and I. gelp 73-c1 and gelp 73-c2. J and K. $p$ values are indicated. A $p$ value below 0.05 indicates a statistically significant difference as determined using the Pearsons's $\chi^{2}$ test. Experiments were repeated three times with a minimal of 15 seedlings per genotype and time point.

the removal of suberin in response to developmental and/ or environmental cues. First, we confirmed that also other fluorescent staining methods besides FY could visualize the local removal of suberin during lateral root formation. Both Auramine $\mathrm{O}$ and Nile Red can be used to visualize suberin in differentiated roots and both confirmed local degradation of suberin in cells overlying the lateral root (Figure 5B and C). Next, we assessed suberin staining in the bodyguard mutant. This $\alpha / \beta$ hydrolase was shown to be implicated in the establishment of the root cap cuticle (Berhin et al., 2019), but it was not clear whether it could also affect suberin accumulation in the endodermis. FY staining in bodyguard roots confirmed the effect on lateral root cap cuticle, but suberin degradation appears to be normal (Figure 5D and Figure S7B and C). When characterizing the expression patterns of the five putative suberin degrading GELPs, we observed three different expression patterns. GELP12 and GELP55 marker lines showed expression in the cortex or no signal in absence of lateral root formation, but were induced in endodermal cells overlying the lateral root from stage I to IV (Figure 5E and Figure S7D). GELP72 and GELP73 were only weakly induced in endodermal cells overlying the lateral root primordium, but from stage III and onwards they were induced in the outer layer of the growing primordium (Figure 5E and Figure S7E). Finally, GELP81 was already present in the endodermis prior to lateral root initiation and was induced in the overlying endodermal cells from stage I to IV. In addition, from stage IV and onwards GELP81 was induced in the outer layer of the primordium similarly to GELP72 and GELP73 (Figure $5 \mathrm{E}$ and Figure $\mathrm{S7C}$ ). In order to characterize a possible role in suberin degradation, we first undertook a gain-offunction approach by generating plant lines in which we could inducibly overexpress each GELP in the endodermis and assess whether this causes suberin removal using FY staining. Indeed, inducible expression of GELP12, GELP55 and GELP72 in the endodermis caused a disappearance of FY staining, whereas no clear effect on FY staining was observed when inducing GELP81 and GELP73 (Figure 5F and Figure S8A). We then tested whether single loss-offunction mutants of each individual GELP affects lateral root formation. We performed the root bending assay in order to synchronously induce lateral roots and to quantify the progression of lateral root development at $18 \mathrm{hr}$ and $42 \mathrm{hr}$ after gravistimulation (Lucas et al., 2008; Péret et al., 2012). Among the three GELPs that can degrade suberin based on FY staining, only one (gelp 72) showed a delayed lateral root development in both alleles and time points (Figure 6D-G). Surprisingly, the single mutants of the GELP73 and GELP81 genes - that did not affect FY staining when overexpressed in the endodermis - did display a delayed lateral root emergence (Figure $6 \mathrm{H}-\mathrm{K}$ ). Thus, a subset of auxin inducible GELPs can degrade suberin, possibly to facilitate lateral root emergence. Moreover, another subset of auxin inducible GELPs is also required for correct lateral root emergence, but may have functions unrelated to suberin degradation that we currently do not understand.

\section{DISCUSSION}

The auxin response of a differentiated tissue is very distinct from whole organ responses. We have shown in this study that differentiated root cells show response to auxin treatment. We achieved the strong enrichment for auxin responses in our specific cell type, the endodermis, by using different, tissuespecific auxin signaling mutants (Figure 1). A similar approach has also been employed to better understand auxin signaling during Arabidopsis embryogenesis (Schlereth et al., 2010). Comparing our data set to those of other auxin induced transcriptomes derived from whole roots or sections (Lewis et al., 2013; Voß et al., 2015) revealed that there was no clear overlap between these different datasets (Figure 2). This illustrates the importance of obtaining auxin-response profiles at cell typespecific resolution. It has been reported that nucleo-cytoplasmic partitioning of Auxin Response Factors was causing an attenuated auxin responsiveness in differentiated root tissues (Powers et al., 2019). While we cannot exclude an overall attenuation of auxin responses, we observed a similar induction of SHY2pro::NLS$3 x m$ VENUS along the differentiated endodermis, suggesting a similar auxin responsiveness of the endodermis along the root, at least in the differentiated zone. Moreover, while qualitatively very different from other auxin response profiles including meristematic tissues, our endodermis-focused response profile of differentiated root sections revealed differential expression of close to a thousand genes at significant amplitudes, not supporting the view of a strong attenuation of auxin responses in differentiated tissues.

Moreover, our functional validation demonstrates that the endodermal auxin response profile obtained is reliable: 24 out of 27 genes tested either showed endodermal or lateral rootassociated expression and among the GELP family members, their expression dynamics successfully predicted their respective roles in suberin biosynthesis or degradation.

\section{GDSL-domain containing genes are required for suberin homeostasis}

Although the Arabidopsis genome contains more than 100 GDSL-domain containing genes, only a few of them have been functionally linked to cell wall modification or have been demonstrated to be able to synthesize or degrade cell wall polymers (Naseer et al., 2012; Philippe et al., 2020; Yeats et al., 2012). Several suberin biosynthetic genes as well as transcriptional regulators have been identified in recent years (Beisson et al., 2007; Cohen et al., 2020; Kosma et al., 2014; Yadav et al., 2014). Although suberin is chemically similar to cutin, there are significant differences in its composition and its deposition within the cell wall and we still do not know how suberin is polymerized and degraded. The finding that the GDSL-domain containing protein CUTICLE DESTRUCTION FACTOR 1 (CDEF1) is able to degrade suberin when overexpressed in the 
bioRxiv preprint doi: https://doi.org/10.1101/2020.06.25.171389; this version posted June 27,2020 . The copyright holder for this preprint (which was not certified by peer review) is the author/funder, who has granted bioRxiv a license to display the preprint in perpetuity. It is made available under aCC-BY 4.0 International license.

\section{bioR Xiv}

endodermis already hinted at the capacity of these types of genes to regulate suberin homeostasis (Naseer et al., 2012). However, till now, no GDSL-domain containing genes responsible for the polymerization of suberin in the endodermis have been identified. Our study now indicates that this was due to a high degree of functional redundancy. Only when all five auxin-repressed GELPs were knocked-out did we obtain roots without detectable suberin (Figure 4). All five of the identified GELPs are predicted to be expressed in the endodermis and secreted, supporting a role in cell wall modification.

It was demonstrated that $\mathrm{ABA}$ treatment induces suberization in both the endodermis and cortex (Barberon et al., 2016) and the fact that all five GELPs required for suberin polymerization were induced by ABA treatment (Figure S4), further support their specific role in suberization. Although the chemical analysis revealed a $-85 \%$ reduction in suberin monomers, it did not hint towards potential substrates for the biosynthetic GELPs. The ultrastructural studies on the roots of the gelp $p^{\text {quint- }}$ mutant also did not show evident agglomerations of unpolymerized material. Rather, a distinct, homogenous zone of low electron density was observed in place of the suberin lamellae. Whether this zone is composed of the remnant, non-polymerized lipidic suberin components (possibly becoming extracted during TEM processing) or whether this is matrix material of unknown, potentially polysaccharide nature remains to be investigated. Nevertheless, our data clearly indicate that the five auxin-repressed GELPs are absolutely required for endodermal suberin formation. In addition, we could show, using a functional GELP38:mCitrine fusion, that the GELPs are localized and active in the apoplast of the endodermis. Due to the demonstrated in vitro activity of CD1, a homologous gene family member regulating cutin polymerization, we consider that the five GELPs we have identified are suberin synthases, mediating polymerization of suberin precursors in the cell wall.

In the same dataset from which we identified the GELPs responsible for suberin polymerization, we additionally identified five GELPs that displayed opposite behavior, being induced by auxin treatment. Our gain- and loss-of-function approaches show that the relationship between suberin degradation and lateral root emergence seems to be a rather complex one. Although we could demonstrate suberin degradation for three of the five auxininduced GELPs, only one of these, GELP72, appeared to play a role in lateral root emergence on its own (Figure 6B-G). The idea that suberin needs to be degraded in order to facilitate lateral root emergence fits with the reduced number of lateral roots observed in the abcg2/ abcg6labcg20 mutant that has higher levels of suberin in its roots (Yadav et al., 2014). It might well be that a defect in suberin degradation interferes with the spatial accommodation responses in the endodermis, resulting in a delayed emergence. Interestingly, both of the auxin-induced GELPs for which we could not show a direct role in suberin degradation (GELP73 and GELP81) also displayed strong effects on lateral root emergence (Figure 6H-K). Although the phenotypes clearly suggest that they are involved in suberin homeostasis, follow-up studies are required to reveal if and how they modify suberin. Both genes appear to peak rather early during lateral root formation (Figure $5 \mathrm{~A}$ ) and could therefore also be involved in the formation of the cuticle at the lateral root primordium that protects the newly formed primordium. Indeed, defects in this structure also result in altered lateral root emergence (Berhin et al., 2019). We observed that several members of the group of auxin-inducible GELPs, besides being expressed in the endodermis, were also induced in the outer layer of the lateral root primordium (Figure 5). This would suggest that both the primordium and the endodermis contribute to suberin degradation and the concomitant formation of the lateral root cuticle. The fact that straight-forward overexpression of a single GELP can be sufficient to degrade suberin, fits to the idea that regulation of GELP expression is important to coordinate the degradation of the suberin lamellae and synthesis of the new cuticle structure. In this aspect it would be interesting to test if there is a functional hierarchy in the group of suberin degraders.

\section{GDSL-domain containing genes: an untapped potential for better understanding cell wall modifications and adaptation to different soil types}

As mentioned before, the Arabidopsis family of GDSL-domain containing proteins contains more than hundred members, for which little functional information is available (Shi et al., 2011; Yeats et al., 2012). Here we demonstrate that five members belonging to this family are essential for suberin formation. Thus, it deserves more attention as its members are likely to perform multiple central biological roles in cell wall modifications during plant development or during adaptation to different stress conditions. Although the functional redundancy within this family is significant, it can nowadays be overcome by modern, gene-editing technologies, as we have shown with the cluster of GELPs required for suberin polymerization. We predict that the suberin mutant described in this work will be a valuable tool to better understand the process of suberin and cutin formation. Using endodermal specific promoters, we can now quickly test which additional GELPs can synthesize suberin. In addition, it is now straightforward to test if cutin synthases such as CD1 are specific for cutin or whether they can also synthesize suberin. The example of the suberin degrading subgroups moreover demonstrates that not all GELPs act redundantly. We are convinced that the GELPs in Arabidopsis and other plants provide a rich, but still untapped potential, to better understand and manipulate cell walls during plant development.

\section{Experimental Procedures}

\section{Plant Material}

For all experiments, Arabidopsis thaliana ecotype Columbia (Col-0; wild-type) was used. Gene numbers, mutants, and transgenic lines used and generated in this study are described in Supplemental Experimental Procedures. The primers used for genotyping and qPCR-based verification of T-DNA lines are indicated in Table S5.

\section{Plant growth conditions}

For all experiments, plants were germinated on solid halfstrength Murashige and Skoog (MS) medium without addition of sucrose. Seeds were surface sterilized, sown on plates, incubated for 2 days at $4^{\circ} \mathrm{C}$ for stratification, and grown vertically in growth chambers at $22^{\circ} \mathrm{C}$, under continuous light $(100 \mu \mathrm{E})$. The microscopic analyses (FDA uptake, FY staining, PI uptake, confocal microscopy) were performed on 5 or 7 -day-old seedlings.

\section{Bending experiments}

Seeds of wild-type Col-0 and gelp mutants were plated on half strength MS containing $120 \times 120 \times 17 \mathrm{~mm}$ square 
bioRxiv preprint doi: https://doi.org/10.1101/2020.06.25.171389; this version posted June 27, 2020. The copyright holder for this preprint (which was not certified by peer review) is the author/funder, who has granted bioRxiv a license to display the preprint in perpetuity. It is made available under aCC-BY 4.0 International license.

Petri dishes, stratified in the dark at $4^{\circ} \mathrm{C}$ for 2 days, and grown at $22^{\circ} \mathrm{C}$ under constant light $(100 \mu \mathrm{E})$. Lateral root stages were determined after plates with 4-day-old seedlings were rotated $90^{\circ}$ degrees and grown for $18 \mathrm{hr}$ and $42 \mathrm{hr}$ for synchronized lateral root induction. After bending for $18 \mathrm{hr}$ and $42 \mathrm{hr}$, the roots were cleared as described by (Voß et al., 2015) and mounted in 50\% glycerol. Determination of lateral root stage in the bent region was done using an upright microscope with differential interference contrast optics. Experiments were repeated three times and each replicate had at least 15 seedlings.

\section{Generation of transgenic lines}

CASP1 pro::shy2-2 was crossed into $s l r-1$ mutant to produce CASP1::shy2-2/slr-1 line. For generating marker lines and overexpression constructs, the In-Fusion Advantage PCR Cloning Kit (Clontech) and Gateway Cloning Technology (Invitrogen) were used. All constructs were transformed by heat shock into Agrobacterium tumefaciens GV3101 strain and then transformed into plants by floral dipping (Clough and Bent, 1998). At least 10 independent transgenic lines were analyzed for expression patterns, and 1 line showing a representative signal and normal segregation was selected for further studies. For transcriptional reporters, the promoter regions were PCR-amplified from Col-0 genomic DNA and cloned into pDONRP4-P1R (www.thermofisher. com). The resulting plasmids were recombined together with pDONRL1-NLS-3xmVENUS-L2 (Gasperini et al., 2015) and the destination vector pFR7m24GW or pFG7m24GW, containing the FastRed or FastGreen cassettes for transgenic seed selection respectively, to create the final PROMOTER::NLS-3xmVENUS expression clones. To be able to induce expression of individual GELPs in the endodermis, the corresponding pDONR221_L1-GELP-L2 clones were created. The resulting clones were recombined with the estradiolinducible pDONR_P4-ELTPproXVE-P1R (Andersen et al., 2018) and destination vector $\mathrm{pB} 7 \mathrm{~m} 24 \mathrm{GW}$, to produce ELTPproXVE::GELP overexpression lines. To generate GELP38proXVE> $>$ GELP38:mCitrine, the promoter region of GELP38pro was PCR-amplified from Col-0 genomic DNA and cloned into linearized p1R4-ML:XVE (Siligato et al., 2016) with KpnI enzyme by Infusion (Takara) cloning to produce the inducible GELP38proXVE promoter clone. The resulting clone was recombined together with pDONR221_L1-GELP38-L2, pDONR_R2-mCitrine-L3 and pFG7m34GW to produce GELP38proXVE>>GELP38:mCitrine construct. See Table S3 and Table S4 for details about the primers used for cloning. The primers used for generating single and multiple CRISPR/Cas9 mutants are indicated in the Table S7. See Table S3 and Table S4 for details about the primers used for cloning. The primers used for generating single and multiple CRISPR/Cas9 mutants are indicated in the Table S7.

\section{Hormonal treatments}

bioRXiv PREPRINT

Abscisic acid (ABA) was stored as a $50 \mathrm{mM}$ stock solution in methanol. When seedlings were subjected to short-term $10 \mu \mathrm{M}$ ABA treatment, the transfer was done when the seedlings were 4-days-old. $\beta$-Estradiol was prepared as 100 $\mathrm{mM}$ stock in DMSO. In case of $\beta$-Estradiol treatment, the seedlings were directly germinated on the media containing $5 \mu \mathrm{M}$ Estradiol. For salt experiments, the seedlings were grown on half-strength MS medium and transferred to $85 \mathrm{mM} \mathrm{NaCl}$ for 10 days. In case of auxin (NAA) treatment for RNAseq experiments, the seedlings were first grown on half-strength MS medium and then transferred to $10 \mu \mathrm{M}$ NAA for 4, 8, 16 and 24 hours. At each time point the, the shoots and the root tips were removed.

\section{Chemical analysis of suberin}

Chemical analysis of suberin was performed on six-day old seedlings. Prior to analysis we confirmed that the used growth conditions did not affect the phenotype of gelpquint-1 and gelp $p^{\text {quint-2 }}$ via FY staining. We used the protocol for the determination of ester-bond lipids as described by Berhin et al. (2019). In brief, $200 \mathrm{mg}$ of seeds were grown on nylon mesh (200 mm pore size). After six days, the roots were shaved off after flash freezing and extracted in isopropanol/0.01\% butylated hydroxytoluene (BHT). They were then delipidized three times $(1 \mathrm{~h}, 16 \mathrm{~h}, 8 \mathrm{~h})$ in each of the following solvents, i.e., chloroform-methanol (2:1), chloroform-methanol (1:1), methanol with $0.01 \%$ BHT, under agitation before being dried for 3 days under vacuum. Depolymerization was performed by base catalysis (Li-Beisson et al., 2013). Briefly, dried plant samples were transesterified in $2 \mathrm{~mL}$ of reaction medium. $20 \mathrm{~mL}$ reaction medium was composed of $3 \mathrm{~mL}$ methyl acetate, $5 \mathrm{~mL}$ of $25 \%$ sodium methoxide in dry methanol and $12 \mathrm{~mL}$ dry methanol. The equivalents of $5 \mathrm{mg}$ of methyl heptadecanoate and $10 \mathrm{mg}$ of $\omega$-pentadeca-lactone/sample were added as internal standards. After incubation of the samples at $60^{\circ} \mathrm{C}$ for $2 \mathrm{~h} 3.5 \mathrm{~mL}$ dichloromethane, $0.7 \mathrm{~mL}$ glacial acetic acid and $1 \mathrm{~mL} 0.9 \% \mathrm{NaCl}(\mathrm{w} / \mathrm{v})$ Tris 100 $\mathrm{mM} \mathrm{pH} 8.0$ were added to each sample and subsequently vortexed for $20 \mathrm{~s}$. After centrifugation (1500 g for $2 \mathrm{~min}$ ), the organic phase was collected, washed with $2 \mathrm{~mL}$ of $0.9 \% \mathrm{NaCl}$, and dried over sodium sul- fate. The organic phase was then recovered and concentrated under a stream of nitrogen. The resulting cutin monomer fraction was derivatized with BFTSA/pyridine $(1: 1)$ at $70^{\circ} \mathrm{C}$ for $1 \mathrm{~h}$ and injected out of hexane on a HP-5MS column (J\&W Scientific) in a gas chromatograph coupled to a mass spectrometer and a flame ionization detector (Agilent $6890 \mathrm{~N}$ GC Network systems). The temperature cycle of the oven was the following: $2 \mathrm{~min}$ at $50^{\circ} \mathrm{C}$, increment of $20^{\circ} \mathrm{C} / \mathrm{min}$ to $160^{\circ} \mathrm{C}$, of $2^{\circ} \mathrm{C} / \mathrm{min}$ to $250^{\circ} \mathrm{C}$ and $10^{\circ} \mathrm{C} / \mathrm{min}$ to $310^{\circ} \mathrm{C}$, held for $15 \mathrm{~min} .3$ independent experiments were performed with 4 replicates for each genotype, respectively, and a representative dataset is presented. The amounts of unsubstituted C16 and C18 fatty acids were not evaluated because of their omnipresence in the plant and in the environment. 
bioRxiv preprint doi: https://doi.org/10.1101/2020.06.25.171389; this version posted June 27,2020 . The copyright holder for this preprint (which was not certified by peer review) is the author/funder, who has granted bioRxiv a license to display the preprint in perpetuity. It is made available under aCC-BY 4.0 International license.

\section{bioR XIV PREPRINT}

\section{Fluorescence Microscopy}

Confocal laser-scanning microscopy images were obtained using either a Zeiss LSM 880, Leica SP8 or Leica SP8-MP microscopes. For green and red fluorophores, the following excitation and detection windows were used: mVENUS/ GFP/FY/FDA $488 \mathrm{~nm}, 500-530 \mathrm{~nm}$; mCITRINE 496 $\mathrm{nm}, 505-530 \mathrm{~nm}$; PI $520 \mathrm{~nm}, 590-650 \mathrm{~nm}$; Calcofluor White 405nm, 430-485 nm; Basic Fuchsin/Nile Red $561 \mathrm{~nm}, 600-630 \mathrm{~nm}$. For multiphoton microscopy the following excitation and detection settings were used: mVENUS/GFP/FY/Calcofluor White 960nm, 435-485nm (Calcofluor White) and 500-550nm (mVENUS/GFP/FY). Methods for imaging the CS lignin and PI penetration were previously described (Fujita et al., 2020; Ursache et al., 2018). The details of modified methanol-based FY staining are presented in Supplemental Experimental Procedures. For visualization of FDA transport, chambered cover glasses (Thermo Scientific), were used where the roots were covered with a slice of agar and time lapses were made right after the application of FDA.

\section{Electron Microscopy}

For chemical fixation, plants were fixed in glutaraldehyde solution (EMS, Hatfield, PA) $2.5 \%$ in phosphate buffer (PB $0.1 \mathrm{M}$ [pH 7.4]) for $1 \mathrm{~h}$ at $\mathrm{RT}$ and post fixed in a fresh mixture of osmium tetroxide 1\% (EMS) with 1.5\% of potassium ferrocyanide (Sigma, St. Louis, MO) in PB buffer for $1 \mathrm{~h}$ at RT. The samples were then washed twice in distilled water and dehydrated in ethanol solution (Sigma, St Louis, MO, US) at graded concentrations (30\%-40 $\min ; 50 \%-40 \mathrm{~min} ; 70 \%-40 \mathrm{~min} ; 100 \%-2 \mathrm{x} 1 \mathrm{~h}$ ). This was followed by infiltration in Spurr resin (EMS, Hatfield, PA, US) at graded concentrations (Spurr 33\% in ethanol4h; Spurr 66\% in ethanol-4h; Spurr 100\%-2x8h) and finally polymerized for $48 \mathrm{~h}$ at $60^{\circ} \mathrm{C}$ in an oven. For the multiple mutant, ultrathin sections of $50 \mathrm{~nm}$ thick were cut transversally at $2 \mathrm{~mm}$ below the hypocotyl-root junction, using a Leica Ultracut (Leica Mikrosysteme GmbH, Vienna, Austria), picked up on a copper slot grid $2 \times 1 \mathrm{~mm}$ (EMS, Hatfield, PA, US) coated with a polystyrene film (Sigma, St Louis, MO, US). For lateral roots, ultrathin sections of $50 \mathrm{~nm}$ thick were cut longitudinally (transversally from main root). For High-Pressure freezing, plants were fixed in glutaraldehyde solution (EMS, Hatfield, PA) $2.5 \%$ in phosphate buffer (PB 0.1 M [pH 7.4]) for $1 \mathrm{~h}$ at RT and post-fixed in a fresh mixture of osmium tetroxide $1 \%$ (EMS) with $1.5 \%$ of potassium ferrocyanide (Sigma, St. Louis, MO) in PB buffer for $1 \mathrm{~h}$ at RT. The samples were then washed twice in distilled water before a High-Pressure Freezing step (HPF). For the High Pressure Freezing, $2 \mathrm{~mm}$ long root pieces were cut below the hypocotyl junction region, and then placed in an aluminum planchet of $3 \mathrm{~mm}$ in diameter with a cavity of $0.2 \mathrm{~mm}$ (Art.241, Wohlwend $\mathrm{GmbH}$, Sennwald, Switzerland) filled with Hexadecene (Merck KGaA, Darmstadt, Germany) covered with a tap planchet (Art.353, Wohlwend GmbH, Sennwald, Switzerland) and directly high-pressure frozen using a HighPressure Freezing Machine HPF Compact 02 (Wohlwend $\mathrm{GmbH}$, Sennwald, Switzerland). The samples were then dehydrated and infiltrated with resin at cold temperature using the Leica AFS2 freeze substitution machine (Leica Mikrosysteme GmbH, Vienna, Austria) with the following protocol: Dehydration in 100\% Acetone (Sigma, St Louis, $\mathrm{MO}, \mathrm{US})$ at graded temperature $\left(-90^{\circ} \mathrm{C}-10 \mathrm{~h}\right.$; from $-90^{\circ} \mathrm{C}$ to $-60^{\circ} \mathrm{C}$ in $2 \mathrm{~h} ;-60^{\circ} \mathrm{C}$ for $8 \mathrm{~h}$; from $-60^{\circ} \mathrm{C}$ to $-30^{\circ} \mathrm{C}$ in $2 \mathrm{~h}$; $-30^{\circ} \mathrm{C}-3 \mathrm{~h}$.) This was followed by infiltration in Spurr resin (EMS, Hatfield, PA, US) at graded concentration and temperature $\left(30 \%-10 \mathrm{~h}\right.$ from $-30^{\circ} \mathrm{C}$ to $0^{\circ} \mathrm{C} ; 66 \%-10 \mathrm{~h}$ from $0^{\circ} \mathrm{C}$ to $20^{\circ} \mathrm{C} ; 100 \%-2 \mathrm{X} 10 \mathrm{~h}$ at $20^{\circ} \mathrm{C}$ ) and finally polymerized for $48 \mathrm{~h}$ at $60^{\circ} \mathrm{C}$ in an oven. Ultrathin sections of $50 \mathrm{~nm}$ thick were cut transversally to the root, using a Leica Ultracut (Leica Mikrosysteme GmbH, Vienna, Austria), picked up on a copper slot grid $2 \times 1 \mathrm{~mm}$ (EMS, Hatfield, PA, US) coated with a polystyrene film (Sigma, St Louis, MO, US). Micrographs and panoramic were taken with a transmission electron microscope FEI CM100 (FEI, Eindhoven, The Netherlands) at an acceleration voltage of $80 \mathrm{kV}$ with a TVIPS TemCamF416 digital camera (TVIPS GmbH, Gauting, Germany) using the software EM-MENU 4.0 (TVIPS GmbH, Gauting, Germany). Panoramic were aligned with the software IMOD (Kremer et al., 1996).

\section{RNA-seq experiments}

Seeds were surface sterilized, sown on plates, incubated 2 days at $4^{\circ} \mathrm{C}$ for stratification, and grown vertically in growth chambers at $22^{\circ} \mathrm{C}$, under continuous light $(100 \mu \mathrm{E})$ for 6 days. For each biological replicate (3 in total) 60 seedlings from each genotype were transferred to plates (20 seedlings per plate) containing $1 / 2$ MS medium supplemented with $10 \mu \mathrm{M}$ NAA and transferred back into the growth chamber. After the desired incubation period $(2,4,8,16$ and 24hrs) seedlings were harvested after removal of the root apical meristem $(-3 \mathrm{~mm})$ and the shoot including hypocotyl and snap frozen in liquid nitrogen. RNA was extracted using a Trizol-based method. After RNase-free DNase (www.qiagen.com) treatment, RNA was cleanedup using a RNeasy mini-elute kit (www.qiagen.com). RNA-seq libraries were prepared as described (Jan et al., 2019). In brief, RNA quality was assessed on a Fragment Analyzer (Advanced Analytical Technologies, Inc., Ankeny, IA, USA). RNA-seq libraries were prepared using $1000 \mathrm{ng}$ of total RNA and the Illumina TruSeq Stranded mRNA reagents (Illumina; San Diego, California, USA) on a Sciclone liquid handling robot (PerkinElmer; Waltham, Massachusetts, USA) using a PerkinElmer-developed automated script. Cluster generation was performed with the resulting libraries using the Illumina TruSeq SR Cluster Kit v4 reagents and sequenced on the Illumina HiSeq 2500 using TruSeq SBS Kit v4 reagents. Sequencing data were processed using the Illumina Pipeline Software version 2.2.

\section{RNA-seq data processing and analysis}

Data processing was performed by the Lausanne Genomic Technologies Facility using their in-house RNA-seq pipeline. Data analysis was done using an in-house RNAseq pipeline that performed the following steps. Quality 
bioRxiv preprint doi: https://doi.org/10.1101/2020.06.25.171389; this version posted June 27,2020 . The copyright holder for this preprint (which was not certified by peer review) is the author/funder, who has granted bioRxiv a license to display the preprint in perpetuity. It is made available under aCC-BY 4.0 International license.

controls were applied for cleaning data for adapters and trimming of low-quality sequence ends. Cleaned data was aligned and read counts computed using two methods: STAR (Dobin et al., 2013) + HTSeq (Anders et al., 2015) and STAR + RSEM (Li and Dewey, 2011). First method generates gene counts and the second method generates isoform counts. TAIR10 genome and Ensembl 21 annotation were used. Additional quality controls were performed using $\mathrm{R}$ for inspecting the sample counts summary, pairwise sample correlations, clustering and sample PCA. Statistical analysis was performed for genes and isoforms with the Bioconductor package EdgeR ( $R$ version 3.4.0) for normalization and limma ( $R$ version 3.18.2) for differential expression. Two types of statistical tests were applied depending on the contrast model tested. A moderated t-test was used for each pairwise comparison in group t0 and group $s l r-1$ vs CASP1pro::shy2-2/slr-1. A moderated F-test was used for each time course model and their interaction. The result files contain one row per gene or transcript. Adjusted $p$-values have been computed for each comparison by the Benjamini-Hochberg method, controlling for false discovery rate (FDR). Genes were considered significant in further analysis if the adjusted $p$-value was equal or below 0.05 and the $\log 2$ fold change was $\geq 1$. Further analysis has been conducted using R (v. 3.4.1). Heatmaps were generated using ComplexHeatmap (Gu et al., 2016) ( v1.14.0) using pearson distance, and "average" for clustering. Non-supervised clustering of genes using kmeans (factoextra v1.0.4, https://github. $\mathrm{com} /$ kassambara/factoextra) suggested 3 clusters as optimal together. This represented a very low resolution and we looked into clusters of size 4-8 which contained slightly lower silhouette values. After testing manually multiple cluster suggestions we settled onto 7 inferred clusters based on the biologically most sensible separation. $\mathrm{GO}$ analysis was conducted using the package topGO [v. 2.28.0, weight01 algorithm; (Alexa and Rahnenfuhrer, 2019)]. GO annotations were obtained through org. At.tairGO (version 3.4.1). For the comparison with Lewis et al. (2013), the published series matrix file was obtained from the GEO archive and the differential gene-expression analysis repeated in order to obtain the expression of all genes. Results were compared to their published table of differentially expressed genes and found to be highly similar. A z-score based on the $\log \mathrm{FC}$ value was calculated for both, our data-sets and the re-analyzed Lewis et al. (2013) data to make the different sets more comparable. For the comparison with Voß et al. (2015) we used directly the published table which included all expressed genes and calculated $\mathrm{z}$-scores for the different time-points. We kept T0, T6, T9, T15 and T24 which resulted in 7145 differentially regulated genes with similar cut-off of $p<0.05$ and a fold-change of 2 .

\section{qPCR analysis}

For qPCR quantifications, the plants were grown on plates with half-strength MS medium covered with mesh. In case of quintuple gelp mutants, only root parts (around $100 \mathrm{mg}$ ) were collected and total RNA was extracted using a Trizol- adapted ReliaPrep RNA Tissue Miniprep Kit (Promega). For verifying the transcript level in single T-DNA lines, RNA extraction from whole seedlings was performed. Reverse transcription was carried out with PrimeScript RT Master Mix (Takara). All steps were done as indicated in manufacturer's manual. The qPCR reaction was performed on an Applied Biosystems QuantStudio3 thermocycler using a MESA BLUE SYBR Green kit (Eurogentech). All transcripts were normalized to ADAPTOR PROTEIN-4 MU-ADAPTIN, AP4M (AT4G24550) expression. All primers used for qPCR are indicated in Table S6.

\section{HRM analysis of CRISPR mutants}

HRM method was employed to screen for the mutants generated using CRISPR/Cas9-based method. Genomic DNA of selected Cas9-free, T2 generation plants, was extracted using CTAB DNA extraction method. The qPCR reaction was performed on Applied Biosystems QuantStudio3 thermocycler using a MeltDoctor HRM Master Mix, according to manufacturer's indications (Applied Biosystems). HPLC-purified primers were used to generate an amplicon of around 200 base pairs. The results were analyzed using High Resolution Melt Software v3.1 (Thermo Fisher Scientific). The selected candidates were verified by sequencing. Primers used for amplification and sequencing the potential mutation sites are indicated in Table S8 and table S9.

\section{Quantification and Statistical Analysis}

For quantifying the FY occupancy, confocal images were analyzed with the Fiji package (http://fiji.sc/Fiji) (Schindelin et al., 2012). Contrast and brightness were adjusted in the same manner for all images. The suberized regions of the roots were measured together with total root lengths to determine the percentage of suberin occupancy. All statistical analyses were done with the GraphPad Prism 8.0 software (https://www.graphpad.com/) or using the R package (http://www.r-project.org). One-way ANOVA was performed, and Tukey's test was subsequently used as a multiple comparison procedure. For the analysis of lateral root development using the bending assay, we used a Pearsons's $\chi^{2}$ test. Details about the statistical approaches used can be found in the figure legends. The data are presented as mean $\pm S D$, and " $n$ " represents number of plant roots. Each experiment was repeated at least 3 times.

\section{ACKNOWLEDGEMENTS}

We would to thank Christopher Grefen and Marie Barberon for insightful discussion about GDSL-domain containing proteins, experimental approaches and feedback on the manuscript. We thank the Electron Microscopy Facility and Imaging Facility of the University of Lausanne and the Center of Microcopy and Image Analysis of the University of Zurich for excellent service and support. Work in the Geldner lab was supported by an ERC Consolidator Grant (GA-N: 616228-ENDOFUN), two consecutive Swiss National Science Foundation (Schweizerischer 
bioRxiv preprint doi: https://doi.org/10.1101/2020.06.25.171389; this version posted June 27,2020 . The copyright holder for this preprint (which was not certified by peer review) is the author/funder, who has granted bioRxiv a license to display the preprint in perpetuity. It is made available under aCC-BY 4.0 International license.

\section{bioR Xiv}

Nationalfonds zur Förderung der Wissenschaftlichen Forschung) grants (CRSII3_136278 and 31003A-156261). Robertas Ursache was supported by an EMBO Long-Term Fellowship (EMBO ALTF 1046-2015). Work in the Nawrath lab was supported by SNSF grant (310030_188672/1). Work in the Vermeer lab was supported by SNSF grants PP00P3_157524 and 316030_164086) and support from the University of Neuchâtel.

\section{AUTHOR CONTRIBUTIONS}

R.U., N.G. and J.E.M.V. conceived, designed and coordinated the project. R.U., C.D.J.T.V, V.D.T., D.d.B., K.G., V.S., T.G.A. and J.E.M.V. performed all eperimental work. E.S.S., S.C. and S.P. analysed NGS data. J.E.M.V. wrote the first draft of the manuscript. R.U. T.G.A. C.N. N.G. and J.E.M.V. revised the manuscript and all authors were involved in the discussion of the work.

\section{COMPETING INTERESTS}

The authors declare no competing interest.

\section{REFERENCES}

Alexa, A., and Rahnenfuhrer, J. (2019). topGO: Enrichment Analysis for Gene Ontology. R package version 2381.

Anders, S., Pyl, P.T., and Huber, W. (2015). HTSeq--a Python framework to work with high-throughput sequencing data. Bioinformatics 31, 166-169.

Andersen, T.G., Molina, D., Kilian, J., Franke, R., Ragni, L., and Geldner, N. (2020). Tissue-autonomous phenylpropanoid production is essential for establishment of root barriers. bioRxiv.

Andersen, T.G., Naseer, S., Ursache, R., Wybouw, B., Smet, W., De Rybel, B., Vermeer, J.E.M., and Geldner, N. (2018). Diffusible repression of cytokinin signalling produces endodermal symmetry and passage cells. Nature 555, 529-533.

Bakan, B., and Marion, D. (2017). Assembly of the Cutin Polyester: From Cells to Extracellular Cell Walls. Plants (Basel) 6.

Banda, J., Bellande, K., von Wangenheim, D., Goh, T., Guyomarc'h, S., Laplaze, L., and Bennett, M.J. (2019). Lateral Root Formation in Arabidopsis: A Well-Ordered LRexit. Trends Plant Sci 24, 826-839.

Barberon, M., Vermeer, J.E., De Bellis, D., Wang, P., Naseer, S., Andersen, T.G., Humbel, B.M., Nawrath, C., Takano, J., Salt, D.E., et al. (2016). Adaptation of Root Function by NutrientInduced Plasticity of Endodermal Differentiation. Cell 164, 447459.

Beisson, F., Li, Y., Bonaventure, G., Pollard, M., and Ohlrogge, J.B. (2007). The acyltransferase GPAT5 is required for the synthesis of suberin in seed coat and root of Arabidopsis. Plant Cell 19, 351-368.

Berhin, A., de Bellis, D., Franke, R.B., Buono, R.A., Nowack, M.K., and Nawrath, C. (2019). The Root Cap Cuticle: A Cell Wall Structure for Seedling Establishment and Lateral Root Formation. Cell 176, 1367-1378 e1368.

Clough, S.J., and Bent, A.F. (1998). Floral dip: a simplified method for Agrobacterium-mediated transformation of
Arabidopsis thaliana. Plant J 16, 735-743.

Cohen, H., Fedyuk, V., Wang, C., Wu, S., and Aharoni, A. (2020). SUBERMAN regulates developmental suberization of the Arabidopsis root endodermis. Plant J.

Dobin, A., Davis, C.A., Schlesinger, F., Drenkow, J., Zaleski, C., Jha, S., Batut, P., Chaisson, M., and Gingeras, T.R. (2013). STAR: ultrafast universal RNA-seq aligner. Bioinformatics 29, 15-21.

Edqvist, J., Blomqvist, K., Nieuwland, J., and Salminen, T.A. (2018). Plant lipid transfer proteins: are we finally closing in on the roles of these enigmatic proteins? J Lipid Res 59, 1374-1382.

Fich, E.A., Segerson, N.A., and Rose, J.K. (2016). The Plant Polyester Cutin: Biosynthesis, Structure, and Biological Roles. Annu Rev Plant Biol 67, 207-233.

Fujita, S., De Bellis, D., Edel, K.H., Koster, P., Andersen, T.G., Schmid-Siegert, E., Denervaud Tendon, V., Pfister, A., Marhavy, P., Ursache, R., et al. (2020). SCHENGEN receptor module drives localized ROS production and lignification in plant roots. EMBO J, e103894.

Fukaki, H., Tameda, S., Masuda, H., and Tasaka, M. (2002). Lateral root formation is blocked by a gain-of-function mutation in the SOLITARY-ROOT/IAA14 gene of Arabidopsis. The Plant journal : for cell and molecular biology 29, 153-168.

Gasperini, D., Chetelat, A., Acosta, I.F., Goossens, J., Pauwels, L., Goossens, A., Dreos, R., Alfonso, E., and Farmer, E.E. (2015). Multilayered Organization of Jasmonate Signalling in the Regulation of Root Growth. PLoS genetics 11, e1005300.

Girard, A.L., Mounet, F., Lemaire-Chamley, M., Gaillard, C., Elmorjani, K., Vivancos, J., Runavot, J.L., Quemener, B., Petit, J., Germain, V., et al. (2012). Tomato GDSL1 is required for cutin deposition in the fruit cuticle. Plant Cell 24, 3119-3134.

Gu, Z., Eils, R., and Schlesner, M. (2016). Complex heatmaps reveal patterns and correlations in multidimensional genomic data. Bioinformatics 32, 2847-2849.

Jan, M., Gobet, N., Diessler, S., Franken, P., and Xenarios, I. (2019). A multi-omics digital research object for the genetics of sleep regulation. Sci Data 6, 258.

Kosma, D.K., Murmu, J., Razeq, F.M., Santos, P., Bourgault, R., Molina, I., and Rowland, O. (2014). AtMYB41 activates ectopic suberin synthesis and assembly in multiple plant species and cell types. Plant J 80, 216-229.

Kremer, J.R., Mastronarde, D.N., and McIntosh, J.R. (1996). Computer visualization of three-dimensional image data using IMOD. J Struct Biol 116, 71-76.

Kumpf, R.P., Shi, C.L., Larrieu, A., Sto, I.M., Butenko, M.A., Peret, B., Riiser, E.S., Bennett, M.J., and Aalen, R.B. (2013). Floral organ abscission peptide IDA and its HAE/HSL2 receptors control cell separation during lateral root emergence. Proceedings of the National Academy of Sciences of the United States of America 110, 5235-5240.

Lai, C.P., Huang, L.M., Chen, L.O., Chan, M.T., and Shaw, J.F. (2017). Genome-wide analysis of GDSL-type esterases/lipases in Arabidopsis. Plant Mol Biol 95, 181-197.

Lewis, D.R., Olex, A.L., Lundy, S.R., Turkett, W.H., Fetrow, J.S., and Muday, G.K. (2013). A Kinetic Analysis of the Auxin Transcriptome Reveals Cell Wall Remodeling Proteins That Modulate Lateral Root Development in Arabidopsis. The Plant cell.

Li, B., and Dewey, C.N. (2011). RSEM: accurate transcript quantification from RNA-Seq data with or without a reference 
bioRxiv preprint doi: https://doi.org/10.1101/2020.06.25.171389; this version posted June 27,2020 . The copyright holder for this preprint (which was not certified by peer review) is the author/funder, who has granted bioRxiv a license to display the preprint in perpetuity. It is made available under aCC-BY 4.0 International license.

genome. BMC Bioinformatics 12, 323.

Li, B., Kamiya, T., Kalmbach, L., Yamagami, M., Yamaguchi, K., Shigenobu, S., Sawa, S., Danku, J.M., Salt, D.E., Geldner, N., et al. (2017). Role of LOTR1 in Nutrient Transport through Organization of Spatial Distribution of Root Endodermal Barriers. Curr Biol 27, 758-765.

Li-Beisson, Y., Shorrosh, B., Beisson, F., Andersson, M.X., Arondel, V., Bates, P.D., Baud, S., Bird, D., Debono, A., Durrett, T.P., et al. (2013). Acyl-lipid metabolism. The Arabidopsis book / American Society of Plant Biologists 11, e0161.

Lucas, M., Godin, C., Jay-Allemand, C., and Laplaze, L. (2008). Auxin fluxes in the root apex co-regulate gravitropism and lateral root initiation. J Exp Bot 59, 55-66.

Naseer, S., Lee, Y., Lapierre, C., Franke, R., Nawrath, C., and Geldner, N. (2012). Casparian strip diffusion barrier in Arabidopsis is made of a lignin polymer without suberin. Proceedings of the National Academy of Sciences of the United States of America 109, 10101-10106.

Péret, B., Li, G., Zhao, J., Band, L.R., Voß, U., Postaire, O., Luu, D.-T., Da Ines, O., Casimiro, I., Lucas, M., et al. (2012). Auxin regulates aquaporin function to facilitate lateral root emergence. Nat Cell Biol 14, 991-998.

Philippe, G., Gaillard, C., Petit, J., Geneix, N., Dalgalarrondo, M., Bres, C., Mauxion, J.P., Franke, R., Rothan, C., Schreiber, L., et al. (2016). Ester Cross-Link Profiling of the Cutin Polymer of Wild-Type and Cutin Synthase Tomato Mutants Highlights Different Mechanisms of Polymerization. Plant Physiol 170, 807-820.

Philippe, G., Sorensen, I., Jiao, C., Sun, X., Fei, Z., Domozych, D.S., and Rose, J.K. (2020). Cutin and suberin: assembly and origins of specialized lipidic cell wall scaffolds. Curr Opin Plant Biol 55, 11-20.

Powers, S.K., Holehouse, A.S., Korasick, D.A., Schreiber, K.H., Clark, N.M., Jing, H., Emenecker, R., Han, S., Tycksen, E., Hwang, I., et al. (2019). Nucleo-cytoplasmic Partitioning of ARF Proteins Controls Auxin Responses in Arabidopsis thaliana. Mol Cell 76, 177-190 e175.

Salminen, T.A., Eklund, D.M., Joly, V., Blomqvist, K., Matton, D.P., and Edqvist, J. (2018). Deciphering the Evolution and Development of the Cuticle by Studying Lipid Transfer Proteins in Mosses and Liverworts. Plants (Basel) 7.

Schindelin, J., Arganda-Carreras, I., Frise, E., Kaynig, V., Longair, M., Pietzsch, T., Preibisch, S., Rueden, C., Saalfeld, S., Schmid, B., et al. (2012). Fiji: an open-source platform for biological-image analysis. Nat Methods 9, 676-682.

Schlereth, A., Moller, B., Liu, W., Kientz, M., Flipse, J., Rademacher, E.H., Schmid, M., Jurgens, G., and Weijers, D. (2010). MONOPTEROS controls embryonic root initiation by regulating a mobile transcription factor. Nature 464, 913-916.

Shi, J.X., Malitsky, S., De Oliveira, S., Branigan, C., Franke, R.B., Schreiber, L., and Aharoni, A. (2011). SHINE transcription factors act redundantly to pattern the archetypal surface of Arabidopsis flower organs. PLoS genetics 7, e1001388.

Siligato, R., Wang, X., Yadav, S.R., Lehesranta, S., Ma, G., Ursache, R., Sevilem, I., Zhang, J., Gorte, M., Prasad, K., et al. (2016). MultiSite Gateway-Compatible Cell Type-Specific Gene-Inducible System for Plants. Plant Physiol 170, 627-641.

Stoeckle, D., Thellmann, M., and Vermeer, J.E. (2018). Breakout-lateral root emergence in Arabidopsis thaliana. Curr Opin Plant Biol 41, 67-72.

\section{bioR Xiv}

Swarup, K., Benkova, E., Swarup, R., Casimiro, I., Peret, B., Yang, Y., Parry, G., Nielsen, E., De Smet, I., Vanneste, S., et al. (2008). The auxin influx carrier LAX3 promotes lateral root emergence. Nat Cell Biol 10, 946-954.

Tian, Q., Uhlir, N.J., and Reed, J.W. (2002). Arabidopsis SHY2/ IAA3 inhibits auxin-regulated gene expression. The Plant cell 14, 301-319.

Ursache, R., Andersen, T.G., Marhavy, P., and Geldner, N. (2018). A protocol for combining fluorescent proteins with histological stains for diverse cell wall components. Plant J 93, 399-412.

Vermeer, J.E., von Wangenheim, D., Barberon, M., Lee, Y., Stelzer, E.H., Maizel, A., and Geldner, N. (2014). A spatial accommodation by neighboring cells is required for organ initiation in Arabidopsis. Science 343, 178-183.

Vishwanath, S.J., Delude, C., Domergue, F., and Rowland, O. (2015). Suberin: biosynthesis, regulation, and polymer assembly of a protective extracellular barrier. Plant cell reports 34, 573586.

Voß, U., Wilson, M.H., Kenobi, K., Gould, P.D., Robertson, F.C., Peer, W.A., Lucas, M., Swarup, K., Casimiro, I., Holman, T.J., et al. (2015). The circadian clock rephases during lateral root organ initiation in Arabidopsis thaliana. Nature communications 6, 7641 .

Yadav, V., Molina, I., Ranathunge, K., Castillo, I.Q., Rothstein, S.J., and Reed, J.W. (2014). ABCG transporters are required for suberin and pollen wall extracellular barriers in Arabidopsis. Plant Cell 26, 3569-3588.

Yeats, T.H., Martin, L.B., Viart, H.M., Isaacson, T., He, Y., Zhao, L., Matas, A.J., Buda, G.J., Domozych, D.S., Clausen, M.H., et al. (2012). The identification of cutin synthase: formation of the plant polyester cutin. Nat Chem Biol 8, 609-611. 
bioRxiv preprint doi: https://doi.org/10.1101/2020.06.25.171389; this version posted June 27, 2020. The copyright holder for this preprint (which was not certified by peer review) is the author/funder, who has granted bioRxiv a license to display the preprint in perpetuity. It is made available under aCC-BY 4.0 International license.

\section{biORXIV PREPRINT}

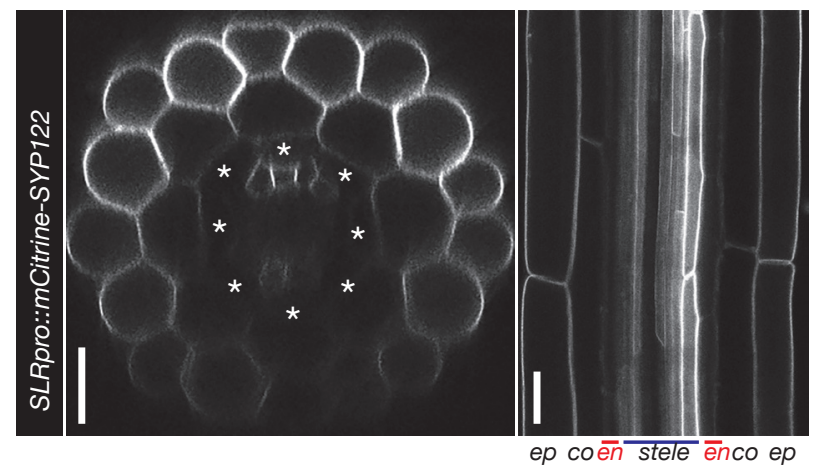

Supplemental Figure S1. SOLITARY ROOT is not expressed in the endodermis.

Confocal images of a root expressing SLRpro::CITRINE:SYP122 confirming that SLR is expressed in the epidermis, cortex, pericycle and weakly in the stele, but not in the endodermis (indicated by asterisks). Scale bar $=25 \mu \mathrm{m}$. 
bioRxiv preprint doi: https://doi.org/10.1101/2020.06.25.171389; this version posted June 27, 2020. The copyright holder for this preprint (which was not certified by peer review) is the author/funder, who has granted bioRxiv a license to display the preprint in perpetuity. It is made available under aCC-BY 4.0 International license.

bioR Xiv PREPRINT

A

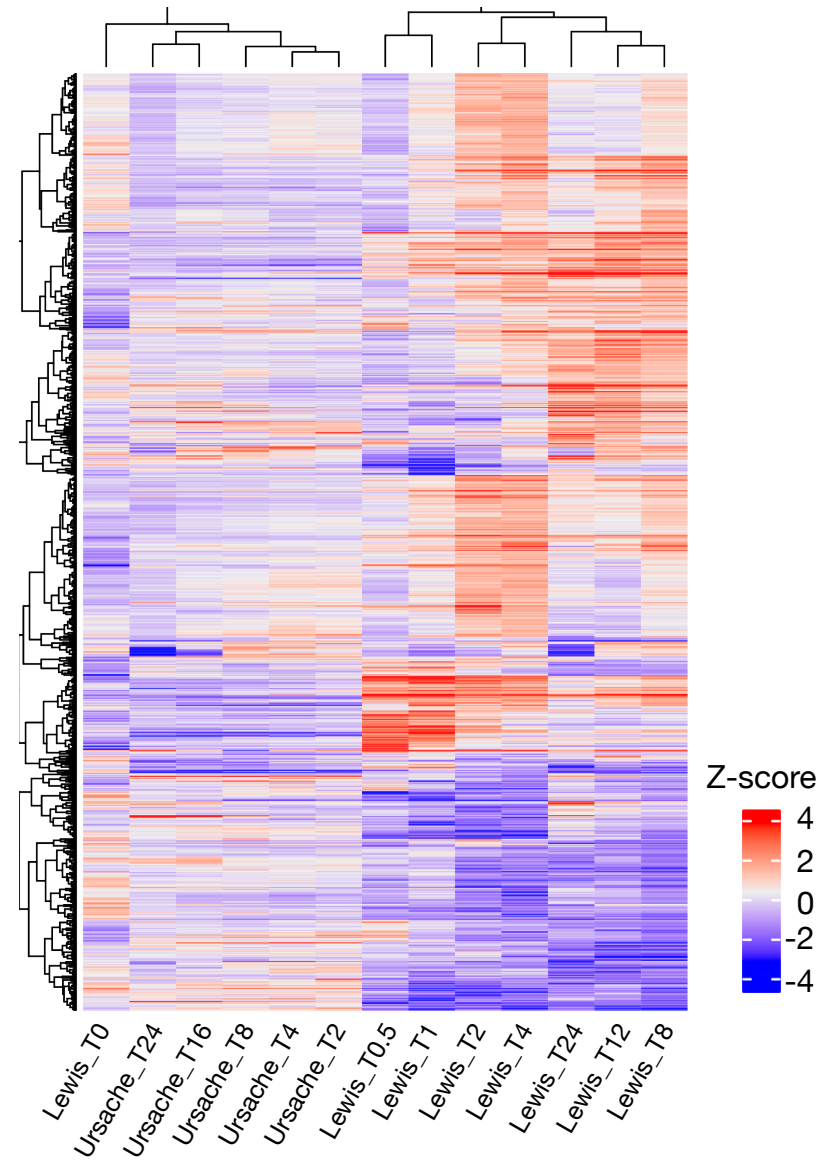

C

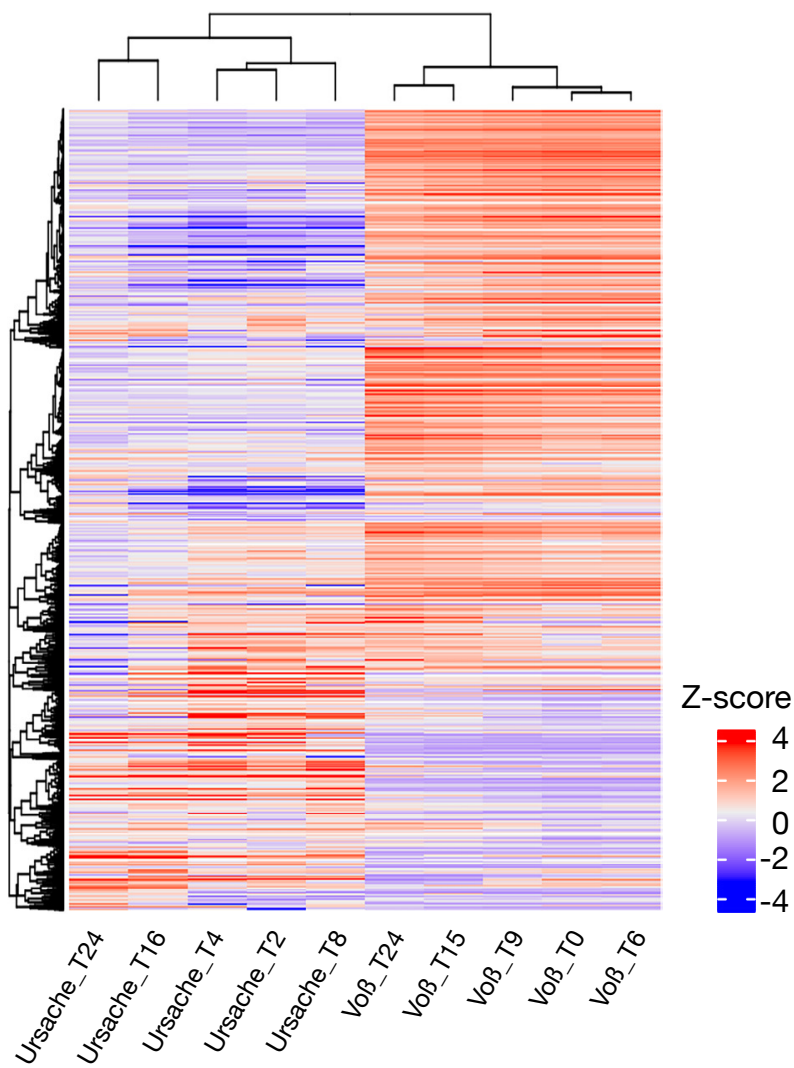

B

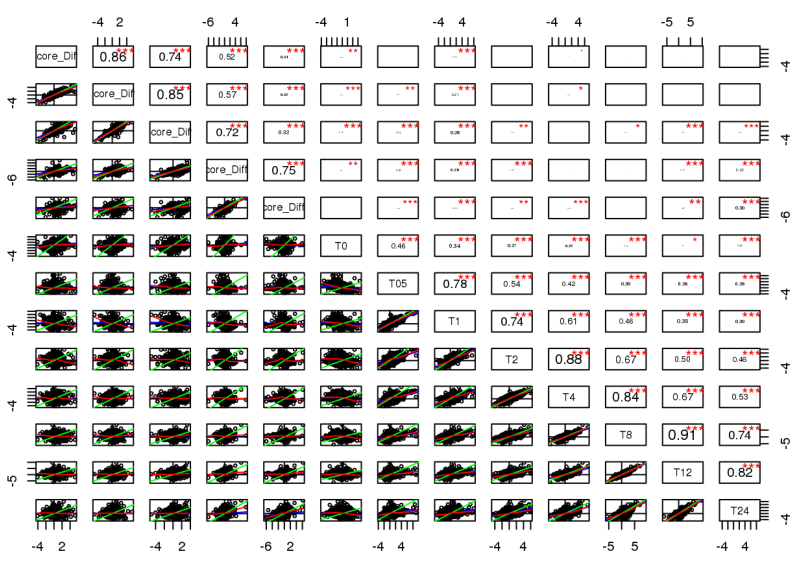

D

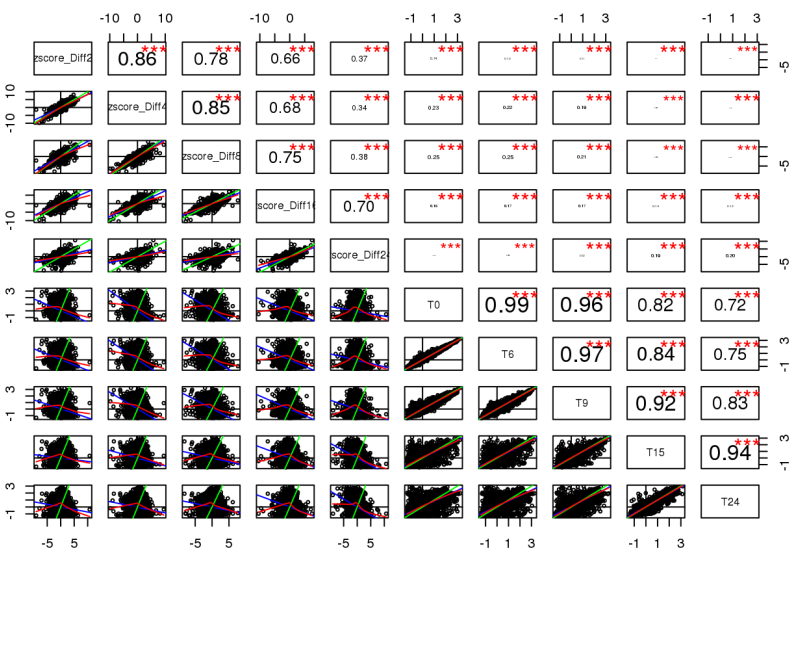

Supplemental Figure S2. Differentiated endodermal cells have a distinct transcriptional response to auxin.

A and B. Comparison of the current dataset (Ursache) with the data set of Lewis et al., (2013). A. Heatmap showing that both datasets cluster separately and do not have significant overlap, which is confirmed by the analysis of correlation between the two data sets (B). C and $\mathbf{D}$. Comparison of the current dataset (Ursache) with the data set of Voß et al., (2015). C. Heatmap showing that both datasets cluster separately and do not have significant overlap, which is confirmed by the analysis of correlation between the two data sets (D). 
bioRxiv preprint doi: https://doi.org/10.1101/2020.06.25.171389; this version posted June 27, 2020. The copyright holder for this preprint (which was not certified by peer review) is the author/funder, who has granted bioRxiv a license to display the preprint in perpetuity. It is made available under aCC-BY 4.0 International license.

\section{bioR $\chi$ IV $^{\text {PREPRINT }}$}

A

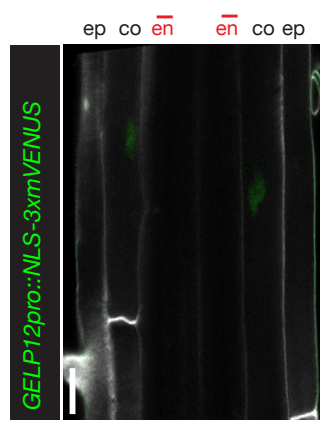

C
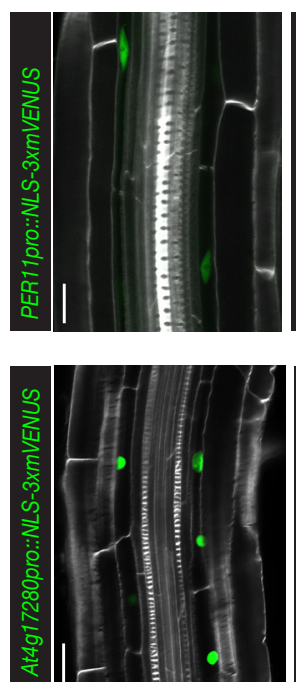

D

Not present in endodermis

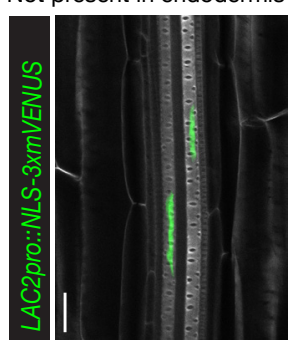

ep co en $\quad \overline{e n}$ coep ep co en $\overline{e n}$ co ep

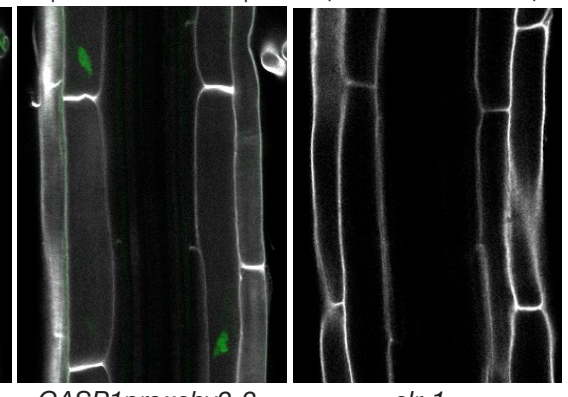

CASP1pro::shy2-2
B

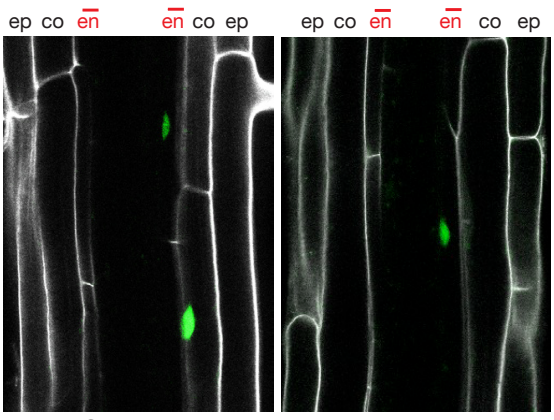

Col-0 + NAA s/r-1 + NAA

Endodermis-specific expression
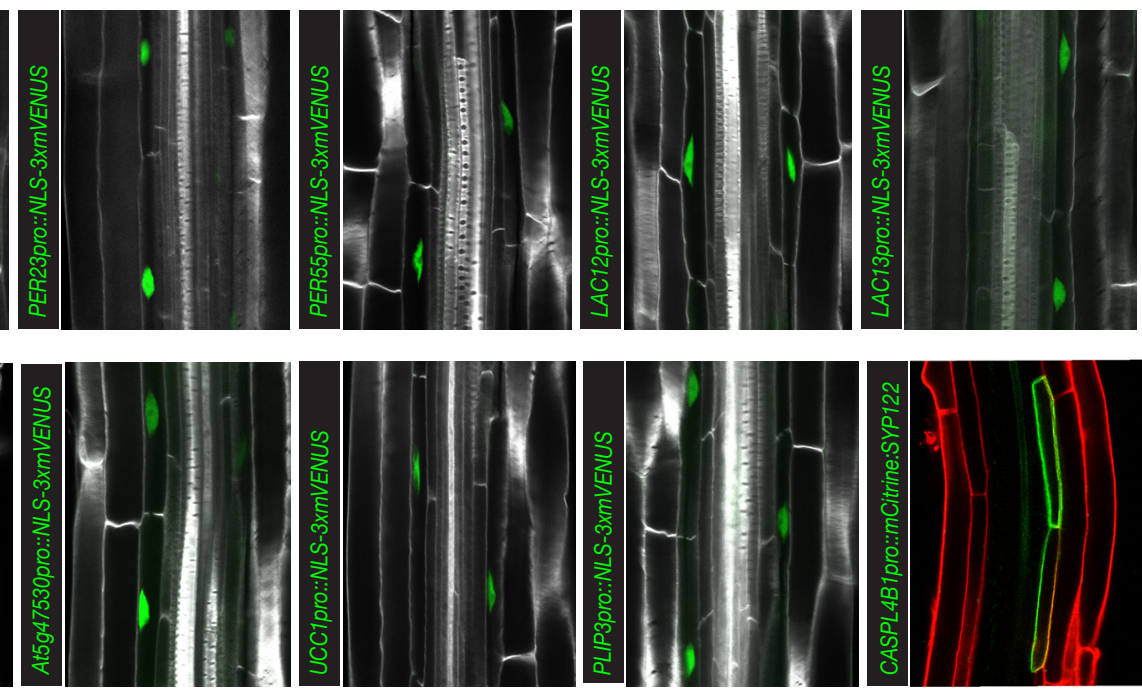

E

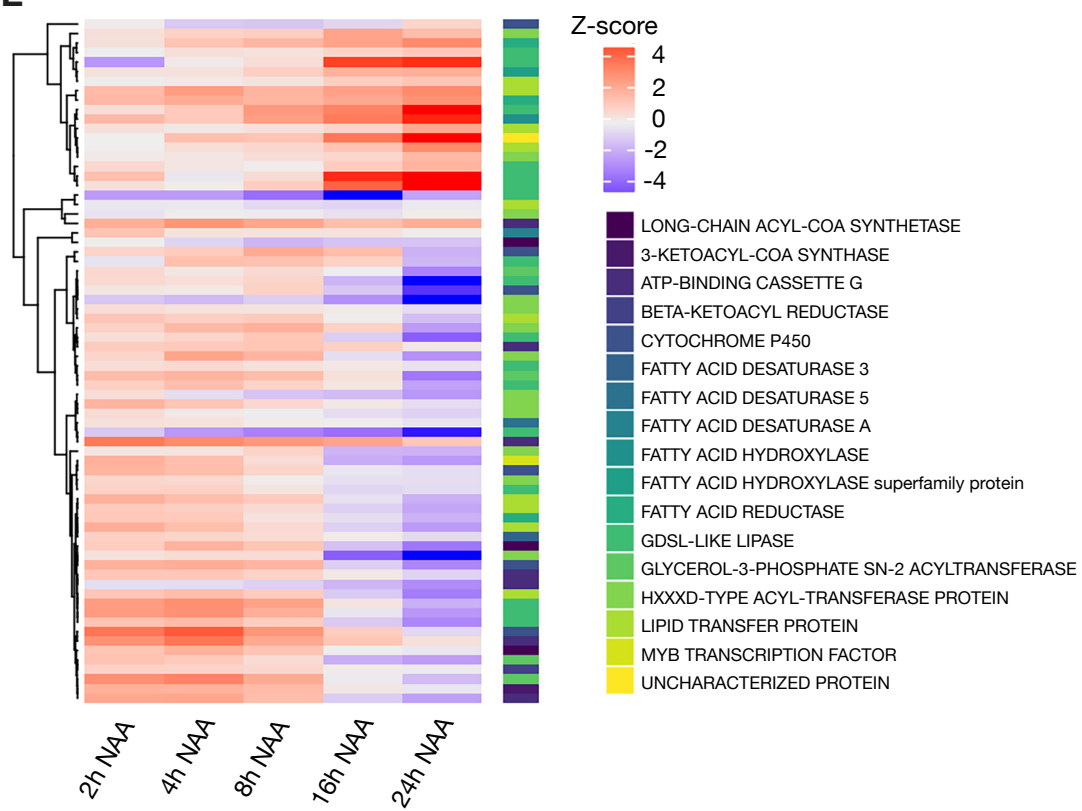

Supplemental Figure S3. A high number of differentially regulated genes are expressed in the endodermis.

A. Confocal images of GELP12pro::NLS-3xmVENUS expression in different genetic backgrounds, showing repression in $s l r-1$ under control conditions. B. Auxin treatment (10 $\mu \mathrm{M}$ NAA, 16hrs) results in induction of GELP12pro::NLS-3xmVENUS expression in the endodermis of $s l r-1$ roots. NLS-3xmVENUS signal is shown in green and CFW staining of cell walls is shown in grey. C. Confocal images of roots expressing transcriptional markers of candidate genes differentially expressed between $s l r-1$ and CASP1pro::shy2-2/slr-1 roots and showing specific expression in the endodermis. D. Confocal images showing xylem-specific expression of LAC2pro::NLS$3 x m$ VENUS. E. Heatmap showing the expression dynamics of suberin-related genes significant differentially expressed. NLS$3 x m V E N U S$ signal is shown in green, CFW staining of cell walls in gray and cell wall staining by PI in red. Scale bars $=20 \mu \mathrm{m}$. 
bioRxiv preprint doi: https://doi.org/10.1101/2020.06.25.171389; this version posted June 27, 2020. The copyright holder for this preprint (which was not certified by peer review) is the author/funder, who has granted bioRxiv a license to display the preprint in perpetuity. It is made available under aCC-BY 4.0 International license.

bioR $\chi$ IV PREPRINT

A

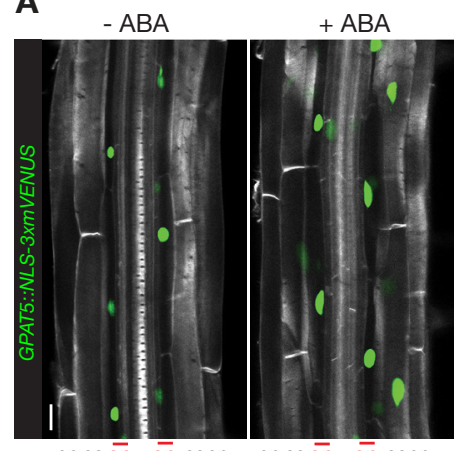

epcoèn $\overline{\bar{n}}$ coep epcoèn $\overline{e n}$ coep

C

gelp96-1 (AT5G37690)

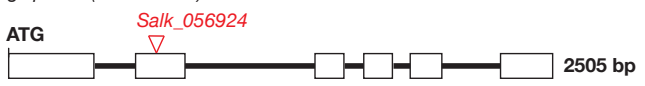

gelp51-1 (AT2G23540)

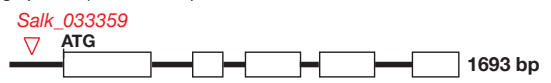

gelp22-1 (AT1G54000)

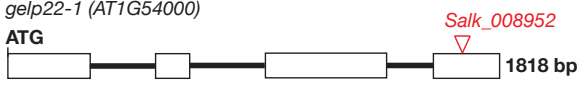

gelp49-1 (AT2G19050) ATG

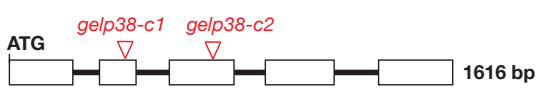

Col-0 GACCAAGCTCCCTAACGCAAGC-TACAGGTT gelp38-c1 (AT1G74460) GACCAAGCTCCCTAACGCAAGCATACAGGTT

Col-0 TTTGATGCCTGTCTATAGCGAC-TCTTGGAA gelp38-c2 (AT1G74460) TTTGATGCCTGTCTATAGCGACCTCTTGGAA

$+\mathrm{ABA}$

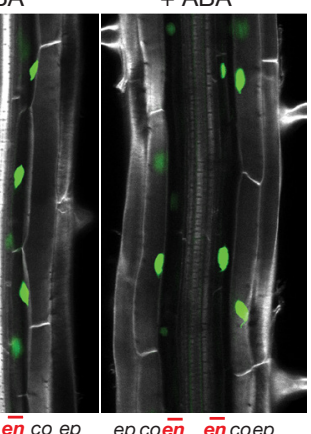

B

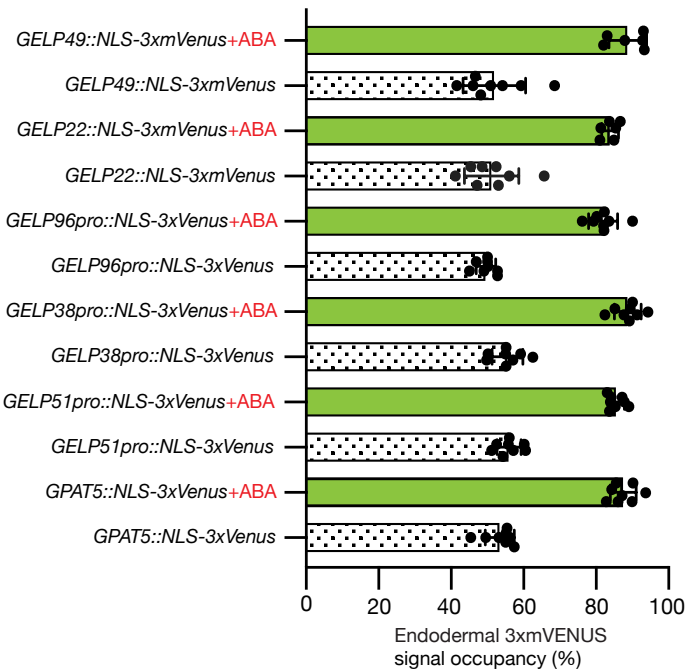

D

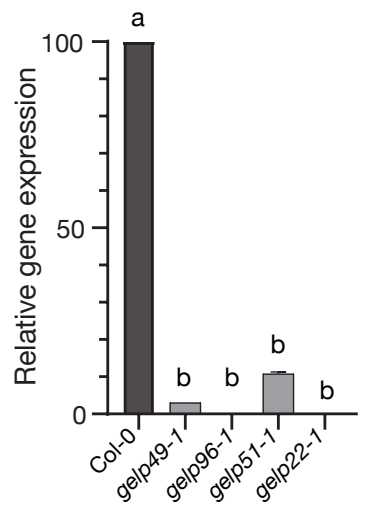

E

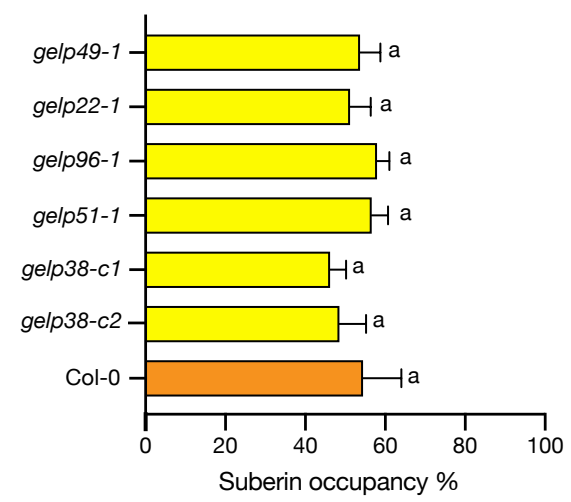

Supplemental Figure S4. Expression of suberin biosynthesis-related GELPs is induced by ABA treatment.

A. Confocal images showing effect of ABA treatment $(1 \mu \mathrm{M}, 24 \mathrm{hr})$ on the expression domain of GPAT5pro::NLS-3xmVENUS and GELP38pro::NLS-3xmVENUS in Arabidopsis roots. B. Quantification of the effect of ABA treatment $(1 \mu \mathrm{M}, 24 \mathrm{hr})$ on the expression of suberin biosynthesis-related GELPs identified as being repressed by auxin treatment. C. Schematic representation of the different single mutants of the suberin biosynthesis-related GELPs used in this study. D. qPCR results showing the effect of the T-DNA insertions of the suberin synthesis-related GELPs used in this study. Experiment was performed on three biological replicates. E. Quantification of suberin occupancy in the endodermis of the single mutants of the suberin biosynthesis-related GELPs using FY staining. Different letters in (D) and $(\mathbf{E})(p<0.05)$ indicate statistically significant differences between means by ANOVA and Tukey's test analysis. ns, not significant. Scale bar in $(\mathbf{A})=25 \mu \mathrm{m}$. 
bioRxiv preprint doi: https://doi.org/10.1101/2020.06.25.171389; this version posted June 27, 2020. The copyright holder for this preprint (which was not certified by peer review) is the author/funder, who has granted bioRxiv a license to display the preprint in perpetuity. It is made available under aCC-BY 4.0 International license.

\title{
bioR Xiv
}

\section{gelp22/38/49/51/96 quintuple mutants}

\author{
gelpquint-1 \\ gelp38-c3 (AT1G74460) \\ PAM \\ Wild type Col-0 TTTGATGCCTGTCTATAGCGA-CTCTTGGAA \\ Quintuple \#1 TTIGATGCCTGTCTATAGCGACCTCTTGGAA \\ gelp51-c1 (AT2G23540) \\ Wild type Col-0 TCAAAGCCTCCGGAGGAACTCC-TACCGGCC \\ Quintuple \#1 TCAAAGCCTCCGGAGGAACTCCATACCGGCC \\ gelp22-c1 (AT1G54000) \\ Wild type Col-0 ACTATTCTGTCCGGCGACAGTGATGGGGTTGTGAAAGA \\ Quintuple \#1 ACTATTCTGTCCGGCGACAGTGA----.----AAGA \\ gelp49-c1 (AT2G19050) \\ Wild type Col-0 CATTTGCAACGACCGAGGCGGCTCTTGGAC \\ ouintuple \#1 CATTTGCAACGACCGAGGCGGC-CTTGGAC \\ gelp96-c1 (AT5G37690) \\ Wild type Col-0 GTTGATGCTGGTTGTGCGGTT--CATAGGTGG \\ Quintuple \#1 GTTGATGCTGGTTGTGCGGTTGCCATAGGTGG \\ Wild type col-0 AAgTTATTAgGGCGAAATCGG-AGATGGAG \\ Quintuple \#1 AAGTTATTAGGGCGAAAATCGGTAGATGGAG
}

gelpquint-2

gelp38-c4 (AT1G74460)

PAM

Wild type Col-0 TTTGATGCCTGTCTATAGCGAC-TCTTGGAA Quintuple \#2 TTTGATGCCTGTCTATAGCGACGTCTTGGA

gelp51-c2 (AT2G23540)

Wild type Col-0 GAGGAGGAGGATCATGAATGC-CACCGGGA Quintuple \#2 GAGGAGGAGGAATCATGAATGCTCACCGGGA

gelp22-c2 (AT1G54000)

Wild type Col-0 ACTATTCTGTCCGGCGACAGTGA-TGGGGTT ouintuple \#2 ACTATTCTGTCCGGCGACAGTGAATGGGGT

gelp49-c2 (AT2G19050)

Wild type Col-0 CATTTGCAACGACCGAGGCGGC-TCTTGGAC ouintuple \#2 CATTTGCAACGACCGAGGCGGCCTCTTGGAC

gelp96-c2 (AT5G37690)

Wild type col-0 AAGTTATTAGGGCGAAAATCGGAGATGGAG Quintuple \#2 AAGTTATTAGGGCGAAAATCGGA--TGGAG

Supplemental Figure S5. CRISPR/Cas9-mediated gelpquint mutants.

Schematic representation of the mutations in the gelp quint-1 and gelpquint-2 mutants. The mutations are indicated in red and the PAM sites in blue. 
bioRxiv preprint doi: https://doi.org/10.1101/2020.06.25.171389; this version posted June 27, 2020. The copyright holder for this preprint (which was not certified by peer review) is the author/funder, who has granted bioRxiv a license to display the preprint in perpetuity. It is made available under aCC-BY 4.0 International license.

bioR $\chi$ IV PREPRINT

A

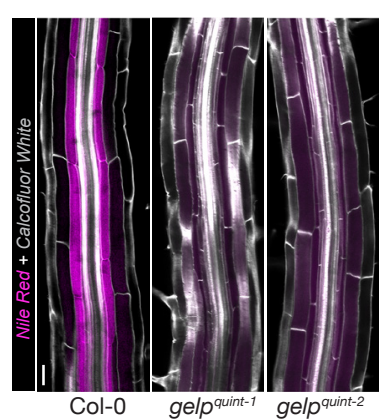

B

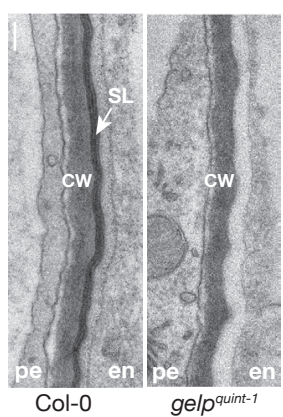

C

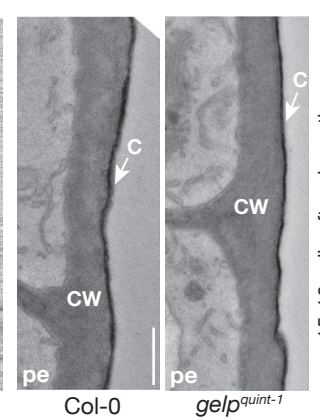

$\mathbf{D}_{\text {Col-0 }}$

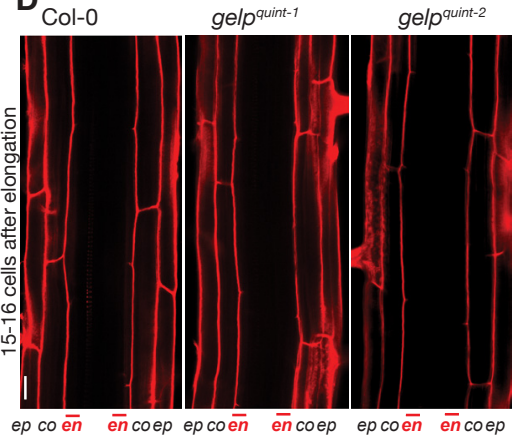

E

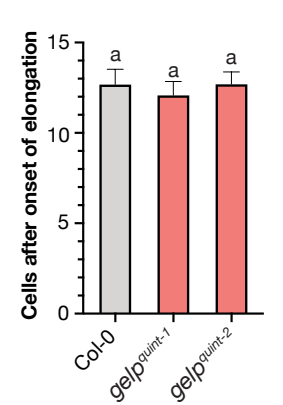

$\mathbf{F}$

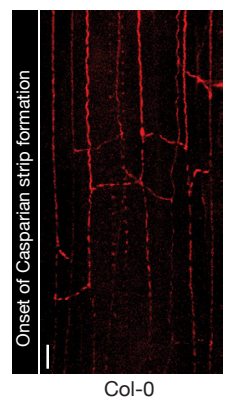

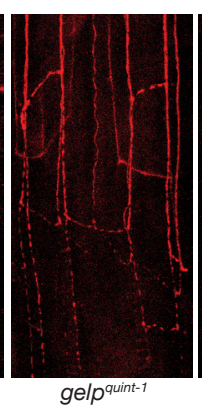

gelpquint-1

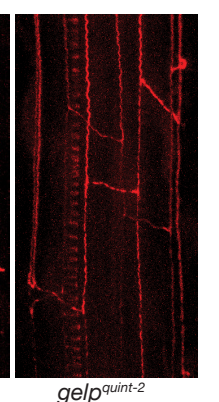

G

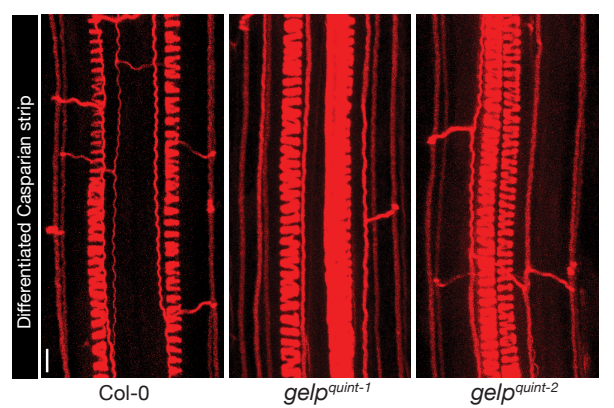

H

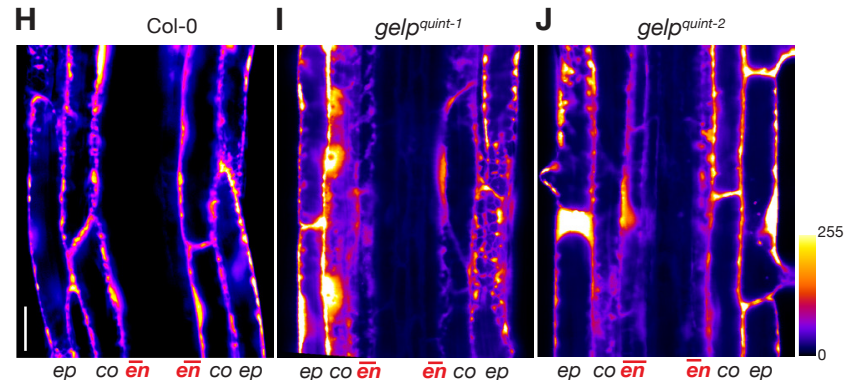

$\mathbf{K}_{4 \text { days } 1 / 2 \mathrm{MS}+8 \text { days } 85 \mathrm{mM} \mathrm{NaCl}}$

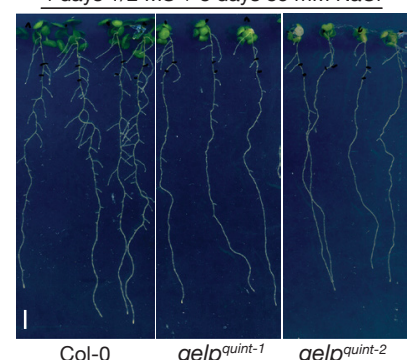

$\mathbf{L}$

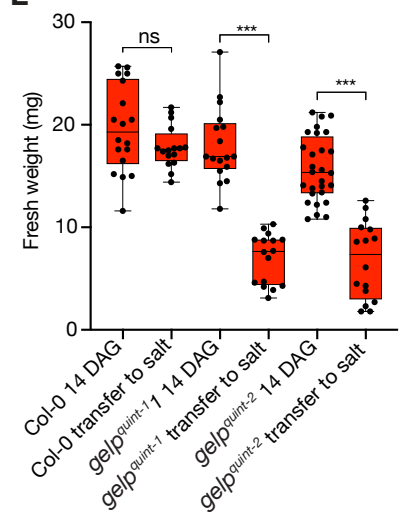

M

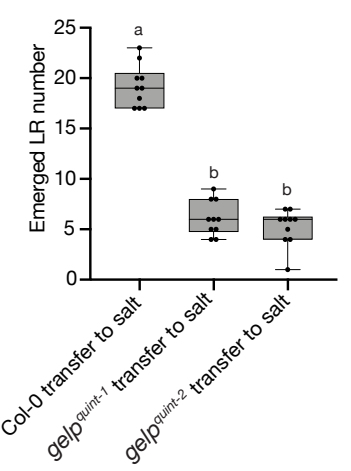

N

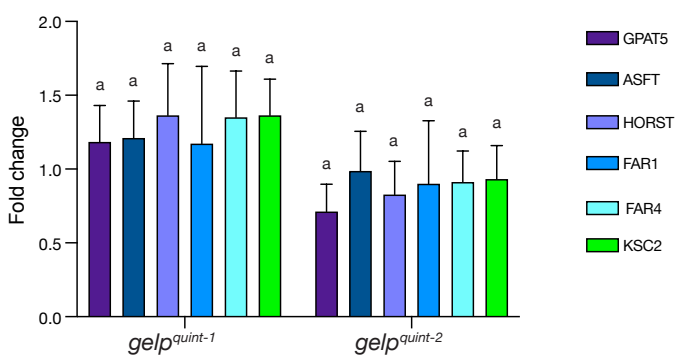

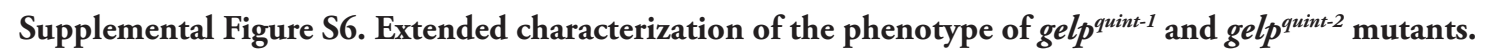

A. Nile Red staining of wild-type and gelpquint-1 and gelpquint-2 roots confirms the absence of suberin in the mutants. B. TEM micrographs of high-pressure frozen roots of wild-type and gelp quint- $^{-1}$ showing the absence of suberin lamella in the suberin biosynthesis mutant. C. TEM micrograph of high-pressure frozen roots of wild-type and gelpquint-1 showing that the lateral root cap cuticle is not affected in the suberin biosynthesis mutant. D. PI-mediated barrier assay on wild-type and gelpquint- and gelp quint-2 roots. E. Quantification of PI uptake in roots of wild-type and gelpquint-1 and gelp ${ }^{\text {quint }-2}$ seedlings. F-G. Basic Fuchsin staining of the Casparian strip in early and differentiated endodermal cells of wild-type and gelpquint-1 and gelpquint-2 roots. H. Fluorescein di-acetate (FDA) uptake assay in wild-type roots showing a suberin mediated block of uptake at the level of the endodermis. I. FDA uptake in assay in gelp $p^{\text {quint- }}$ and $(\mathbf{J})$ gelp $^{\text {quint-2}}$ mutant roots, showing FDA uptake is not blocked at the level of the endodermis. K. Salt stress assay showing that gelpquint-1 and gelpquint-2 mutant seedlings are more sensitive to mild salt stress ( $85 \mathrm{mM} \mathrm{NaCl})$ compared to wild-type. L. Quantification of the effect of prolonged salt stress on the fresh weight of wild-type and gelpquint-1 and gelpquint-2 seedlings. M. Quantification of emerged lateral roots in wild-type and gelp quint-1 and gelpquint-2 mutants after 12 days of exposure to salt. $\mathbf{N}$. Quantification of the expression of known suberin biosynthetic genes in gelp quint-1 and gelpquint-2 mutants. Results are presented as fold-change compared to their expression levels in wild-type. Results were obtained from three biological replicates. Different letters in $(\mathbf{E})$ and $(\mathbf{M})(\mathrm{p}<0.001)$ and asterisks in $(\mathbf{L})(p<0.001)$ indicate statistically significant differences between means by ANOVA and Tukey's test analysis. ns, not significant. Scale bars for $(\mathbf{A}),(\mathbf{D}),(\mathbf{F}),(\mathbf{G}),(\mathbf{H}-\mathbf{J})=25 \mu \mathrm{m}$. Scale bars for $(\mathbf{B})$ and $(\mathbf{C})=1 \mu \mathrm{m}$, for $(\mathbf{K})=5 \mathrm{~mm}$. 
bioRxiv preprint doi: https://doi.org/10.1101/2020.06.25.171389; this version posted June 27, 2020. The copyright holder for this preprint (which was not certified by peer review) is the author/funder, who has granted bioRxiv a license to display the preprint in perpetuity. It is made available under aCC-BY 4.0 International license.

\section{bioR $\chi$ IV PREPRINT}

A

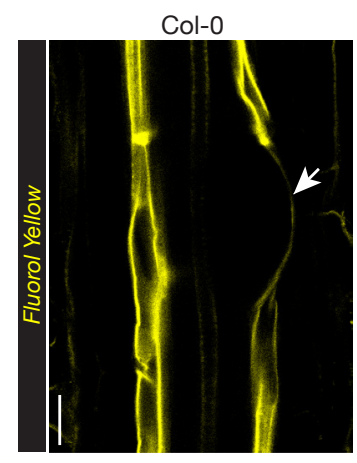

C bodyguard

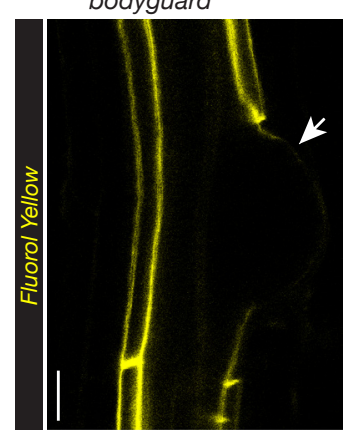

D Stage 0

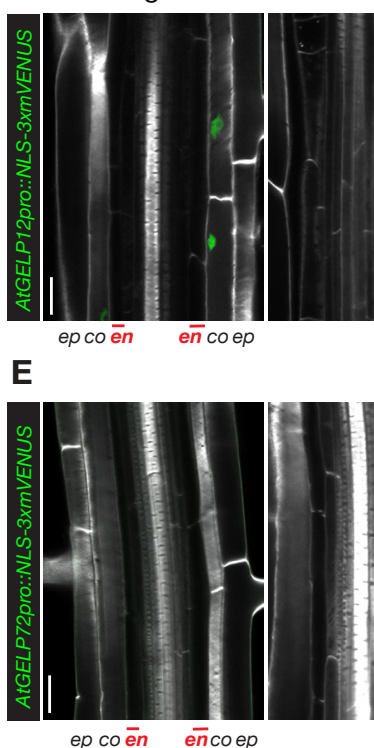

Stage I

E
Stage IV-V

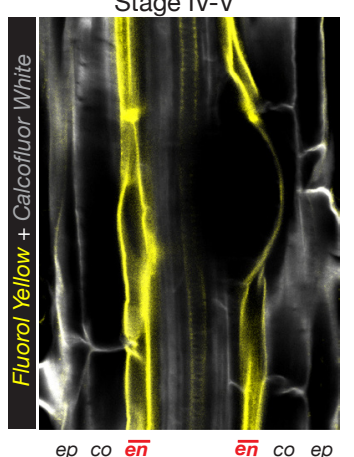

Stage VI-VII

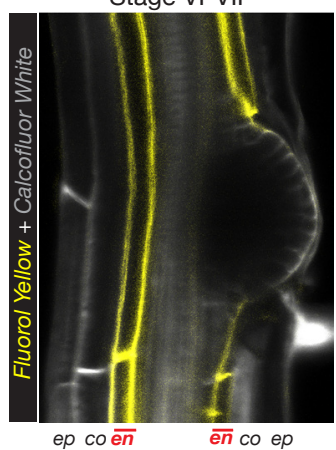

Stage II
B
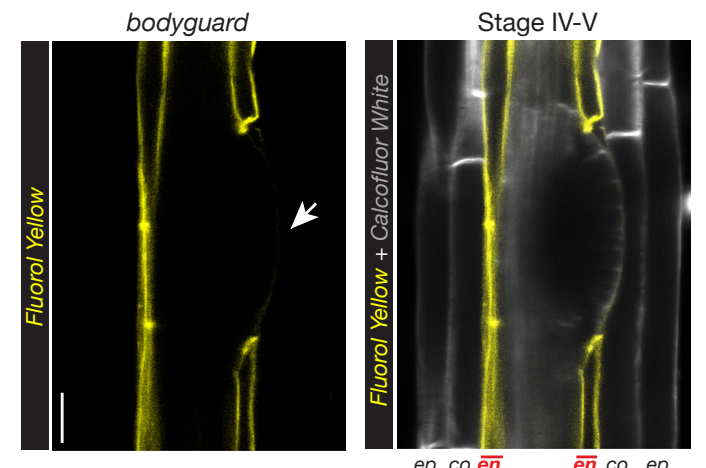

ep co ē

$\overline{e n}$ co ep

Stage Stage IV

Stage V Stage VI
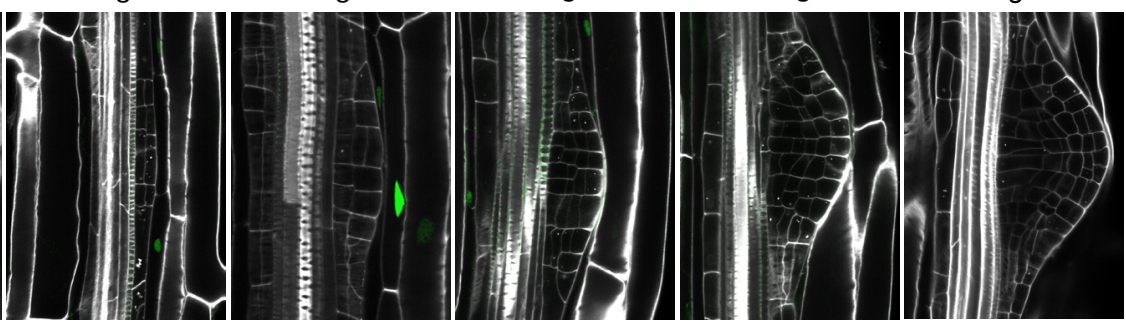

$\mathbf{F}$
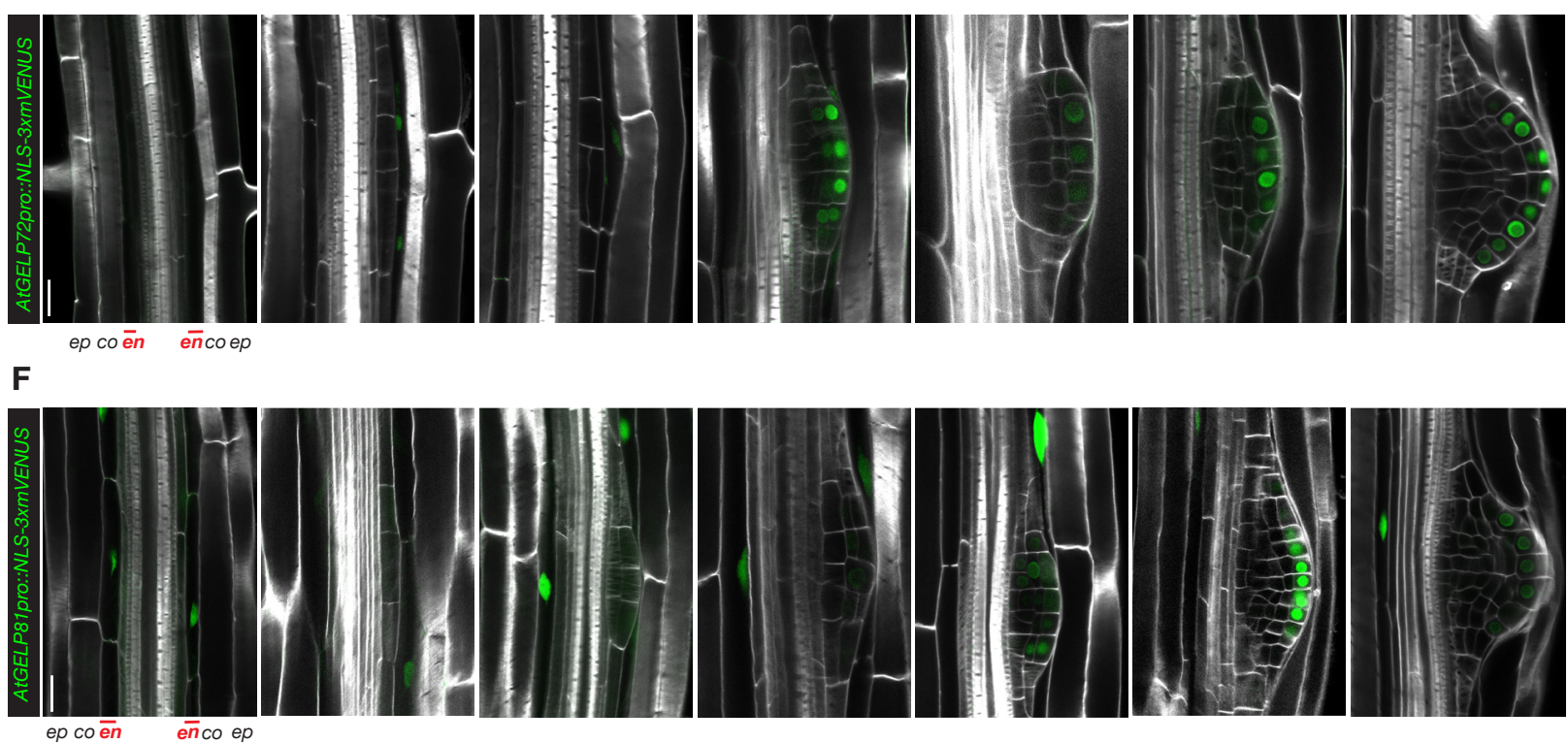

Supplemental Figure S7. Auxin-upregulated GELPs show three distinct expression patterns.

A. FY staining of wild-type Col-0 root at the site of lateral root emergence highlighting the presence of cuticle (indicated by arrow). B-C. FY staining of bodyguard mutant root at the site lateral root emergence. The absence of cuticle highlights the gap in FY staining in endodermis. D-F. Confocal images showing the expression patterns of GELP12 (D), GELP72 (E) and GELP81 (F) during lateral root emergence. NLS-3xmVENUS signal is in green and Calcofluor White staining of cell walls is in gray. Scale bars $=25 \mu \mathrm{m}$. 
bioRxiv preprint doi: https://doi.org/10.1101/2020.06.25.171389; this version posted June 27, 2020. The copyright holder for this preprint (which was not certified by peer review) is the author/funder, who has granted bioRxiv a license to display the preprint in perpetuity. It is made available under aCC-BY 4.0 International license.

\section{bioR Xiv PREPRINT}

A

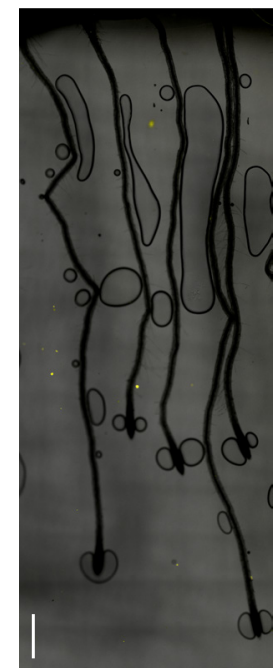

ELTPproXVE>> GELP12

B

Col-0

gelp12-c1 (AT1G28650)

Col-0

gelp12-c2 (AT1G28650)

Col-0

gelp55-c1 (AT2G30310)

Col-0

gelp55-c2 (AT2G30310)

\section{Col-0}

gelp72-c1(AT3G48460)

Col-0

gelp73-c1 (AT3G50400)

Col-0

gelp73-c2 (AT3G50400)

\section{Col-0}

gelp81-c1 (AT4G26790)

gelp81-c2 (AT4G26790)

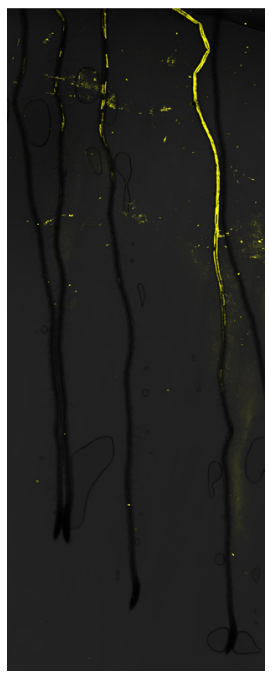

ELTPproXVE>> GELP55 T2-9

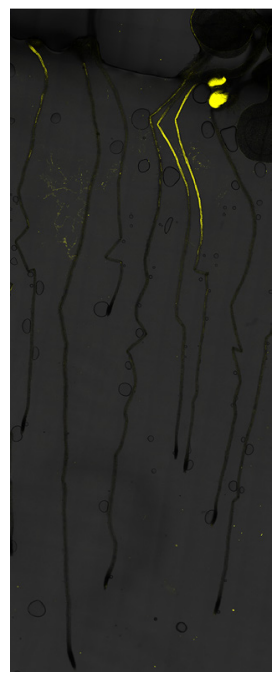

ELTPproXVE>> GELP72 T2-6

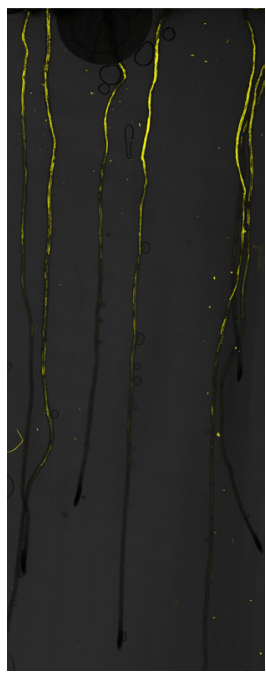

ELTPproXVE>> GELP73 T2-2

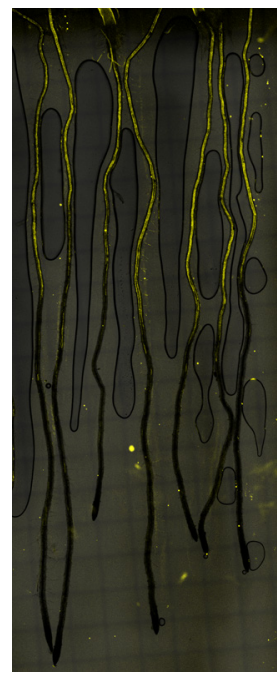

ELTPproXVE>> GELP81 T2-2
Single CRISPR mutants for auxin-upregulated GELPs:
gRNA1

PAM

AAGCTTACGATGAGCGAAGCC-ATGAGGAGA AAGCTTACGATGAGCGAAGCCCATGAGGAGA

AAGCTTACGATGAGCGAAGCCATGAGGAGA AAGCTTACGATGA $-------C A T G A G G A G A$

GGTTGCCGAAATATTGTGGTC-GGAGGGTTA GGTTGCCGAAATATTGTGGTCCGGAGGGTTA

GGTTGCCGAAATATTGTGGTC-GGAGGGTTA GGTTGCCGAAATATTGTGGTCAGGAGGGTTA

TGCTAACGTTAAGCATCCAGTTGCTGGATG TGCTAACGTTAAGCATCCAGT-GCTGGATG

ACAATTACCTAGTCCCTITTGTCGCGGCTC ACAATTACCTAGTCCCTIT-TCGCGGCTC

CCATCTCGTGGAAATCCAACC-GGCCGGTIT CCATCTCGTGGAAATCCAACCTGGCCGGTIT
gRNA2

PAM
GTTTTACAAGAAAGGCACGAT-CCAAGGCGG GTTTTACAAGAAAGGCACGATTCCAAGGCGG

GTTTTACAAGAAAGGCACGAT-CCAAGGCGG GTTTTACAAGAAAGGCACGATTCCAAGGCGG

CAATGTAATTGTAGGCAGC-TTCCGAGGGAT CAATGTAATTGTAGGCAGCTTTCCGAGGGAT

TATGGACGCTCGGAAATTTGT-GGTGGGAAA TATGGACGCTCGGAAATTTGTTGGTGGGAAA

Supplemental Figure S8. Overexpression of three auxin-induced GELPs leads to suberin degradation.

A. FY staining on roots of Col-0 treated with $\beta$-Estradiol results in normal suberin pattern, whereas inducible endodermis-specific overexpression of GELP12, GELP55 or GELP72 results in degradation of suberin highlighted by absence of FY signal. The overexpression of GELP73 and GELP81 results in a normal suberin pattern similar to wild-type. B. Schematic representation of the mutations in the auxin-upregulated single GELP mutants. The mutations are indicated in red and the PAM sites in blue. Scale bars in $(A)=500 \mu \mathrm{m}$. 
bioRxiv preprint doi: https://doi org/10.1101/2020 06.25.171389; this version posted June 27,2020 . The copyright holder for this preprint (which was not certified by peer review) is the author/funder, who has granted bioRxiv a license to display the preprint in perpetuity. It is made available under aCC-BY 4.0 International license.

\section{bioR XIV PREPRINT}

\section{Supplemental Experimental Procedures}

\section{Plant material and constructions}

The following T-DNA tagged and transgenic lines were used in this study: gelp49 (SALK_015138C); gelp51 (SALK_033359C); gelp96 (SALK056924C); gelp96 (SALK056924C) were requested from NASC center; SHY2pro::NLS-3xmVENUS, CASP1pro::shy2-2, DR5::NLS-3xVENUS (Vermeer et al., 2014); GPAT5 pro::NLS-3xmVENUS (Ursache et al., 2018), slr-1 (Fukaki et al., 2002) were described previously.

The corresponding gene numbers are as follow: SLR, At4g14550; SHY2, At1g04240; ELTP, At2g48140; GPAT5, At3g11430; SYP122, At3g52400; BDG, At1g64670; HORST, At5g58860; ASFT, At5g41040; FAR1, At5g22500; FAR4, At3g44540; KCS2, At1g04220; GELP12, At1g28650; GELP55, At2g30310; GELP72, At3g48460; GELP81, At4g26790; GELP73, At3g50400; GELP49, At2g19050; GELP51, At2g23540; GELP96, At5g37690; GELP38, At1g74460; GELP22, At1g54000; GELP103, At5g45960; PER10, At1g49570; PER11, At1g68850; PER23, At2g38390; PER28, At3g03670; PER55, At5g14130, PER59, At5g19890; LAC2, At2g29130; LAC12, At5g05390; LAC13, At5g07130; LAC16, At5g58910; UCC1, At2g32300; PLIP3, At3g62590; CASPL4B1, At2g38480; CASPL1A1, At1g14160; CYTOCHROME 6561 and DOMON DOMAIN-CONTAINING PROTEIN, At4g17280; CYTOCHROME b561 and DOMON DOMAINCONTAINING PROTEIN, At5g47530.

\section{Methanol-based Fluorol Yellow staining of suberin in combination with Calcofluor White}

For most experiments suberin lamellae were observed in 5 or 7-day-old roots using Fluorol Yellow (FY 088, SANTA CRUZ BIOTECHNOLOGY) staining. Seedlings were incubated in methanol at room temperature for at least three days, stained with FY 088 (0.01\%, methanol) for 1 hour at room temperature, rinsed in methanol and counterstained with aniline blue $(0.5 \%$, methanol) at room temperature for 1 hour in darkness, washed, and visualized using 1-well chambered cover glass (ThermoFisher Scientific, Catalog Nr. 155361). In order to combine with Calcofluor White for cell wall staining, the seedlings were incubated first in Calcofluor White solution $(0.1 \%$, in methanol), for three days and stained with FY as described above.

\section{Supplemental references}

Fukaki, H., Tameda, S., Masuda, H., and Tasaka, M. (2002). Lateral root formation is blocked by a gain-of-function mutation in the SOLITARY-ROOT/IAA14 gene of Arabidopsis. The Plant journal : for cell and molecular biology 29, 153-168.

Ursache, R., Andersen, T.G., Marhavy, P., and Geldner, N. (2018). A protocol for combining fluorescent proteins with histological stains for diverse cell wall components. Plant J 93,
399-412.

Vermeer, J.E., von Wangenheim, D., Barberon, M., Lee, Y., Stelzer, E.H., Maizel, A., and Geldner, N. (2014). A spatial accommodation by neighboring cells is required for organ initiation in Arabidopsis. Science 343, 178-183. 
bioRxiv preprint doi: https://doi org/10.1101/2020 06.25.171389; this version posted June 27,2020 . The copyright holder for this preprint (which was not certified by peer review) is the author/funder, who has granted bioRxiv a license to display the preprint in perpetuity. It is made available under aCC-BY 4.0 International license.

\section{bioR $\chi$ iv ${ }^{\text {PREPRINT }}$}

Supplemental Table S1. Significant differentially expressed genes in slr-1 versus CASP1pro:shy2-2/slr-1 roots.

\begin{tabular}{|c|c|c|c|c|c|c|c|}
\hline \multirow{3}{*}{ Group } & \multirow{3}{*}{ Time point } & \multicolumn{6}{|c|}{ F-test Post Hoc classification } \\
\hline & & \multicolumn{3}{|c|}{ FDR $<0.05$} & \multicolumn{3}{|c|}{ FDR $<0.05$, Fold change $>2$} \\
\hline & & ALL & UP & DOWN & $\overline{A L L}$ & UP & DOWN \\
\hline \multirow{5}{*}{ 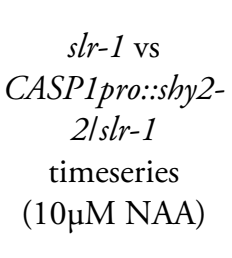 } & $2 \mathrm{hr}$ & 3043 & 1530 & 1513 & 865 & 469 & 396 \\
\hline & $4 \mathrm{hr}$ & 2974 & 1523 & 1451 & 933 & 522 & 411 \\
\hline & $8 \mathrm{hr}$ & 2736 & 1458 & 1278 & 824 & 478 & 346 \\
\hline & $16 \mathrm{hr}$ & 2278 & 1267 & 1011 & 818 & 509 & 309 \\
\hline & $24 \mathrm{hr}$ & 3093 & 1450 & 1643 & 1014 & 559 & 455 \\
\hline
\end{tabular}

Supplemental Table S2. Transcriptional reporters used for confirmation of RNAseq data.

\begin{tabular}{|c|c|c|c|}
\hline Reporter & At number & Detected in the endodermis & Alternative localization \\
\hline GELP55pro::NLS-3xmVENUS & At2g30310 & Yes & \\
\hline GELP12pro::NLS-3xmVENUS & At $\lg 28650$ & Yes & \\
\hline GELP72pro::NLS-3xmVENUS & At3g48460 & Yes & \\
\hline GELP73pro::NLS-3xmVENUS & Atlg 50400 & Yes & \\
\hline GELP81pro::NLS-3xmVENUS & At3g26790 & Yes & \\
\hline GELP96pro::NLS-3xmVENUS & At5g37690 & Yes & \\
\hline GELP22pro::NLS-3xmVENUS & Atlg5 54000 & Yes & \\
\hline GELP38pro::NLS-3xmVENUS & At $\lg 74460$ & Yes & \\
\hline GELP51pro::NLS-3xmVENUS & At2g23540 & Yes & \\
\hline GELP49pro::NLS-3xmVENUS & At2g19050 & Yes & \\
\hline UCC1pro::NLS-3xmVENUS & At2g32300 & Yes & \\
\hline PER55pro::NLS-3xmVENUS & At5g14130 & Yes & \\
\hline PER23pro::NLS-3xmVENUS & At $2 \mathrm{~g} 38390$ & Yes & \\
\hline PER1 1pro::NLS-3xmVENUS & Atlg68850 & Yes & \\
\hline PER59pro::NLS-3xmVENUS & At5g19890 & Yes & \\
\hline LAC12pro::NLS-3xmVENUS & At $5 \mathrm{~g} 05390$ & Yes & \\
\hline LAC13pro::NLS-3xmVENUS & At5g07130 & Yes & \\
\hline LAC16pro::NLS-3xmVENUS & At5g58910 & Yes & \\
\hline PLIP3pro::NLS-3xmVENUS & At3g62590 & Yes & \\
\hline At4g17280pro::NLS-3xmVENUS & At $4 \mathrm{~g} 17280$ & Yes & \\
\hline At5g47530pro::NLS-3xmVENUS & At5g47530 & Yes & \\
\hline PER10pro::NLS-3xmVENUS & Atlg 49570 & No & xylem \\
\hline GELP103pro::NLS-3xmVENUS & At5g45960 & No & Not detected \\
\hline LAC2pro::NLS-3xmVENUS & At2g29130 & No & xylem \\
\hline CASPL4B1pro::CITRINE:SYP122 & At $2 \mathrm{~g} 38480$ & Yes & \\
\hline CASPL1B2pro::CASPL1B2:CITRINE & At4g20390 & Yes & \\
\hline CASPL1A1pro::CASPL1A2:CITRINE & Atlg14160 & Yes & \\
\hline
\end{tabular}


bioRxiv preprint doi: https://doi org/101101/2020 06 25.171389; this version posted June 27,2020 . The copyright holder for this preprint (which was not certified by peer review) is the author/funder, who has granted bioRxiv a license to display the preprint in perpetuity. It is made available under aCC-BY 4.0 International license.

\section{bioRxiv}

Table S3. List of primers for cloning promoters into pDONR_P4R1 entry clone for Gateway assembly.

\begin{tabular}{|c|c|c|}
\hline Promoter Name & Forward primer & Reverse primer \\
\hline GELP49pro & AAAAGTTGACCCGAAGTGACGTTCAT & $\begin{array}{l}\text { TTGTACAAACTTGTTTTAGTAAATTAATGAC } \\
\text { CAG }\end{array}$ \\
\hline GELP51pro & $\begin{array}{l}\text { ATAGAAAAGTTGGATGATGATGAAGATGATA } \\
\text { C }\end{array}$ & $\begin{array}{l}\text { TTGTACAAACTTGTATTTCTTGATTTTGAGA } \\
\text { AATG }\end{array}$ \\
\hline GELP96pro & AAAGTTGTTTTGACCCAAAGGTGAGA & $\begin{array}{l}\text { TTGTACAAACTTGTTGTGTTTTGTGTTGAT } \\
\text { TTCACTCC }\end{array}$ \\
\hline GELP38pro & $\begin{array}{l}\text { ATAGAAAAGTTGTGTTGTTTGAGGAGGAGT } \\
\text { TC }\end{array}$ & $\begin{array}{l}\text { TTGTACAAACTTGTGTCGCCAAATTTGAATG } \\
\text { TGTG }\end{array}$ \\
\hline GELP22pro & $\begin{array}{l}\text { ATAGAAAAGTTGGTCTCTAAAATCAATATTT } \\
\text { AG }\end{array}$ & TTGTACAAACTTGTTTAGAGAGAGGGAG \\
\hline GELP12pro & $\begin{array}{l}\text { ATAGAAAAGTTGAAGGAGCAGTTAGAATTCA } \\
\text { TTTG }\end{array}$ & $\begin{array}{l}\text { TTGTACAAACTTGTCGTCTCTATTACTCAAT } \\
\text { TTTTAG }\end{array}$ \\
\hline GELP55pro & AAAAGTTGAAGAAGAAGAAGAACCAAC & $\begin{array}{l}\text { TTGTACAAACTTGTTGTGATAATTAATTTGA } \\
\text { TTTGTTG }\end{array}$ \\
\hline GELP72pro & $\begin{array}{l}\text { ATAGAAAAGTTGTGTTGGAATTAGAAACAGA } \\
\text { GG }\end{array}$ & $\begin{array}{l}\text { TTGTACAAACTTGTTGTGATAAGGAAGTGA } \\
\text { GATTTG }\end{array}$ \\
\hline GELP73pro & AAGTTGTTGTTTGTTTTTTGTATGT & $\begin{array}{l}\text { TTGTACAAACTTGTTGTCACGAAATGGTTT } \\
\text { CTG }\end{array}$ \\
\hline GELP81pro & $\begin{array}{l}\text { ATAGAAAAGTTGCTGGAGATCCACCACAGAT } \\
\text { GAAC }\end{array}$ & $\begin{array}{l}\text { TTGTACAAACTTGTGCTTTTTACACAAGTTT } \\
\text { TTTCAAT }\end{array}$ \\
\hline PER1Opro & $\begin{array}{l}\text { AAAAGTTGATCTCAAGAAACCAAACTC } \\
\text { TCACGG }\end{array}$ & $\begin{array}{l}\text { TTGTACAAACTTGTGATGATGAAATGAAAGA } \\
\text { TA TATGATCG }\end{array}$ \\
\hline PER11pro & AAAGTTGATGGTATTTTGATGTAAAC & $\begin{array}{l}\text { TTGTACAAACTTGTATTTAATTTCTTCTATC } \\
\text { GGAAAAC }\end{array}$ \\
\hline PER23pro & AAAGTTGTTATGCATGTTGCCATGTT & $\begin{array}{l}\text { TTGTACAAACTTGTTTTTTCAGGAGGGAGA } \\
\text { CAA AAAG }\end{array}$ \\
\hline$P E$ & TTGCGCTTCCGGCACTGAGCA & $\begin{array}{l}\text { TTGTACAAACTTGTCGTGATCGATTTTTCT } \\
\text { CCTTT }\end{array}$ \\
\hline PER59pro & AAGTTGGCGACCATATGATACCTG & $\begin{array}{l}\text { TTGTACAAACTTGTTATCTAGATAGCTTGTT } \\
\text { TAAAAGAC }\end{array}$ \\
\hline$L A C$ & AAAAGTTGCACCTAAACAACAAGAAAC & $\begin{array}{l}\text { TTGTACAAACTTGTGTTCAATATTTGTTTGA } \\
\text { ATATTG }\end{array}$ \\
\hline LAC12pro & AAAAGTTGAGGACTCTCTTCTCTGTA & $\begin{array}{l}\text { TTGTACAAACTTGTTAAGTGTGTTTAAGCTT } \\
\text { TGAG }\end{array}$ \\
\hline UCC1pro & ГTGTT & $\begin{array}{l}\text { TTGTACAAACTTGTATCTTCTTATATCCTTT } \\
\text { TTCTTTTTGGGGG }\end{array}$ \\
\hline SLRpro & AAAGTTGGACC & $\begin{array}{l}\text { TTGTACAAACTTGATCTCTTCTTGCTGTCTA } \\
\text { TAT }\end{array}$ \\
\hline At4g17280pro & $\begin{array}{l}\text { ATAGAAAAGTTGTGTA } \\
\text { G }\end{array}$ & $\begin{array}{l}\text { TTGTACAAACTTGGAATCAGAAGGTTAGAAA } \\
\text { G }\end{array}$ \\
\hline At5g47530pro & $\begin{array}{l}\text { ATAGAAAAGTTGGTCCTTTAATGCTCAAGAT } \\
\text { TAACCCTTC }\end{array}$ & $\begin{array}{l}\text { TTGTACAAACTTGGGAAACAGAATCTCGAGT } \\
\text { AATGATTAAAAGAT }\end{array}$ \\
\hline LAC13pro & $\begin{array}{l}\text { ATAGAAAAGTTGCTCTGGTAAATCTATAAGG } \\
\text { TGAGCT }\end{array}$ & $\begin{array}{l}\text { TTGTACAAACTTGTGCGCTCACTTACTCGA } \\
\text { AGAGAAAGAG }\end{array}$ \\
\hline CASPL4B1pro & AACACTAAAC & $\begin{array}{l}\text { TTGTACAAACTTGATTACAGATCTCAAAACT } \\
\text { TTGGTCGG }\end{array}$ \\
\hline CASPL1B2pro & $\begin{array}{l}\text { ATAGAAAAGTTGTTGATGTATCCTAGAGGA } \\
\text { GC }\end{array}$ & $\begin{array}{l}\text { TTGTACAAACTTGTTGTTGATGCAGTGAGT } \\
\text { GATC }\end{array}$ \\
\hline CASPL1A1pro & $\begin{array}{l}\text { ATAGAAAAGTTGTTACCAACATTTCATTATT } \\
\text { C }\end{array}$ & $\begin{array}{l}\text { TTGTACAAACTTGTTTTTGCTCTGTGACTG } \\
\text { TTTAC }\end{array}$ \\
\hline PLIP3pro & $\begin{array}{l}\text { ATAGAAAAGTTGTGCTCTTCTCTCGCTTTC } \\
\text { GCTCTCTC }\end{array}$ & $\begin{array}{l}\text { TTGTACAAACTTGTCCAATTCAAACAAAAAC } \\
\text { TCTTTCCTT }\end{array}$ \\
\hline
\end{tabular}


bioRxiv preprint doi: https://doi org/101101/2020 06.25.171389; this version posted June 27,2020 . The copyright holder for this preprint (which was not certified by peer review) is the author/funder, who has granted bioRxiv a license to display the preprint in perpetuity. It is made available under aCC-BY 4.0 International license.

Table S4. List of primers for cloning genomic fragments into pDONR221 Gateway entry clone.

\begin{tabular}{|c|c|c|}
\hline Line & Forward primer & Reverse primer \\
\hline GELP49 & AAAAAGCAGGCTATGGCCGAGGCAATATTCAAAG & $\begin{array}{l}\text { AGAAAGCTGGGTTTAATCTTGCAAGCCAAG } \\
\text { AAAG }\end{array}$ \\
\hline GELP51 & AAAAAGCAGGCTATGGCCACAAGAGCTTCTAC & $\begin{array}{l}\text { AGAAAGCTGGGTTCATATCTCTAAGTTTGC } \\
\text { TGAG }\end{array}$ \\
\hline GELP96 & AAAAAGCAGGCTATGATGATCCTTAGGCTGGCTC & $\begin{array}{l}\text { AGAAAGCTGGGTTTTGACGTGGTTTAGGAG } \\
\text { CAGGAG }\end{array}$ \\
\hline GELP38 & AAAAAGCAGGCTATGAAGTTCTGCGCGATATTCG & $\begin{array}{l}\text { AGAAAGCTGGGTTGTTATTGTCGGAAGAAG } \\
\text { GAG }\end{array}$ \\
\hline GELP22 & $\begin{array}{l}\text { AAAAAGCAGGCTATGATGGCAAACAACTGTAATT } \\
\mathrm{T}\end{array}$ & $\begin{array}{l}\text { AGAAAGCTGGGTTGTAATACTCGTAACCGC } \\
\text { GGCTAG }\end{array}$ \\
\hline GELP12 & $\begin{array}{l}\text { AAAAAGCAGGCTATGACGACGACTCTCCTCATGG } \\
\text { C }\end{array}$ & $\begin{array}{l}\text { AGAAAGCTGGGTTTCCACTGAAATCATAAGA } \\
\text { GCC }\end{array}$ \\
\hline GELP55 & $\begin{array}{l}\text { AAAAAGCAGGCTATGTCTACATCTAAAACCATAG } \\
\text { TG }\end{array}$ & $\begin{array}{l}\text { AGAAAGCTGGGTTAGCCTTAATCCAGCCTC } \\
\text { GAATC }\end{array}$ \\
\hline GELP72 & $\begin{array}{l}\text { AAAAAGCAGGCTATGTCTTCСТCTATCTCTCССС } \\
\text { TCC }\end{array}$ & $\begin{array}{l}\text { AGAAAGCTGGGTTTAAATAGTTTAGTTTCTT } \\
\text { GATC }\end{array}$ \\
\hline GELP73 & $\begin{array}{l}\text { AAAAAGCAGGCTATGAAGAAATCTATTTTCTTTG } \\
\text { TCCC }\end{array}$ & $\begin{array}{l}\text { AGAAAGCTGGGTTAAGGTCACGAAGGTGGA } \\
\text { GGAGG }\end{array}$ \\
\hline GELP81 & $\begin{array}{l}\text { AAAAAGCAGGCTATGCAGCGAAACAGAGTTCTTG } \\
\text { CG }\end{array}$ & $\begin{array}{l}\text { AGAAAGCTGGGTTCTGAAACCGAGATAAGT } \\
\text { CGTAT }\end{array}$ \\
\hline CASPL1B2 & $\begin{array}{l}\text { AAAAAGCAGGCTTAACAATGGCCAGAGAGAAGAT } \\
\text { TG }\end{array}$ & $\begin{array}{l}\text { AGAAAGCTGGGTTGACGACGGAGGTTGTG } \\
\text { GTG }\end{array}$ \\
\hline CASPL1A1 & $\begin{array}{l}\text { AAAAAGCAGGCTTAACAATGGAAGAAGCAAAGCA } \\
\text { TAATG }\end{array}$ & $\begin{array}{l}\text { AGAAAGCTGGGTTGTGGCGAGAGAGGGAGA } \\
\text { TAG }\end{array}$ \\
\hline
\end{tabular}

Table S5. Primers for genotyping T-DNA lines.

\begin{tabular}{lllll}
\hline Gene & T-DNA lines & AGI $\mathbf{n r}$. & Forward primer & Reverse primer \\
\hline GELP49 & SALK_015138 & At2g19050 & TGTTTGCTATATCGGTAGCGG & ACGTTCTAGGAGCAAGGAAGG \\
GELP51 & SALK_033359 & At2g23540 & TCCGGCTAATAAAGCTTTTCC & TGTTGGGGACTAGAATCACATG \\
GELP96 & SALK_056924 & At5g37690 & TGCAAAAGCAATCTGAAGACC & TCACATCGTAATTTTTATGATCCG \\
GELP38 & SALK_138130 & At1g74460 & TCGATCATCTGCCTGAATTTC & TTTCGTTCAAGATTCCACCAC \\
\hline
\end{tabular}

Table S6. qPCR primers.

\begin{tabular}{lllll}
\hline Gene & T-DNA lines & AGI nr. & Forward primer & Reverse primer \\
\hline GELP49 & SALK_015138 & At2g19050 & CGAGTGCCTTGCTATTTTGTTTTCG & CCCGTGAACGGTGGAATGTAATC \\
GELP51 & SALK_033359 & At2g23540 & TGTCCATGCAAACGTCTACGATCTC & AAGTCGGTCCGCACGGAATTATAC \\
GELP96 & SALK_056924 & At5g37690 & CCGGAGCTAAATTCTCTTCGCAGA & TAGCCGAATCGGACGGATGAAATG \\
GELP38 & SALK_138130 & At1g74460 & GTTTGGTGAAGCCTATGACCTCGTC & CATCGGCACGCATGAAGTCAAATC \\
CLATHRIN & n.a. & At4g24550 & AGCATACACTGCGTGCAAAG & TCGCCTGTGTCACATATCTC \\
GPAT5 & n.a. & At3g11430 & ACCGTGTCGCTAATTTGTTTGTTGG & CCGTCGTGAATATCACCGGAAGT \\
HORST & n.a. & At5g58860 & GGAGACACGTGGCAATGATCAGGA & GTCGAGCCTCTTGGCACGAAAGT \\
ASFT & n.a. & At5g41040 & CCCGATCCTGAAACTCTAGGGAAGC & CCGAGAACAAACCCTCCACATTTGA \\
FAR1 & n.a. & At5g22500 & GGAGCCCTGAATGTTCTCAACTTCG & GAGAGTCTCCCCCATCTTGAATGGT \\
FAR4 & n.a. & At3g44540 & CATGCAACGGTTTCACAGTGAGGT & TGAGCGGTCCAAATGTGTTGACG \\
KCS2 & n.a. & At1g04220 & CCTTCGTTATCGGCTATGATCGTGA & TGCAGTTTGAGAGAAGCATTGATCG \\
\hline
\end{tabular}


bioRxiv preprint doi: https://doi.org/10.1101/2020.06.25.171389; this version posted June 27, 2020. The copyright holder for this preprint (which was not certified by peer review) is the author/funder, who has granted bioRxiv a license to display the preprint in perpetuity. It is made available under aCC-BY 4.0 International license.

\section{biORXIV PREPRINT}

Table S7. Primers for gRNA cloning (red color indicates 20 nt protospacer sequence).

\begin{tabular}{llll}
\hline Gene & gRNA & Forward primer & Reverse primer \\
\hline GELP22 & gRNA1 & ATTGTCTGTCCGGCGACAGTGATG & AAACCATCACTGTCGCCGGACAGA \\
GELP38 & gRNA1 & GTCATGCCTGTCTATAGCGACTCT & AAACAGAGTCGCTATAGACAGGCA \\
& gRNA2 & ATTGAGCTCCCTAACGCAAGCTAC & AAACGTAGCTTGCGTTAGGGAGCT \\
GELP49 & gRNA1 & ATTGGCAACGACCGAGGCGGCTCT & AAACAGAGCCGCCTCGGTCGTTGC \\
GELP51 & gRNA1 & ATTGGCCTCCGGAGGAACTCCTAC & AAACGTAGGAGTTCCTCCGGAGGC \\
& gRNA2 & GTCAGGAGGAATCATGAATGCCAC & AAACGTGGCATTCATGATTCCTCC \\
GELP96 & gRNA1 & ATTGTGCTGGTTGTGCGGTTGCAT & AAACATGCAACCGCACAACCAGCA \\
& gRNA2 & GTCAATTAGGGCGAAAATCGGAGA & AAACTCTCCGATTTCGCCCTAAT \\
GELP12 & gRNA1 & ATTGTTACGATGAGCGAAGCCATG & AAACCATGGCTTCGCTCATCGTAA \\
& gRNA2 & ATTGTACAAGAAAGGCACGATCCA & AAACTGGATCGTGCCTTTCTTGTA \\
GELP55 & gRNA1 & ATTGGCCGAAATATTGTGGTCGGA & AAACTCCGACCACAATATTTCGGC \\
& gRNA2 & ATTGGTAATTGTAGGCAGCTTCCG & AAACCGGAAGCTGCCTACAATTAC \\
GELP72 & gRNA1 & ATTGAACGTTAAGCATCCAGTTGC & AAACGCAACTGGATGCTTAACGTT \\
GELP73 & gRNA1 & ATTGTTACCTAGTCCCTTTTGTCG & AAACCGACAAAAGGGACTAGGTAA \\
& gRNA2 & ATTGCTCGTGGAAATCCAACCGGC & AAACGCCGGTTGGATTTCCACGAG \\
GELP81 & gRNA1 & ATTGAGTAATCCCGGCCATATGGC & AAACGCCATATGGCCGGGATTACT
\end{tabular}

